\title{
A BIOMECHANICAL STUDY OF A NOVEL BIOMIMETIC HIP IMPLANT
}

by

Shaheen Khurshid

B.Sc. (Mechanical Engineering), 2000

University of Engineering and Technology, Punjab, Pakistan

\author{
A Thesis \\ Presented to Ryerson University \\ in partial fulfilment of the \\ requirements for the \\ Degree of Master of Applied Science \\ in the Program of \\ Mechnical Engineering \\ PROPERTY OF \\ RYERSON UNIVERSITY LIBRARY
}

Toronto, Ontario, Canada, 2009

Shaheen Khurshid, 2009 


\section{Author's Declaration}

I hereby declare that I am the sole author of this thesis.

I authorise Ryerson University to lend this thesis to other institutions of individuals for the purpose of scholarly research.

I further authorise Ryerson University to reproduce this thesis by photocopying or by other means, in total or in part, at the request of other institutions or individuals for the purpose of scholarly research. 


\title{
A BIOMECHANICAL STUDY OF A NOVEL BIOMIMETIC HIP IMPLANT
}

\author{
Shaheen Khurshid \\ Masters of Applied Science \\ Department of Mechanical \& Industrial Engineering \\ Ryerson University, Toronto, Ontario, Canada, 2009
}

\begin{abstract}
A three dimensional finite element (FE) model of a novel carbon fibre polyamide12 composite hip stem was used to compare with two commercially available (Exeter and Omnifit) hip stems to minimize stress shielding and bone resorption. A virtual axial load of $3000 \mathrm{~N}$ was applied to the FE model which replicated the experimental study. Strain and stress distributions were computed and compared with experimental results. Experimentally, three hip stems had their distal portions rigidly mounted and had strain gauges placed along the surface at 3 medial and 3 lateral locations. From the FE analysis, the von mises stress range for the composite hip stem was $200 \%$ and $45 \%$ lower than that in the Omnifit and Exeter implants, respectivley. The aggregate average difference between $\mathrm{FE}$ and experimental microstrains for four proximal strain gauge locations were $7.5 \%$ (composite), 11.5\% (Exeter), 14.6\% (Omnifit), and the composite hip stem's stiffness $(1982 \mathrm{~N} / \mathrm{mm})$ was lower than the metallic hip stem stiffnesses (Exter, 2460 $\mathrm{N} / \mathrm{mm}$; Omnifit, $2543 \mathrm{~N} / \mathrm{mm}$ ). This study showed considerable improvement in stress transfer to bone tissue.
\end{abstract}




\section{Acknowledgements}

It is with sincere gratitude that I recgonise my instructors, peers, and friends who helped me piece together this thesis study from the ground up:

My supervisor Dr. Habiba Bougherara, for her consistent guidance throughout the duration of this study. In addition to her instruction on composite laminates, I am grateful for her muchneeded encouragement that helped me see this thesis through.

Dr. Radovan Zdero, for his expert advice on experimental biomechanics, and for the use of the Martin Orthopaedic Biomechanics Laboratory at St. Michael's Hospital, Toronto.

Mr. Suraj Shah of the University of Toronto, and Mr. Anton Dubov of Ryerson University, for their invaluable expertise in experimental preparation and geometry modelling. Without the collaboration and guidance of them both, essential portions of this thesis would not have been possible.

Ms. Leah Rogan, and the School of Graduate Studies at Ryerson University, for their assistance throughout the course of my post-graduate studies.

Last, but certainly not least, I recognise my parents, for their selfless, unconditional support in good times and bad. To you both, I will always remain indebted. 


\section{Table of Contents}

Author's Declaration ii

Abstract . iii

Acknowledgements iv

Table of Contents V

List of Figures ix

List of Tables xii

List of Medical Terminology $[1,2]$. xiv

List of Abbreviations. xvi

Nomenclature xvii

CHAPTER 1. .1

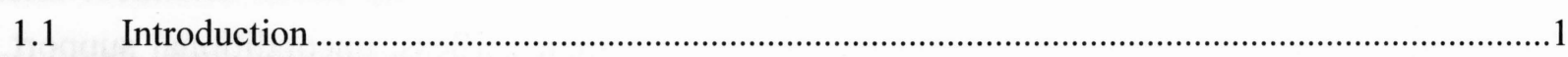

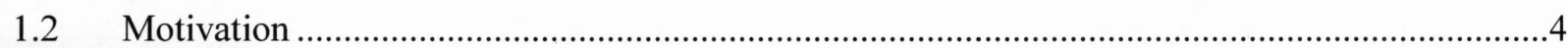

1.2.1 Statistical Analysis of Hip Replacements in Canada.......................................................4

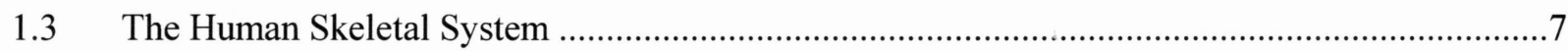

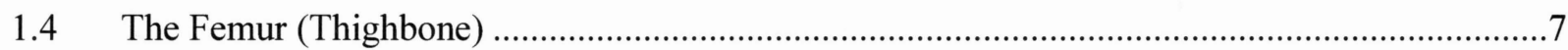

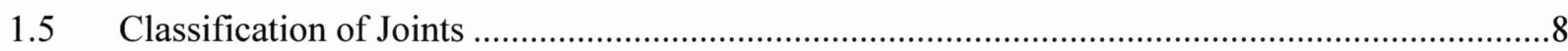

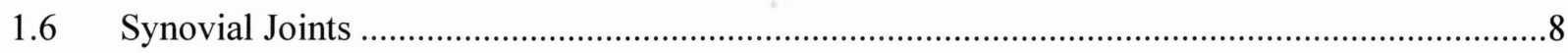

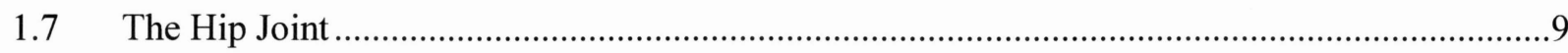

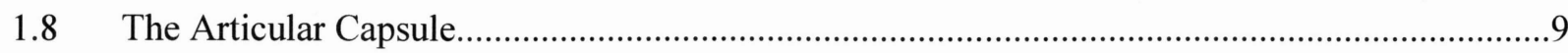

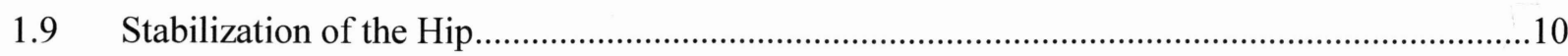

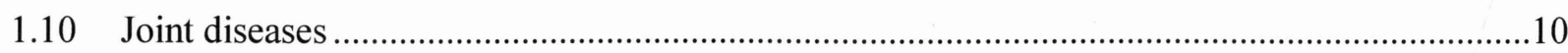

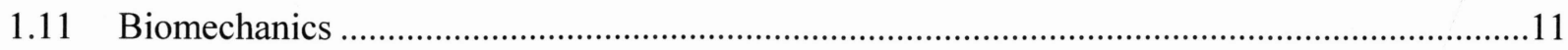




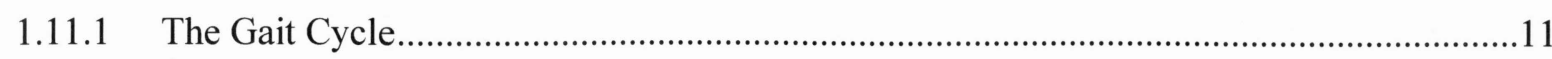

1.12 Relevant Structural Loads on the Hip Joint ......................................................................13

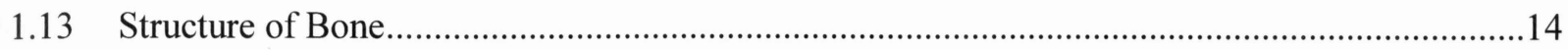

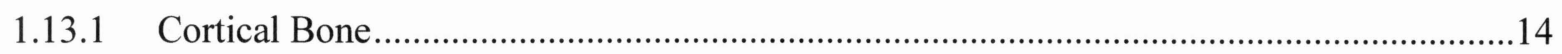

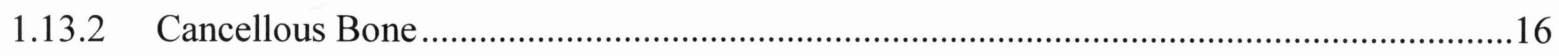

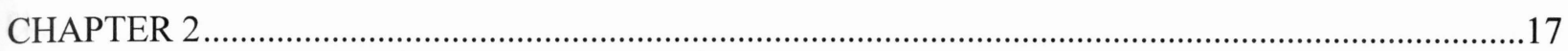

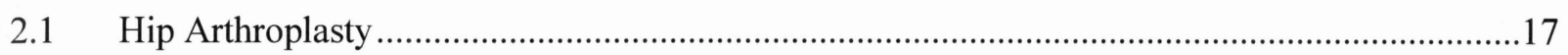

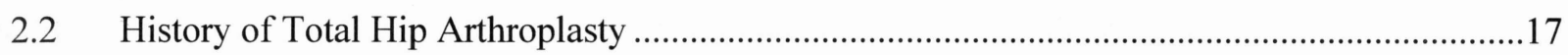

2.3 Indications for the Replacement of Hip Joint ..................................................................... 19

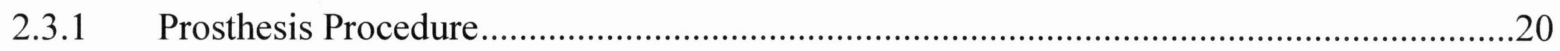

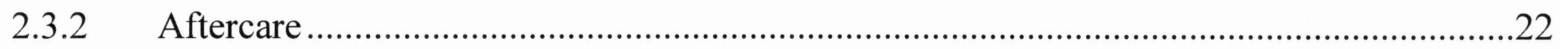

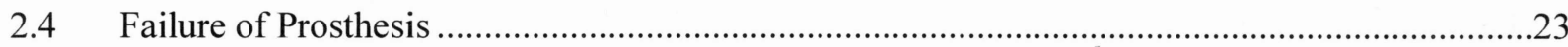

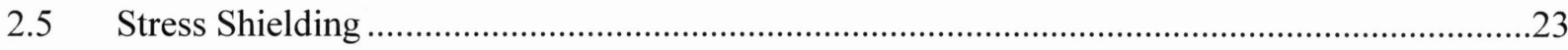

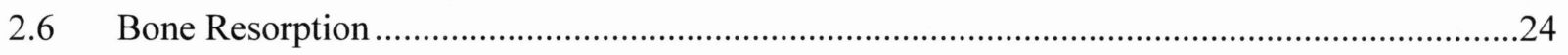

2.7 Need of the Polymer Composites for Orthopaedic Implants................................................25

2.8 Carbon Fibre Reinforced Polyamide 12 (CF/PA12) ..........................................................25

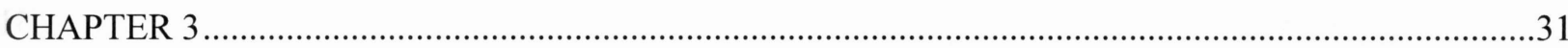

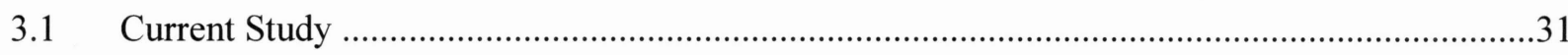

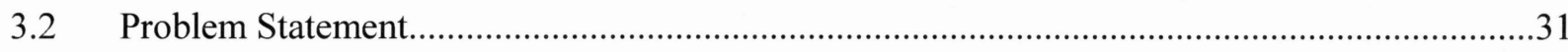

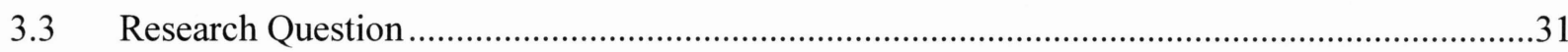

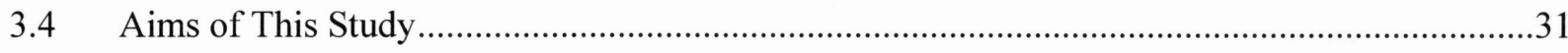

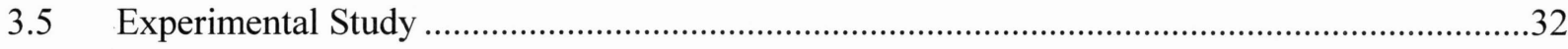

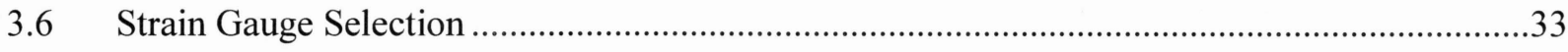

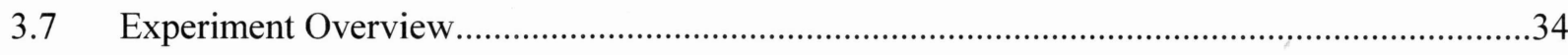

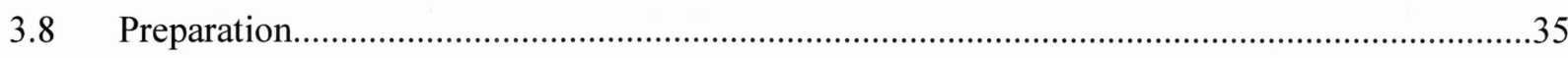

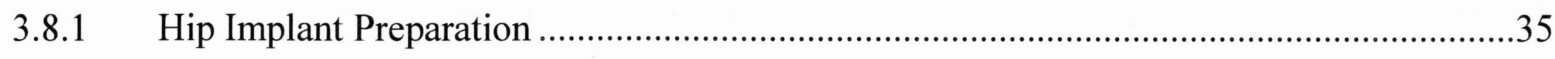




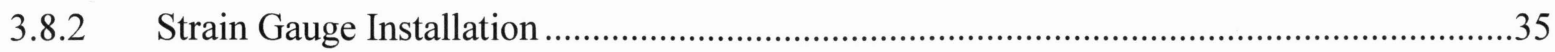

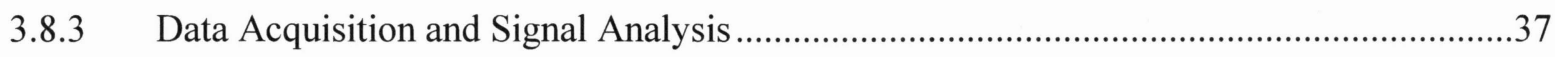

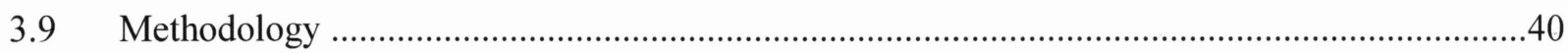

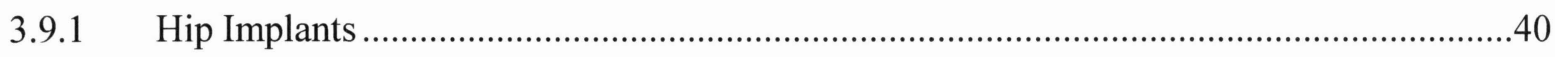

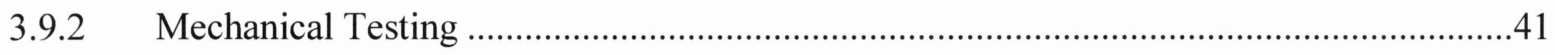

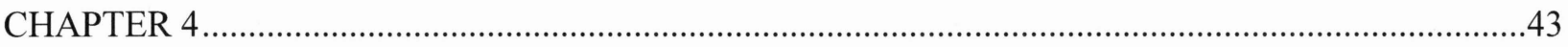

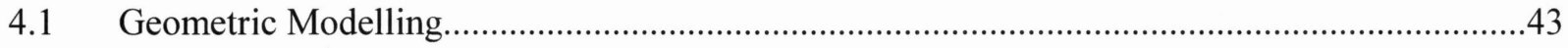

4.1.1 Composite (CF/PA12) Hip Stem and Components .....................................................43

4.1.2 Stryker Exeter Hip Stem and Components................................................................44

4.1.3 Stryker Omnifit Eon Hip Implant and Components ........................................................45

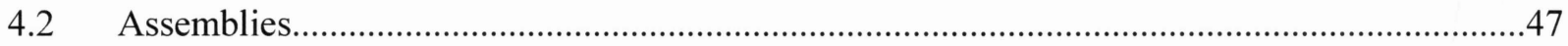

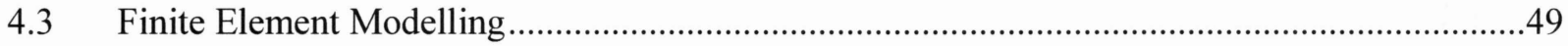

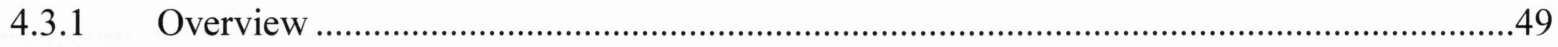

4.3.2 Importance and Need of Finite Element Analysis ...........................................................49

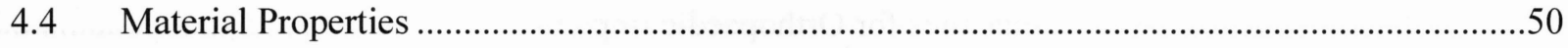

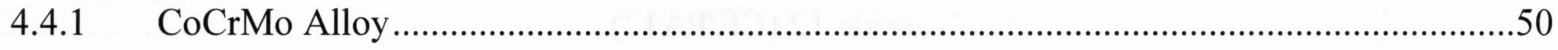

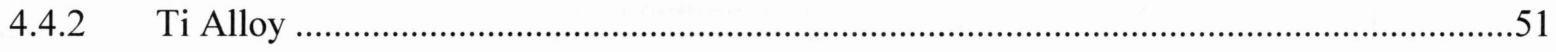

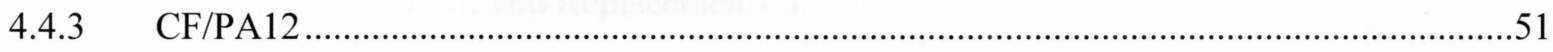

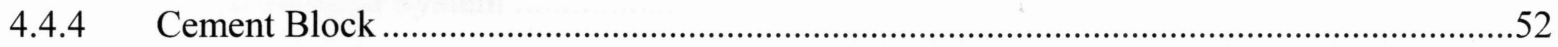

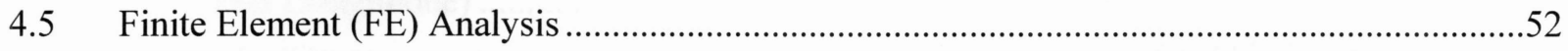

4.5.1 SOLID187 3-D 10-Node Tetrahedral Structural Solid....................................................52

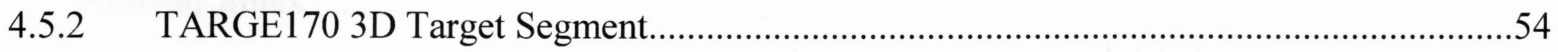

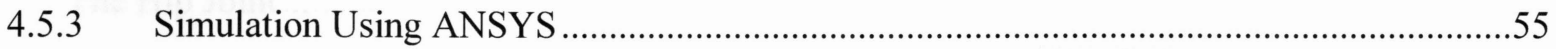

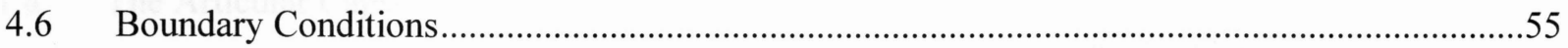

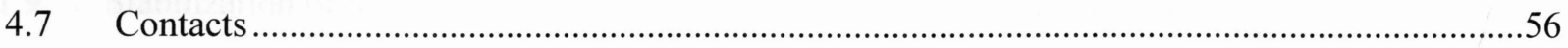

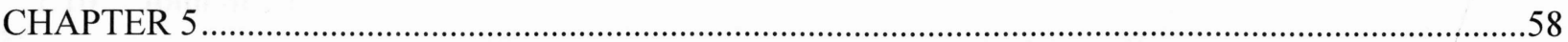




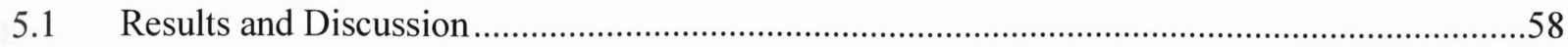

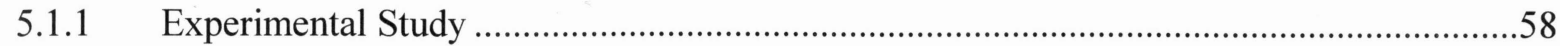

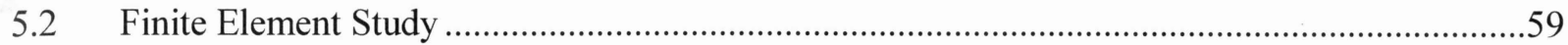

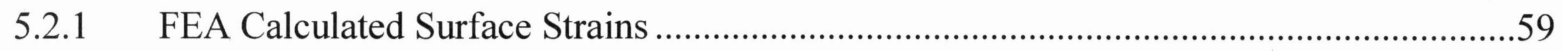

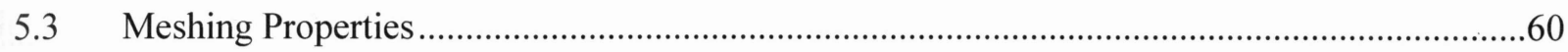

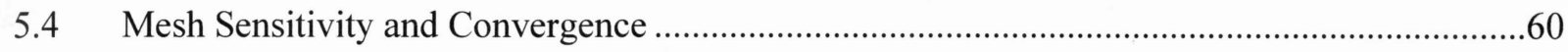

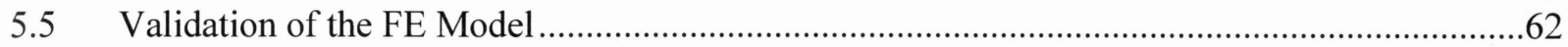

5.5.1 Comparing the Experimental and FEA Strain Measurements.............................................62

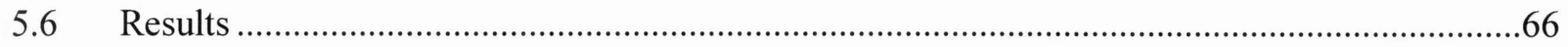

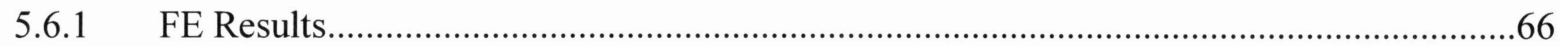

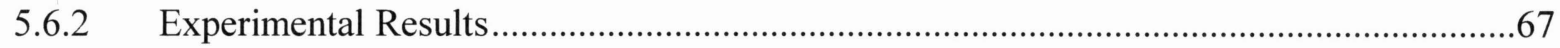

5.7 Validating the FE Model Using Experimental Results.................................................................68

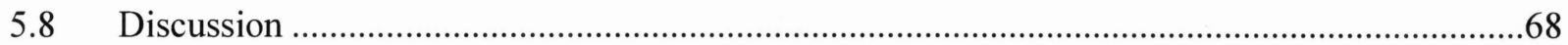

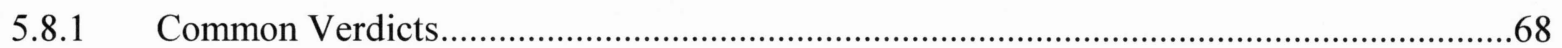

5.8.2 Composite Versus Standard Hip Implants...........................................................................68

5.8.3 Comparison with the Previous Studies............................................................................69

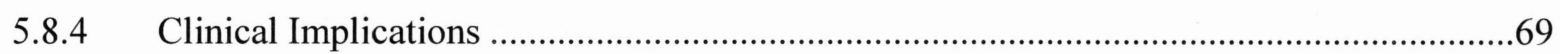

5.9 Concluding Statement and Future Considerations ………….....................................................

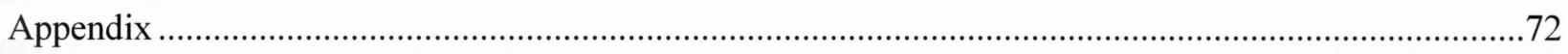

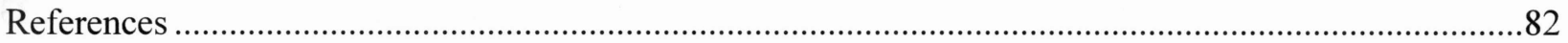




\section{List of Figures}

Figure 1.1An Arthritic Hip Joint (Left), An X-Ray of Artificial Hip Joint (Right) ..................................2

Figure 1.2 Number of Hospitalisations for Hip Replacements in Canada, 1995-2006 [27].......................5

Figure 1.3 Chart of Primary Surgeries Compared to Revisions, 2005-2006 [27] .................................6

Figure 1.4 The Right Femur, Anterior view (left), Posterior view (right) [31] .......................................

Figure 1.5 The Right Hip Joint (Coronal View) [31] .........................................................................

Figure 1.6 Anterior View (left), Posterior View (right) [32].......................................................... 10

Figure 1.7 A Healthy Hip (Left) and an Arthritic Hip (Right) [3] ......................................................11

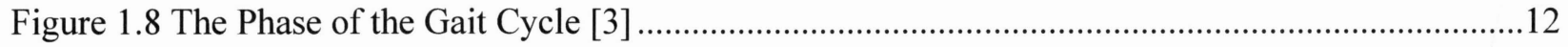

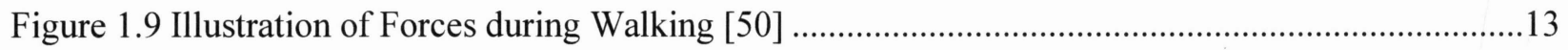

Figure 1.10 Comparison of Hip Motion during Walking of a Normal and an Osteoarthritic (OA) Subject

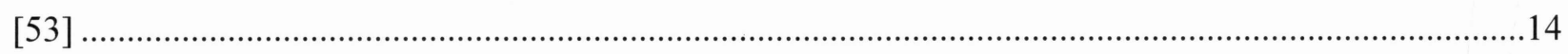

Figure 2.1 Normal Hip Joint (Left), and Diseased Hip Joint (Right) [3] .............................................20

Figure 2.2 Head of Femur and Layer of Hip Socket are Removed [3] .................................................21

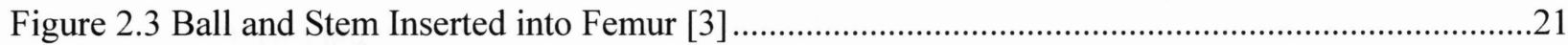

Figure 2.4 Before and After Prosthesis (Left), and an Illustration of Human Pelvis with a Healthy Hip Joint on the Right and an Artificial Hip Joint on the Left (Right) [3] ..................................................22

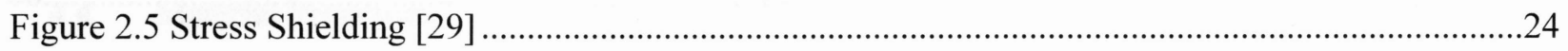

Figure 2.6 Inflatable Bladder Moulding to Manufacture CF/PA12 THA Femoral Stems [103]................26

Figure 2.7 Compression Stress-Strain Curve of CF/PA12 Cylinders by Campbell et al $[24,102] \ldots \ldots \ldots \ldots . .28$

Figure 2.8 Failed Stem Samples After Compression Testing: a) Barrelling, and b) Buckling Along the $45^{\circ}$

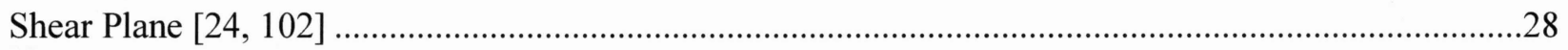

Figure 3.1 Vishay® 350-Ohms Uniaxial Linear-Pattern Strain Gauge Model CEA-06-125UW-350 [116] .33

Figure 3.2 Instron ${ }^{\circledR}$ FastTrack ${ }^{\mathrm{TM}} 8874$ (Left) [117], Instron ${ }^{\circledR}$ FastTrack ${ }^{\mathrm{TM}} 8800$ Controller Panel (Right) [118] .34

Figure 3.3 Three Lead Wire Conductors Separated and Soldered to a Strain Gauge. 37

Figure 3.4 Illustration of Circuit Options to Connect a Strain Gauge to the Quarter Bridge Circuit [120] 38

Figure 3.5 A Two-Channel DSub-15-Pin Connector can be attached to Wiring from Two Strain Gauges39 Figure 3.6 UNI2-8 All-Purpose Eight-Channel Amplifier (Left) [119] is Installed in the CRONOS-PL Unit to Accept the Four DSub-15 Connectors (Right) ...............................................................................39

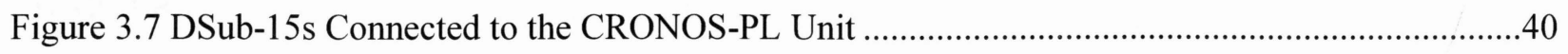


Figure 3.8 Locations of the Six Strain Gauges on All Three Hip Stems and the Virtual Axial Force on Their Femoral Heads

Figure 4.1 Composite (CF/PA12) Hip Stem and its components. (a). Hip Stem, (b). Femoral Head, (c). Cement Block, and (d). Acetabular Cup Indenter....

Figure 4.2 Stryker Exeter Hip Stem and its Components. (a). Hip Stem, (b). Femoral Head, (c). Cement Block, and (d). Acetabular Cup Indenter.

Figure 4.3 Stryker Omnifit Eon Hip Implant and its Components. (a). Hip Stem, (b). Femoral Head,

(c). Cement Block, (d). Acetabular Cup Indenter..... . .46

Figure 4.4 Transparent Assembly of the Composite Hip Stem 47

Figure 4.5 Transparent Assembly of the Stryker Exeter Hip Stem .48

Figure 4.6 Transparent Assembly of the Stryker Omnifit Eon Hip Stem ..............................................48

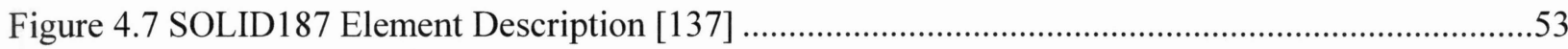

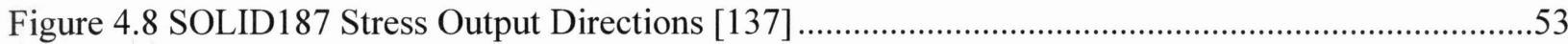

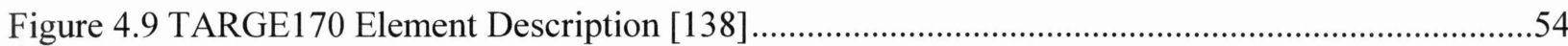

Figure 4.10 Boundary Conditions on the Assembly for the $3000 \mathrm{~N}$ Load .............................................55

Figure 4.11 Contact Locations in the Composite Hip Stem Assembly ..................................................56

Figure 4.12 Contact Locations in the Exeter Hip Stem Assembly .....................................................56

Figure 4.13 Contact Locations in the Omnifit Eon Hip Stem Assembly ............................................57

Figure 5.1 Column Chart Showing Gauge Locations and Their Corresponding Experimentally Measured

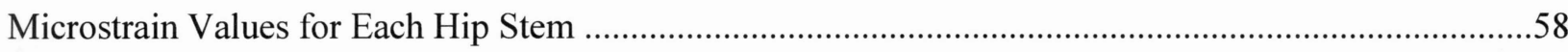

Figure 5.2 Column Chart Showing Gauge Locations and Their Corresponding Microstrains Values for

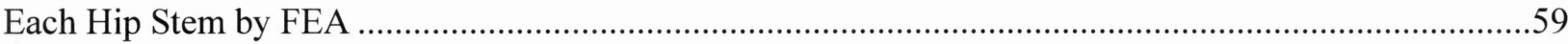

Figure 5.3 Locations of the Vertices Used to Test for Mesh Sensitivity ...............................................60

Figure 5.4 From Left to Right (Mesh Relevance 0\%, 20\%, 40\%, 60\%, 70\%, 80\%, 90\%, and 100\%,

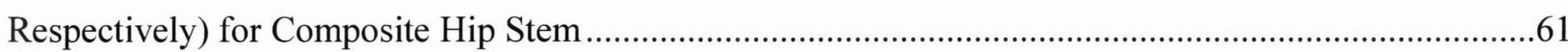

Figure 5.5 From Left to Right (Mesh Relevance 0\%, 20\%, 40\%, 60\%, 70\%, 80\%, 90\%, and 100\%, Respectively) for Exeter Hip Stem.

Figure 5.6 From Left to Right (Mesh Relevance 0\%, 20\%, 40\%, 60\%, 70\%, 80\%, 90\%, and 100\%, Respectively) for Omnifit Eon Hip Stem 61

Figure 5.7 Composite Hip Stem - Comparing FEA and Experimental Strain Measurements. .63

Figure 5.8 Composite Hip Stem - Comparing FEA and Experimental Strain Measurements. .64

Figure 5.9 Composite Hip Stem - Comparing FEA and Experimental Strain Measurements..... .64

Figure 5.10 Equivalent (Von-Mises) Elastic Microstrains for Composite, Exeter, and Omnifit Hip Stems, Respectively (From Left to Right) 
Figure 5.11 Equivalent (Von-Mises) Elastic Stresses for Composite, Exeter, and Omnifit Hip Stems,

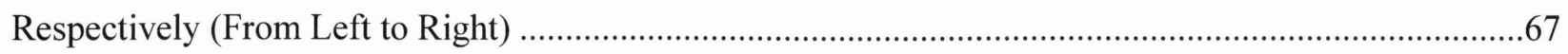

Figure 1 Change in Microstrain Values at Vertex 1 in the Composite Hip Stem ....................................72

Figure 2 Change in Microstrain Values at Vertex 2 in the Composite Hip Stem ....................................73

Figure 3 Change in Microstrain Values at Vertex 4 in the Composite Hip Stem ....................................73

Figure 4 Change in Microstrain Values at Vertex 1 in the Exeter Hip Stem ...........................................74

Figure 5 Change in Microstrain Values at Vertex 2 in the Exeter Hip Stem ..........................................75

Figure 6 Change in Microstrain Values at Vertex 4 in the Exeter Hip Stem .........................................75

Figure 7 Change in Microstrain Values at Vertex 5 in the Exeter Hip Stem ...........................................76

Figure 8 Change in Microstrain Values at Vertex 1 in the Omnifit Hip Stem ..........................................77

Figure 9 Change in Microstrain Values at Vertex 2 in the Omnifit Hip Stem ........................................77

Figure 10 Change in Microstrain Values at Vertex 4 in the Omnifit Hip Stem .......................................78

Figure 11 Change in Microstrain Values at Vertex 5 in the Omnifit Hip Stem .........................................79 


\section{List of Tables}

Table 1.1 Hip Replacements in Canada by Type of Surgery, 2002-2006 [27] ......................................6

Table 1.2 Mean Anisotropic Elastic Properties of Femoral Cortical Bone [57] ......................................15

Table 1.3 Mean Anisotropic Ultimate Properties of Femoral Cortical Bone [57] ..................................15

Table 1.4 Proximal Cancellous Bone Pproperties .......................................................................... 16

Table 2.1 CF/PA12 Composite Constituent Properties [103] ..............................................................27

Table 2.2 Compression Test Results of CF/PA12 Specimens by Campbell et al [24, 102] ....................27

Table 2.3 Compression Test Results of CF/PA12 Cylinders Compared to Cortical Tissue [25]...............30

Table 3.1 Vishay® 350-Ohms Strain Gauge Specifications [116] ....................................................33

Table 4.1 Cobalt-Chromium Alloy Properties ...............................................................................

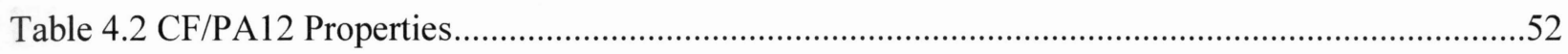

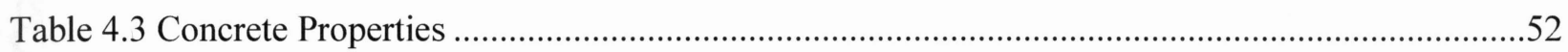

Table 5.1 Gauge Locations and Their Corresponding Experimentally Measured Microstrain Values for

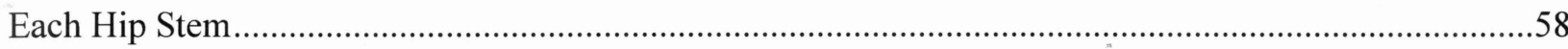

Table 5.2 Gauge Locations and Their Corresponding Microstrain Values for Each Hip Stem by FEA.....59

Table 5.3 Mesh Characteristics, Nodes and Associated Vertex Microstrains ...........................................62

Table 5.4 FEA and Experimental Surface Strain Results for Composite Hip Stem (Location of Gauge Readings Suspected of Error are Shaded in Grey)

Table 5.5 FEA and Experimental Surface Strain Results for Exeter Hip Stem (Location of Gauge Readings Suspected of Error are Shaded in Grey)

Table 5.6 FEA and Experimental Surface Strain Results for Omnifit Hip Stem (Location of Gauge

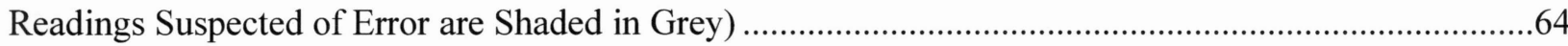

Table 5.7 Microstrain Distribution Obtained From FE Analysis on the Hip Prostheses..........................66

Table 1 Mesh Relevance, Nodes, and Microstrain Values at Vertex 1 in the Composite Hip Stem...........72

Table 2 Mesh Relevance, Nodes, and Microstrain Values at Vertex 2 in the Composite Hip Stem...........72

Table 3 Mesh Relevance, Nodes, and Microstrain Values at Vertex 4 in the Composite Hip Stem...........73

Table 4 Mesh Relevance, Nodes, and Microstrain Values at Vertex 1 in the Exeter Hip Stem.................74

Table 5 Mesh Relevance, Nodes, and Microstrain Values at Vertex 2 in the Exeter Hip Stem.................74

Table 6 Mesh Relevance, Nodes, and Microstrain Values at Vertex 4 in the Exeter Hip Stem.................75

Table 7 Mesh Relevance, Nodes, and Microstrain Values at Vertex 5 in the Exeter Hip Stem.................76

Table 8 Mesh Relevance, Nodes, and Microstrain Values at Vertex 1 in the Omnifit Hip Stem ..............76

Table 9 Mesh Relevance, Nodes, and Microstrain Values at Vertex 2 in the Omnifit Hip Stem ..............77

Table 10 Mesh Relevance, Nodes, and Microstrain Values at Vertex 4 in the Omnifit Hip Stem .............78 
Table 11 Mesh Relevance, Nodes, and Microstrain Values at Vertex 5 in the Omnifit Hip Stem ............78

Table 12 Microstrain Ratios of Composite/Exeter and Their Average Value..........................................79

Table 13 Microstrain Ratios of Composite/Omnifit and Their Average Value .......................................79

Table 14 Microstrain Ratios of Exeter/Omnifit and Their Average Value .............................................80

Table 15 Microstrain Ratios of Composite/Exeter and Their Average Value..........................................80

Table 16 Microstrain Ratios of Composite/Omnifit and Their Average Value .....................................8

Table 17 Microstrain Ratios of Exeter/Omnifit and Their Average Value .............................................80

Table 18 FEA and Experimental Surface Microstrain, \%Difference and Their Aggregate Average

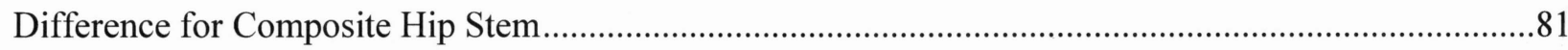

Table 19 FEA and Experimental Surface Microstrain, \%Difference and Their Aggregate Average

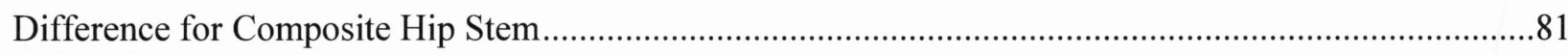

Table $20 \mathrm{FEA}$ and Experimental Surface Microstrain, \%Difference and Their Aggregate Average

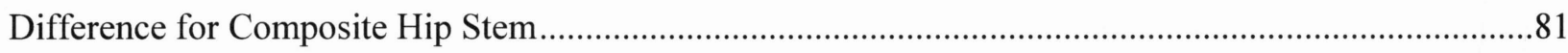




\section{List of Medical Terminology [1,2]}

Abduction

Adduction

Arthritis

Arthroplasty

Articular

Biomimetic

Cancellous Bone

Cortical

CT or CAT

Diarthrosis

Distal

Femur

Lateral

Medial

Osteoarthritis

Osteolysis

Osteoporosis

Prosthesis

Proximal outward movement, away from the median axis of the body

inward movement, towards the median axis of the body

acute or chronic inflammation of a joint, often accompanied by pain and structural changes and having diverse causes, as infection, crystal deposition, or injury

the surgical repair of a joint or the fashioning of a movable joint, using the patient's own tissue or an artificial replacement

of or related to the joints

imitating biology and/or living tissue

spongy bone tissue

hard, compact bone tissue

computer tomography or computed axial tomography; an X-ray technique for producing cross-sectional image of the body

freely movable joint, synovial joint

situated away from the point of origin or attachment, as of a limb or bone; terminal

thighbone; a bone in the human leg extending from the pelvis to the knee, that is the longest, largest, and strongest in the body

direction away from the midline of the body or the sagittal plane

inward direction towards the midline of the body

the most common form of arthritis, usually occurring after middle age, marked by chronic breakdown of cartilage in the joints leading to pain, stiffness, and swelling.

dissolution or degeneration of bone tissue through disease

increase in bone porosity and subsequent decrease in bone density through disease; usually occurs after osteopenia

an implant; a device, either external or implanted, that substitutes for or supplements a missing or defective part of the body

situated toward the point of origin or attachment, as of a limb or bone 
Resorption

Sagittal plane

Synarthrosis

Synovial dissolution or removal of a substance; e.g. bone tissue a longitudinal plane that divides the body of a bilaterally symmetrical animal into right and left sections

immovable joint

belonging to, or related to the synovial joint or diarthrosis (see diarthrosis) 


\section{List of Abbreviations}

ACL Anterior Cruciate Ligament

AP

Anteroposterior

ASTM American Society of Testing and Materials

BMD Bone Mineral Density

CF Carbon Fibre

CF/PEEK Carbon Fibre-Reinforced Polyether-Ether-Ketone

CIHI Canadian Institute for Health Information

CJRR Candian Joint Replacement Registry

CoCrMo Cobalt-Chromium-Molybdenum Alloy

CT

Computer Tomography, or Computed Axial Tomography (CAT)

DICOM Digital Imaging and Communications in Medicine

FEA Finite Element Analysis

GF Gauge Factor

IGES Initial Graphics Exchange Specification

IV Intravenus

NSAID Non-Steroidal Anti-Infalmmatory Drug

OA Osteoarthritis

PA Polyamide

PCA Porous Coated Anatomical

PCL Posterior Cruciate Ligament

PMMA Polymethyl Methacrylate

THA Total Hip Arthroplasty 


\section{Nomenclature}

\section{Latin}

$\begin{array}{ll}A & \text { Cross section area of a conductor } \\ I & \text { Current } \\ E & \text { Elastic modulus / Modulus of elasticity / Young's modulus } \\ G & \text { Shear modulus } \\ G F & \text { Gauge factor of a strain gauge } \\ L & \text { Length of a conductor/resistor (e.g. strain gauge foil) } \\ R & \text { Resistance of a conductor } \\ R_{1}, R_{2}, R_{3}, R_{4} & \text { Resistance of a Wheatstone bridge circuit element } \\ R_{G} & \text { Resistance of a strain gauge } \\ V & \text { Voltage } \\ V_{E X} & \text { Source excitation voltage in a Wheatstone bridge ciruit } \\ V_{o} & \text { Output voltage in a Wheatstone bridge circuit }\end{array}$

\section{Greek}

$\Delta$

$\Omega$

$\varepsilon$

$\mu \varepsilon$

$v$

$\rho$
Change in a property; usually followed by the notation of the property

Ohms, unit of resistance

Strain

Microstrain $\left(\varepsilon \times 10^{-6}\right)$

Poisson's ratio

Resistivity of a conductor 


\section{CHAPTER 1}

\subsection{Introduction}

Humans encounter many dangers from day to day life; however, some of these dangers are often masked. For example, playing on a swing set, running down a flight of stairs or even playing hockey are all activities that don't appear threatening; however, by examining all the possible scenarios, it becomes evident that bodily harm (fractures) can be caused by numerous things. Usually, dangerous sports or the day to day accidents carry most of the blame. The femur bone is the biggest, strongest and longest bone in the entire human body. Located in the thigh area, the femur is usually very strong; however, when excess force is added, pressure builds and the femur becomes damaged. Osteoporosis is another form of damage to the bones. Usually found in the elderly, this disease can cause severe deterioration in the bones. In this particular illness, the bone mineral density (BMD) is reduced. Mostly found in women after menopause, osteoporosis can also develop in men and can also occur in the presence of hormonal disorders, as well as other chronic diseases. Most doctors and specialists say that, based on studies, the life expectancy of the patient, as well as the quality of life can be greatly affected. Osteoporosis is one of many different variations of bone diseases that can be contracted over a lifetime. It can cause the bones to become brittle which results in the weakening of the bones. The consequences of these illnesses can cause bones to break easily, as well as develop cancer [3, 4].

Total hip arthroplasty is the ideal treatment for people with degenerative hip diseases. THR (total hip replacement) is one of the most successful, as well as common surgical procedures performed today. After such a procedure, most patients regain regular range of motion, better physical ability and an improved quality of life. THR could be performed on the hip joint, composed of a ball and a socket covered in cartilage. Throughout these procedures, doctors may choose to replace both the ball and the socket or simply one of the two. Figure 1.1 shows diagrams of hip arthroplasty on a left hip bone, as well as an x-ray demonstrating the after effects of the surgery and what is left inside the body $[4,5]$. 

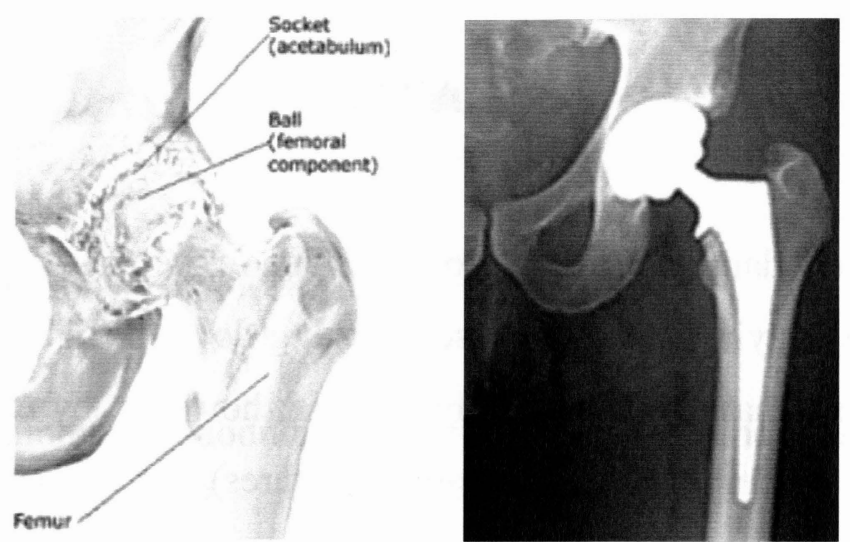

Figure 1.1An Arthritic Hip Joint (Left), An X-Ray of Artificial Hip Joint (Right)

Around one million people worldwide undergo total hip arthroplasty each year, with high clinical success rates reported to be $93 \%$ at 10 years and $85 \%$ at 15 years following surgery [6]. This is the most widespread surgical treatment for addressing the severe pain, loss of function, and instability associated with degeneration of articular cartilage of the human hip joint and surrounding soft tissue inflammation. This condition then leads to high or uneven stress distributions across the hip joint surface [7-9]. The most commonly used implant in hip arthroplasty surgeries is the THR, which consists of a cobalt-chrome or ceramic femoral head that is inserted over the neck of a cobalt-chrome or titanium alloy stem. The surgical procedure for implanting such a device involves removal of the patient's natural femoral head and insertion of the stem into the canal. The most susceptible regions to failure in these standard metallic THR are those where two contacting surfaces have similar mechanical properties, such as implantcement, bone-cement, and implant interfaces. Bone stress shielding is a persistent challenge because of the large difference in mechanical stiffness between the metallic stem and the host femur, which subsequently leads to bone resorption and implant loosening. This has motivated the development of hip stems from other materials which are more closely stiffness matched with the host femur. One approach is the use of low modulus titanium based alloys, which have an elastic modulus ranging from 60-80 GPa. When compared with conventional biomedical titanium (Ti-6Al-4V) stems, the low modulus alloys are able to reduce stress shielding, but their moduli are still 4-5 times higher than that of the host femur [10-17]. To overcome the problem of stress shielding and bone resorption, carbon fibre composite stems have shown reasonable results. Carbon fibre polyamide12 (CF/PA12) is biocompatible and its cross weave surface texture permits good bony on-growth. It can reduce stress shielding as compared to a stainless 
steel stem, and from mechanical tests, it is observed that it is similar to the flexural modulus of human cortical bone [18-25].

There has been no experimental study that determined the surface strains and stresses of hip prostheses manufactured from $\mathrm{CF} / \mathrm{PA} 12$ and compared them directly to standard metallic hip stems under the same conditions. The basic purpose of this study was to compare the mechanical behaviour of the novel composite hip stem with two commercially available metallic hip stems, Exeter and Omnifit, manufactured by Stryker (Mahwah, NJ, USA). An FE model was developed to find the hip stress and strain values under elastic axial load and these values were validated using experimental tests. To reduce stress shielding and minimize implant loosening, it was assumed that the composite hip stem would carry less axial load as compared to the two metallic hip implants.

This study covers a broad range of disciplines between physiology and engineering, the reviewed literature has been divided under relevant chapters for the convenience of the reader. Chapter 2 describes the statistics of primary orthopaedic replacements conducted in Canada and discusses the increasing number of primary and revision hip replacements procedures. Chapter 3 provides a description of the human hip, touching on relevant subtopics of joint anatomy, diseases, biomechanics, and mechanical properties. Chapter 4 discusses hip replacements, prosthetic hip implants and their failure, indications for the replacement of hip joint, stress shielding, bone resorption, and descriptions of polymer composites relevant to this study. Chapter 5 lays out the research question, the goals and scope of this study. Chapter 6 describes the experimental study conducted, the stain gauges used in the experimental study, and preparation of hip implants for the experiment. Chapter 7 describes and displays the CAD modelling of the implant geometry required to develop the finite element model. Chapter 8 concerns all the finite element analysis conducted for this study, including tests of the conventional and composite femoral components. Chapter 9 discusses the results of the experimental and finite element studies, their validation and their interpretation. Chapter 10 discusses the limitations of this study, a brief commentary on the future work possible based on this study, including the potential of the validated finite element model developed in this study for further hip implant-related research. 


\subsection{Motivation}

Osteoarthritis (OA), also known under the term "wear and tear", is the most common form of arthritis. Osteoarthritis can become apparent when the cartilage gradually begins to break down. As this cushioning is continually reduced, the patient can begin to feel pain in the joints: the back, knees, hips and feet usually fall victim to this type of arthritis because of the high weight bearing [26]. As the life expectancy increases, it is no surprise that OA also increases, as obesity is one of the influencing factors associated with OA [5]. OA comprises a large group of disorders affecting the joints, ligaments, tendons, bones and other components of the musculoskeletal system. Hip replacements provide great success as treatment for hip joint arthritis. These procedures are a successful way of improving not only the quality of life, but also improving chronic pain. Not only is it a cost-effective treatment, but it can also increase the patient's ability to function independently in day to day life. Successful replacements of damaged, arthritic and badly injured hips have contributed to enhanced mobility and comfortable, independent living for many people who would otherwise be disabled [27].

\subsubsection{Statistical Analysis of Hip Replacements in Canada}

The Canadian Joint Replacement Registry (CJRR) is an organization that collects demographic, surgical and implant data on hip replacement procedures in Canada. Managed by the Canadian Institute of Health Information (CIHI), the CJRR has already recognized 68,746 hospitalizations for hip and knee replacements for Canadian residents in 2005-2006. Many studies have indicated that since 1995-1996, there has been a significant 10 year increase of $101 \%$ from only 34,281 procedures as well as a one year increase of 17\% from only 58,714 procedures in 2004-2005. This one year increase is superior to that observed in the last fiscal year, when only one year augmentation from the previous year was approximately $9.7 \%$. The studies conducted by the CJRR have also concluded that in 1995-1996, the number of hip replacements $(17,358)$ have significantly exceeded the knee replacements in Canada (16,923). In the year 2005-2006, the number of hospitalizations for knee replacements stood respectively at 40,701 and 28,045 hospitalizations were counted for hip replacements. With these statistics, it is evident that knee replacements in 2005-2006 have almost doubled since 1995-1996. The number of hip replacements has increased by $62 \%$ in comparison to $1995-1996$, and by $12 \%$ in comparison to 2004-2005 as shown in Figure 1.2 [27]. 
Of the 13,000 hip replacements performed on Canadians in 2005-2006, 11,430 (88\%) involved primary surgeries and the remaining 1,521 involved revisions. Of the revisions, 1,094 surgeries ( $8.5 \%$ of the total) were first revisions, $248(1.9 \%)$ were second revisions, $83(0.6 \%)$ were third revisions, and the remaining $0.2 \%$ are fourth revisions.

Figure 1.3 puts these statistics in perspective. In the Table 1.1, column ' $\mathrm{N}$ ' displays the number of replacements, and the column '\%' displays the same data as a percentage of the total number of replacements performed in that year.

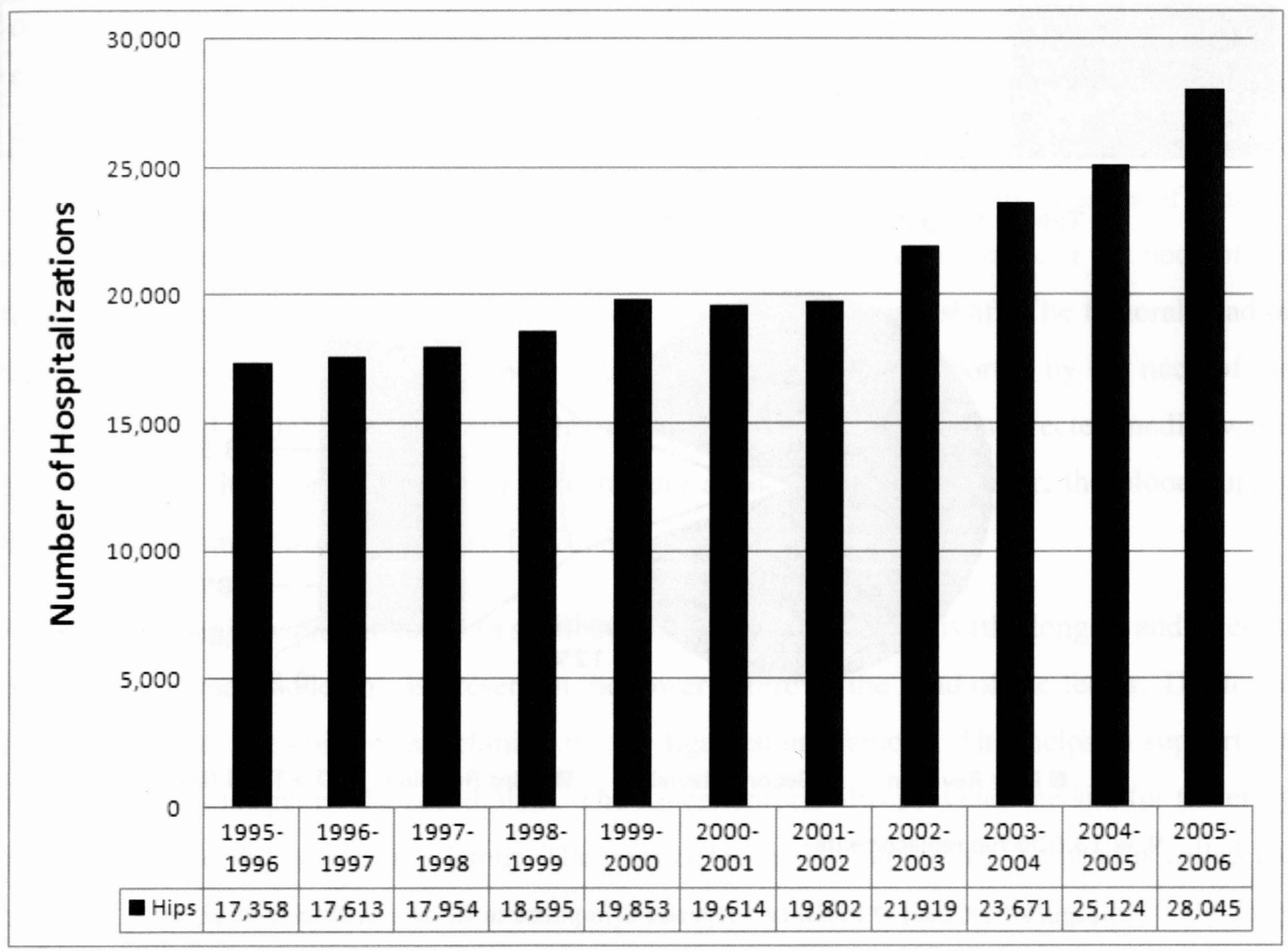

Figure 1.2 Number of Hospitalisations for Hip Replacements in Canada, 1995-2006 [27] 


\begin{tabular}{|l|r|r|r|r|r|r|r|r|r|}
\hline \multirow{2}{*}{$\begin{array}{l}\text { Type of } \\
\text { Replacement }\end{array}$} & \multicolumn{2}{|c|}{$2002-2003$} & \multicolumn{2}{|c|}{$2003-2004$} & $2004-2005$ & \multicolumn{2}{|c|}{$2005-2006$} & \multicolumn{2}{|c|}{$\begin{array}{l}\text { 3-Year } \\
\text { Increase }\end{array}$} \\
\cline { 2 - 12 } & $\mathbf{N}$ & $\%$ & $\mathbf{N}$ & $\%$ & $\mathrm{~N}$ & $\%$ & $\mathbf{N}$ & $\%$ & $\%$ \\
\hline Primary & 7,520 & $\mathbf{8 7}$ & 10,154 & $\mathbf{8 7}$ & 12,687 & $\mathbf{8 8}$ & 11,430 & 88 & 52 \\
\hline Revision & 1,111 & 13 & 1,555 & 13 & 1,691 & 12 & 1,521 & 12 & 37 \\
\hline First revision & 804 & 9 & 1,123 & 10 & 1,247 & 9 & 1,094 & 8 & 36 \\
\hline Second revision & 224 & 3 & 306 & 3 & 316 & 2 & 248 & 2 & 11 \\
\hline Third revision & 65 & 1 & 80 & 1 & 80 & 1 & 83 & 1 & 28 \\
\hline$>$ Third revision & 18 & 0 & 46 & 0 & 48 & 0 & 32 & 0 & 78 \\
\hline Excision & 4 & 0 & 3 & 0 & 11 & 0 & 8 & 0 & 100 \\
\hline Not Stated & 14 & 0 & 17 & 0 & 44 & 0 & 41 & 0 & 193 \\
\hline Total & $\mathbf{8 , 6 4 9}$ & 100 & 11,729 & 100 & 14,433 & 100 & 13,000 & 100 & 50 \\
\hline
\end{tabular}

Table 1.1 Hip Replacements in Canada by Type of Surgery, 2002-2006 [27]

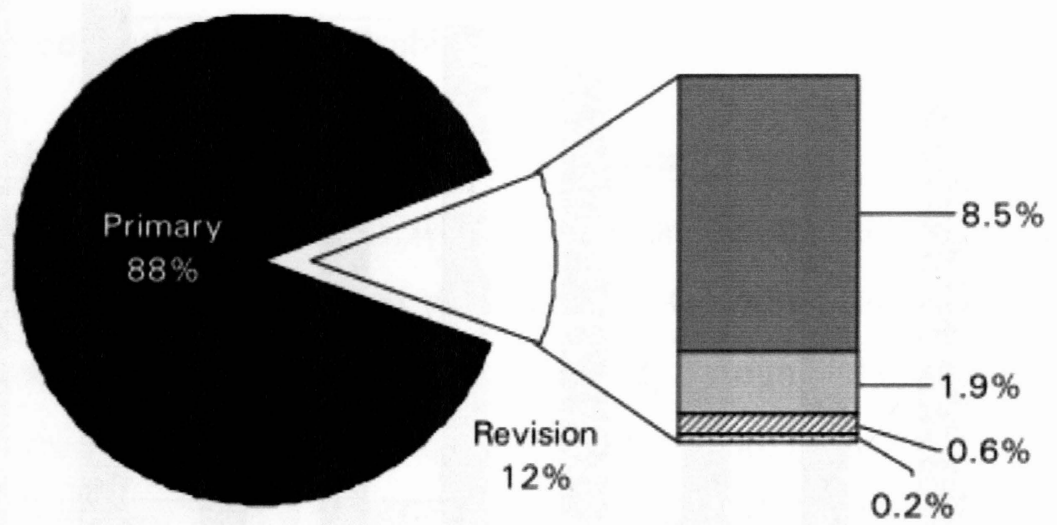

a First Revision $\square$ Second Revision $\square$ Third Revision $\square>$ Third Revision

$\mathrm{N}=13.000$ hip replacements

Figure 1.3 Chart of Primary Surgeries Compared to Revisions, 2005-2006 [27]

It is clear from the Table 1.1 that primary and revision surgeries have generally increased since 2002-2003. The trend in primary hip replacement procedures and the subsequent increase in revision surgeries indicate that this procedure will continue to remain a popular treatment for hip joint arthritis. The Canadian Joint Replacement Registry states that increase in revision surgeries is driven by the annual increase in primary hip replacements [27]. 


\subsection{The Human Skeletal System}

The human body is supported by a framework of strong bones that are linked at moveable joints. It consists of 206 bones that act as scaffolding for our body and allow us to move with precision and fluidity. Their main function is to produce blood cells and store important minerals, much needed by our body [28].

\subsection{The Femur (Thighbone)}

The femur, also known as the thighbone, is the longest, heaviest and strongest bone in the human body. At the proximal (at the acetabulum) is the hip and at the distal end (distant from the body) is the knee, in other words, it is the bone in the leg that extends from the hip to the knee. The average human femur is 48 centimetres (19 in) in length and $2.34 \mathrm{~cm}$ (0.92 in) in diameter, and can support up to 30 times the weight of an adult. The proximal end mainly consists of femoral neck and femoral head which can be seen in the Figure 1.4. The femoral neck or the neck of the femur is a flattened bone connecting the femoral head with a femoral shaft. The femoral head or the head of the femur is the highest part of the thigh bone and is supported by the neck of the femur. The head is globular and forms rather more than a hemisphere. It is directed medial-ward, upward, and a little forward. If there is a fracture at the neck of the femur, the blood supply through the ligament becomes crucial $[3,29,30]$.

A roughened shallow pit, the fovea (a small cuplike depression) femoris (the longest and thickest bone of the human skeleton), is present in the lower centre of the head of the femur. The fovea femoris provides the point of attachment for the ligamentum femoris. This helps to support the head of the femur against the acetabulum. The fovea femoris also provides the site for the entry of an artery into the head of the femur. The constricted region supporting the head is called the neck and, due to its fragility, can be commonly fractures in older bones, which makes the elderly very susceptible for those types of injuries [31]. 


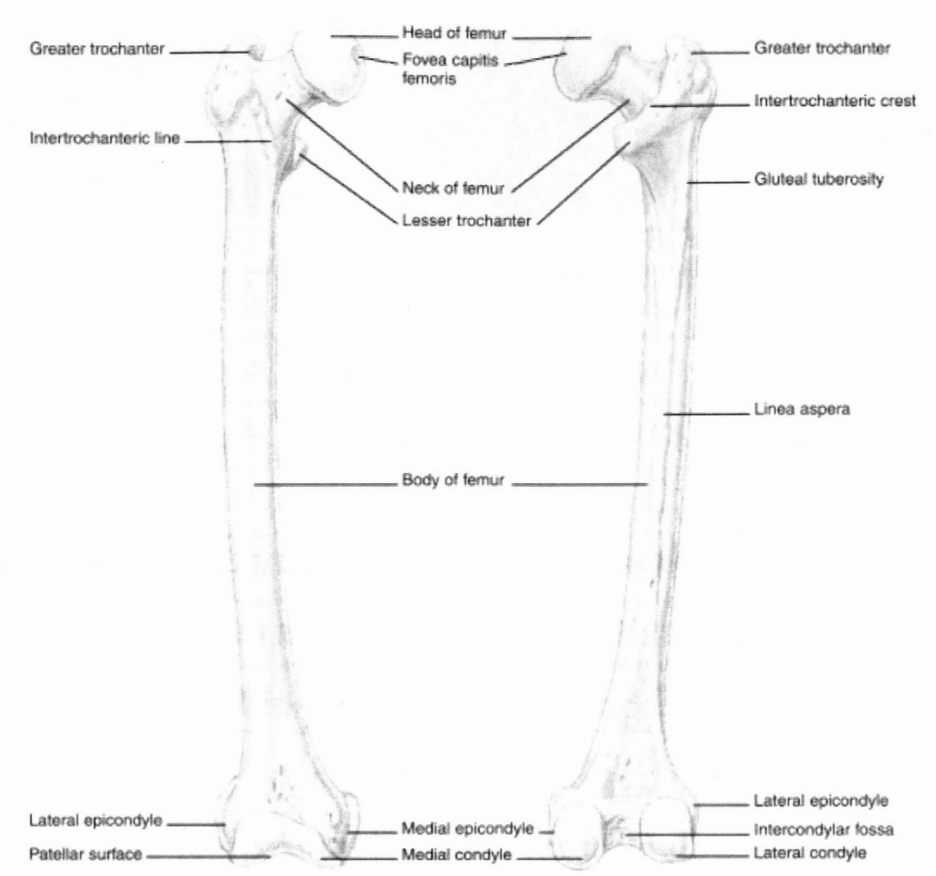

Figure 1.4 The Right Femur, Anterior view (left), Posterior view (right) [31]

\subsection{Classification of Joints}

The meeting places of bones throughout the body are also known as joints. Joints known as gliding joints move smoothly across each other, hinge joints simply bend and the ball socket joints can move in a variety of directions [28]. Each joint tolerates a specific range of motion, and a variety of bony surfaces, cartilages, ligaments, tendons, and muscles work together to keep movement within the normal range. Joints are usually divided into three categories, based on the range of motion permitted: the immovable joint is a synarthrosis joint, a joint capable of slight movement is known as an amphiarthrosis joint and the joints that have free movement are known as a diarthrosis or a synovial joint. These synovial joints are specialized for movement, permitting a wide range of motion. Usually, under normal conditions, the bony surfaces located in the synovial joints do not come in contact with one another because of the specific articular cartilage. These cartilages are comprised of soft tissues which act as shock absorbers and also help in reducing friction within the joint [32].

\subsection{Synovial Joints}

Synovial joints are complex joints and are bounded by joint capsule containing synovial fluid. The synovial joints are composed of a thick layer of dense connective tissues. A synovial 
membrane lines the joint cavity but stops at the edges of the articular cartilages. Membranes in the synovial joint produce the fluid that fills the joint cavity. Synovial fluid not only provides lubrication for the joint, but also acts as a shock absorber [32].

Based on the shape of the articular surfaces and the kinds of motion they permit, synovial joints are categorized as gliding, hinge, pivot, condyloid, saddle, and ball-and-socket joints [31].

\subsection{The Hip Joint}

The hip is a ball and socket joint. Primarily, it functions as a ball bearing. The complex design allows the hip to flex, extend and move from side to side (also called abduction and adduction), and rotate (called internal and external rotation) [33].

\subsection{The Articular Capsule}

The articular capsule of the hip joint is extremely dense, strong, and deep. Unlike the capsule of the shoulder joint, the capsule of the hip joint contributes extensively to joint stability. The capsule extends from the lateral and inferior surfaces of the pelvic girdle to the intertrochantric line and intertrochantric crest of the femur, enclosing both the femoral head and neck. This arrangement helps keep the head from moving away from the acetabulum. Moreover, a circular rim of fibrous cartilage, called the acetabular labrum, increases the depth of the acetabulum [32]. Figure 1.5 shows coronal view of the right hip joint and labels some of the important parts.

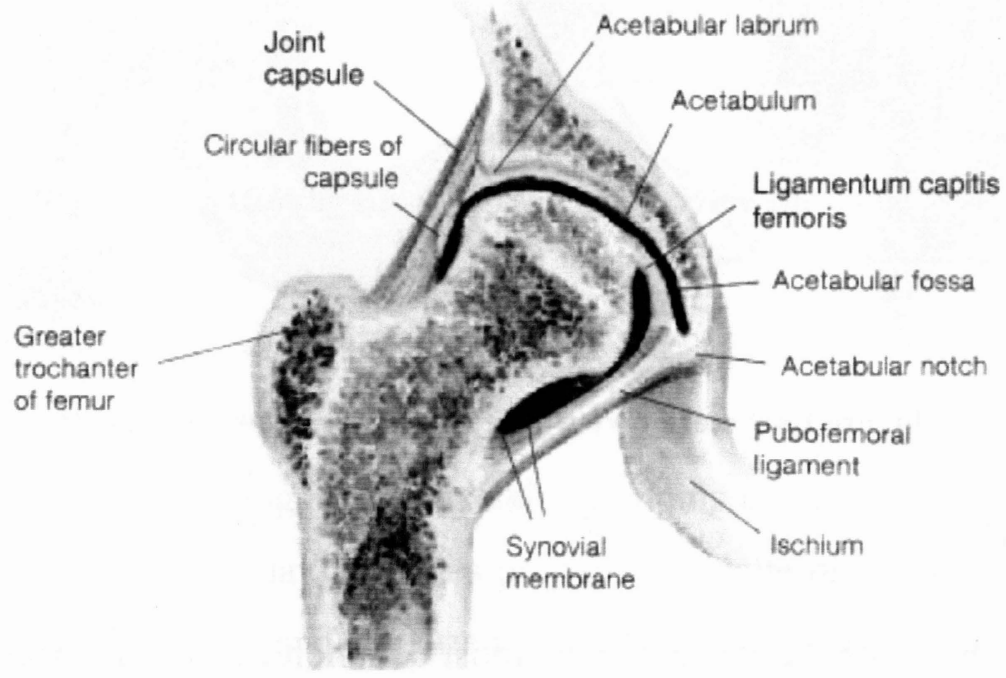

Figure 1.5 The Right Hip Joint (Coronal View) [31] 


\subsection{Stabilization of the Hip}

Like any other joint or bone in our body, it is always important to keep it in the greatest health possible. Therefore, it is always essential to exercise and keep hip stability whenever possible. The hip is a very important part of the human body, responsible for much of our mobility. Keeping fit is, not only the new trend adapted by our society, but very important to a healthy as well as a longer life. Hip stabilization is comprised of four broad ligaments made to reinforce the articular capsule. Three of those ligaments: the iliofemoral, pubofemoreal and ischiofemoral, are regional thickenings of the capsule. The transverse acetabular ligament crosses the acetabular notch and completes the inferior border of the acetabular fossa. Any additional stabilization of the hip joint is provided by the bulk of the surrounding muscles. Although flexibility, extension, adduction, abduction and rotation are permitted, hip flexion is the most important movement. All of these movements are restricted by the combination of ligaments, capsular fibers, depth of the bony socket, and the bulk of the surrounding muscles. The semi-complete bony socket enclosing the head of the femur, the strong articular capsule, the stout supporting ligaments, and the dense muscular padding make this an extremely stable joint [32]. Figure 1.6 shows the anterior and posterior views of the hip joint.

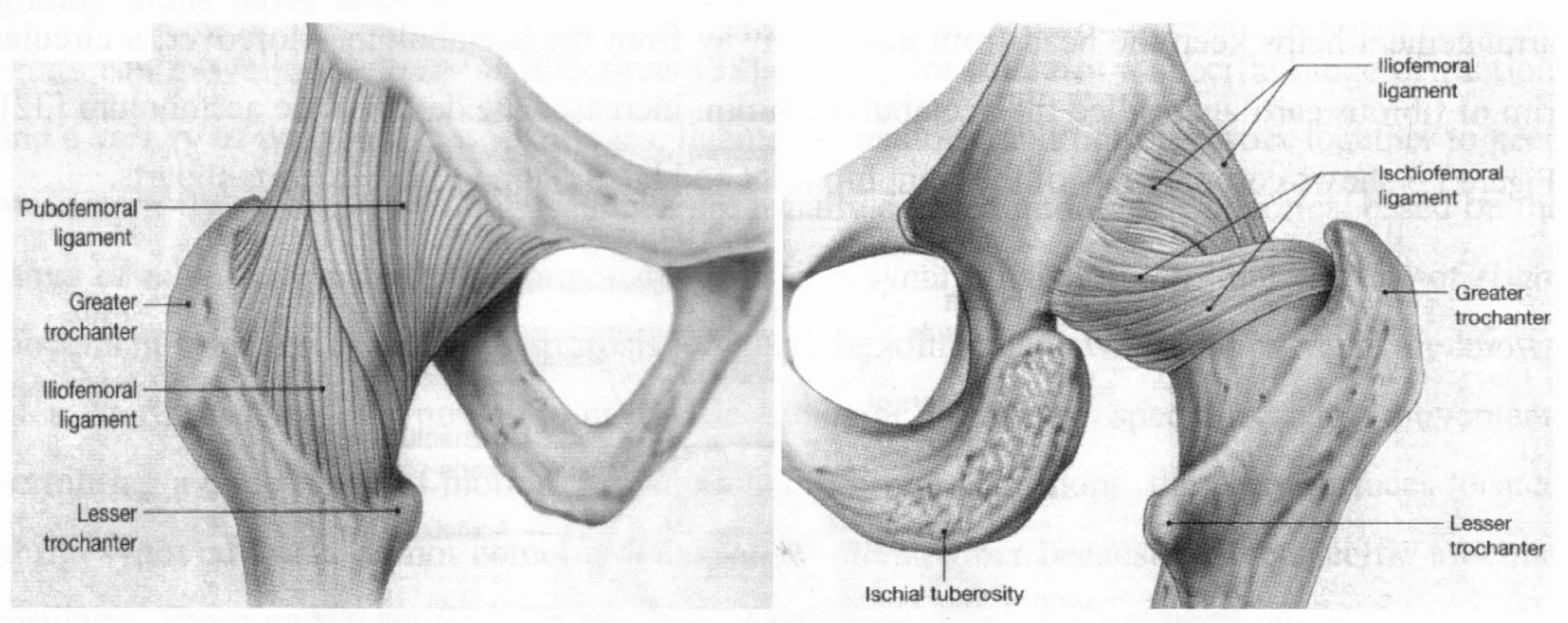

Figure 1.6 Anterior View (left), Posterior View (right) [32]

\subsection{Joint diseases}

Osteoarthritis and rheumatoid arthritis are the most common causes of chronic hip pain and loss of hip function. Osteoarthrits is the most common form of arthritis, usually occuritng after 
middle age. It starts with the breakdown of cartilage in the joints, which causes the bones to rub against one another, leading to pain, stiffness, and swelling. In an osteoarthritic hip joint the quantity of bone mass close to the joint surface increases, this is called sclerosis because the bone substance is harder. The contours of the bone ends enlarge and bony spurs form at the periphery of the hip joint. Small fragments of joint cartilage float in the joint space and cause secondary inflammation of the synovium (the lining of the joint space) with swelling of the joint. Rheumatoid arthritis is a condition where the synovial membrane thickens and inflames, secreting too much synovial fluid into the joint space. Chronic inflammation of the synovial membrane can lead to a loss of articular cartilage, and subsequently loss of joint function. This contributes to much pain, and gradual functional loss of the hip [3, 34, 35]. A healthy and an arthritic hip joint are shown in Figure 1.7.

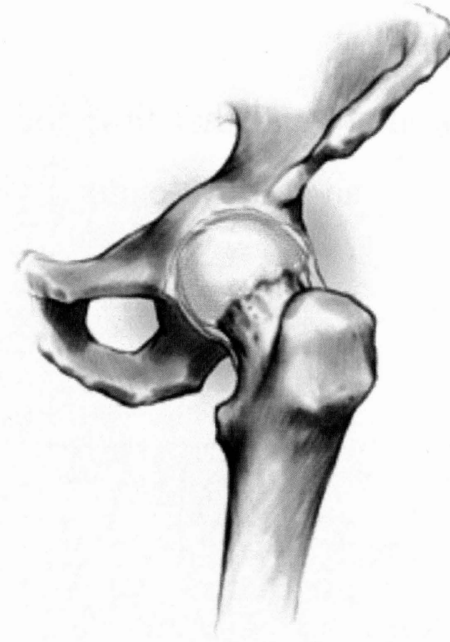

A Healthy Hip

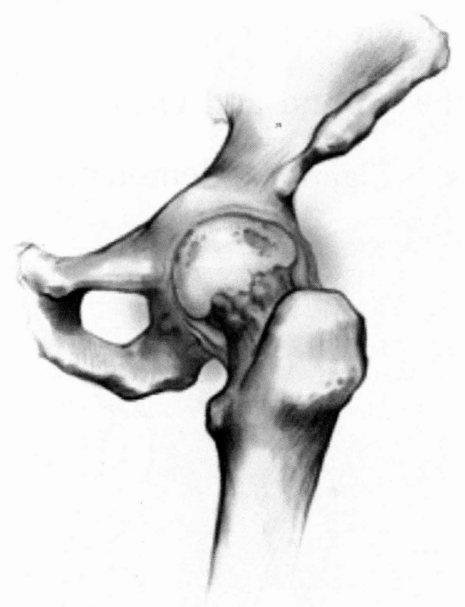

An Arthritic Ho

Figure 1.7 A Healthy Hip (Left) and an Arthritic Hip (Right) [3]

\subsection{Biomechanics}

\subsubsection{The Gait Cycle}

For everyday tasks such as walking, climbing stairs, jumping and running etc, the hip joint is an integral mechanism. These everyday activities produce a unique biomechanical load pattern on the hip joint. The most common and important activity is simple level walking. Walking is a repeated cycles of gait, in which one gait cycle is understood to begin when one foot contacts the ground until the same foot contacts the ground again [3, 36-38]. It is estimated that an average 
adult takes around 1-1.5 million steps annually [39]. There are two primary phases of gait, the stance phase and the swing phase. Stance phase is $60 \%$ of the gait and the swing phase is $40 \%$ approximately [38]. The loading response, mid-stance, terminal stance, and the pre-swing are the further divisions of the stance phase. The moment at which the foot comes into contact with the ground is the beginning of the loading response. It ends when the toes of the opposite leg leave the ground. Mid-stance begins at the contralateral toe-off, and ends when the body centre of gravity is directly over the reference foot. At this moment, the terminal stance starts and ends when the foot of the other leg contacts the ground. At the contralateral initial contact, the preswing begins and ends when the toes of the reference leg leave the ground [3, 36, 38, 40, 41]. The initial swing, mid-swing, and the terminal swing are the further divisions of the swing phase. The initial swing stage starts at toe-off, and continues until the reference knee reaches a maximum flexion of around 60 degrees. Mid-swing starts and ends from the maximum knee flexion to until the knee is perpendicular to the ground. Terminal swing starts when the knee is perpendicular to the ground and ends at initial contact and that time the gait cycle starts over again $[3,36,38,40]$. Figure 1.8 demonstrates the human gait cycle along with the percentages of stance and swing phases.

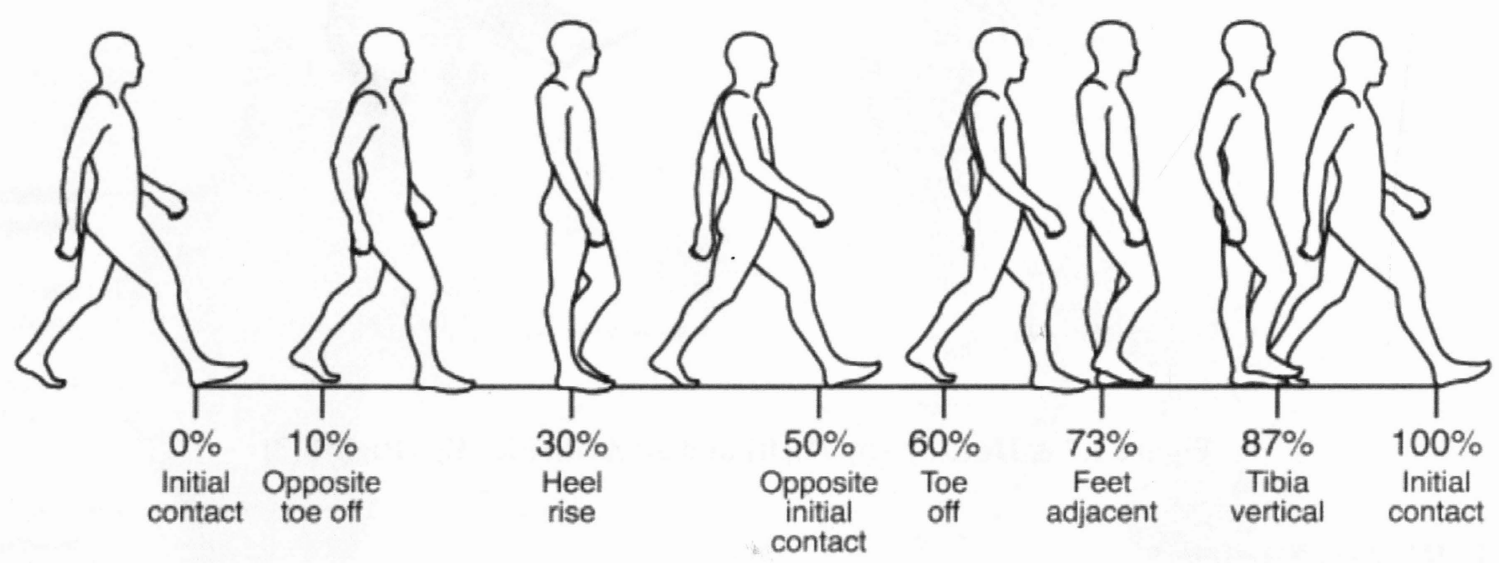

\begin{tabular}{|l|c|c|c|c|c|c|}
\hline $\begin{array}{c}\text { Loading } \\
\text { response }\end{array}$ & $\begin{array}{c}\text { Mid } \\
\text { stance }\end{array}$ & $\begin{array}{c}\text { Terminal } \\
\text { stance }\end{array}$ & $\begin{array}{c}\text { Pre } \\
\text { swing }\end{array}$ & $\begin{array}{c}\text { Initial } \\
\text { swing }\end{array}$ & $\begin{array}{c}\text { Mid } \\
\text { swing }\end{array}$ & $\begin{array}{c}\text { Terminal } \\
\text { swing }\end{array}$ \\
\hline \\
Right stance phase $=60 \%$ & \multicolumn{3}{|c}{ Right swing phase $=40 \%$} \\
\hline
\end{tabular}

Figure 1.8 The Phase of the Gait Cycle [3] 


\subsection{Relevant Structural Loads on the Hip Joint}

There are several studies and investigations held on human walking and load on the hip joint performed by researchers [42-50]. During normal gait, the hip joint experiences compressive loads that are between 2-4 times the body weights. A variety of studies are conducted on hip prostheses on the basis of this range [42, 46, 51]. The force system at the tip joint is statically indeterminate and more forces act across the joint than can be determined from the equation of equilibrium [52]. Figure 3.6 shows the forces and their lever arms acting around the hip joint during walking. In equilibrium, the sum of the rotational torque (i.e. force $\mathrm{x}$ distance) acting around the hip will be zero, which is given by formulae, $\mathrm{BW} \times \mathrm{b}=$ Abductor $\mathrm{x}$ a, and the Abductor is, Abductor $=\mathrm{BW} \times \mathrm{b} / \mathrm{a}$. These are derived from the Figure 1.9 [50].

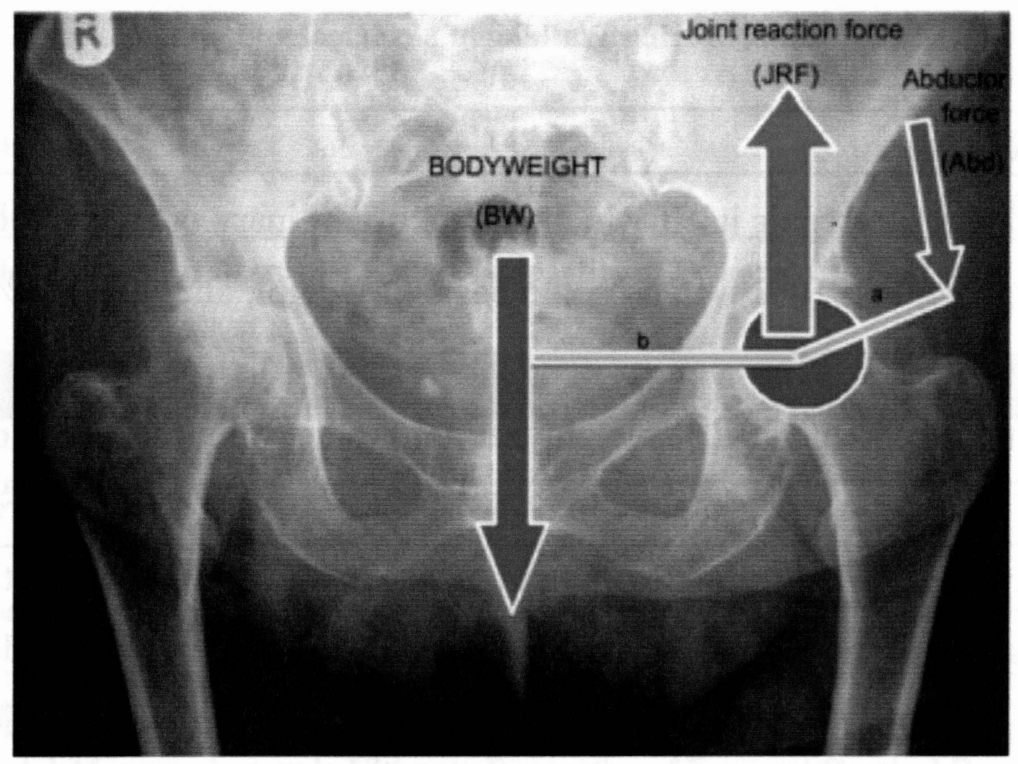

Figure 1.9 Illustration of Forces during Walking [50]

The range of motion of the hip is much greater than what is required for normal activities such as walking. This leads to the fact that the surrounding bone and ligaments of the hip joint do not provide any rotational stability to the hip during the walking cycle and the stability is provided by the action of muscle forces only [49]. Figure 1.10 illustrates the comparison of hip motion during walking for a normal and an osteoarthritic subject. 


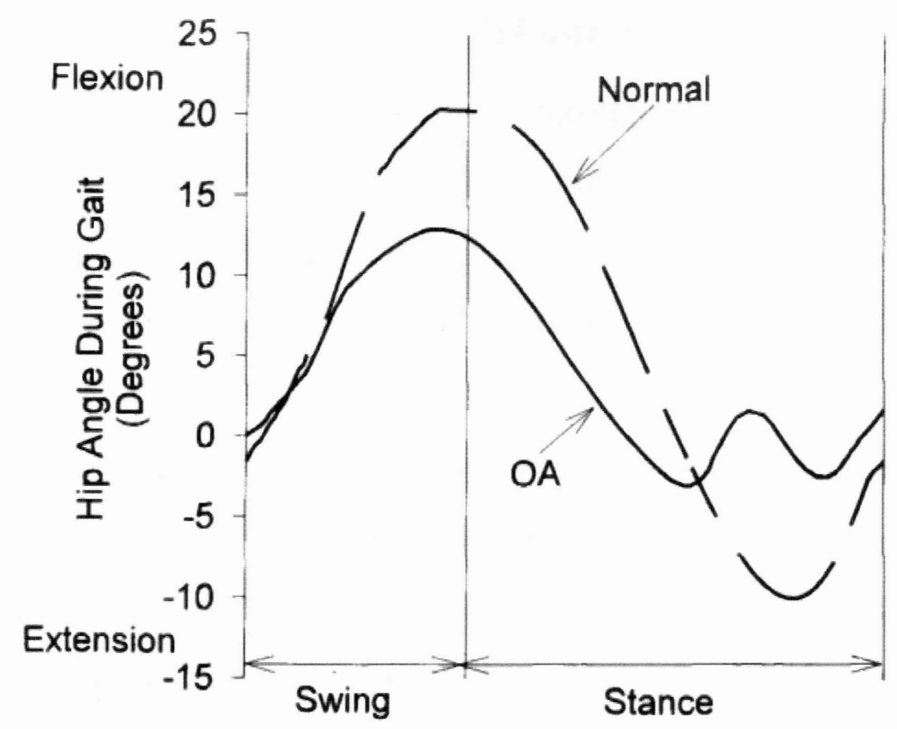

Figure 1.10 Comparison of Hip Motion during Walking of a Normal and an Osteoarthritic (OA) Subject [53]

\subsection{Structure of Bone}

The bone has the ability to repair itself which is an extraordinary property. Bone is around $60 \%$ inorganic, $30 \%$ organic, and $10 \%$ water, on the basis of weight, and $40 \%, 35 \%$, and $25 \%$ are the volume fractions, respectively. The inorganic phase of bone is a ceramic crystalline material which consists of type I collagen (90\% weight fraction), other minor collagen of types III and VI, and a variety of non-collagen proteins $[52,54]$. Bone tissue is a hierarchical, anisotropic composite at many levels. At the highest hierarchical level (1-2 $\mathrm{mm}$ scale), there are two basic types of bone tissue - cortical, and cancellous bone. Cortical bone, is the densest bone in the skeletal structure. The central shaft of long bones such as the femur is made of cortical bone. Cancellous bone, otherwise known as spongy bone, is much less dense than cortical bone and is found at the ends of long bones. While cortical bone is a tightly packed tissue, cancellous bone is a highly porous cellular solid $[52,55,56]$.

\subsubsection{Cortical Bone}

Cortical bone facilitates bone's main function, such as, to support the body, to protect organs, to provide levers for movement, and to store and release chemical elements, mainly calcium and phosphorous. It forms the outer shell of most bones. It is harder, stronger and stiffer than cancellous bone and contributes about $80 \%$ of the weight of a human skeleton. It is generally transversely isotropic in humans which means that its material has one primary axis in the 
longitudinal direction, and is isotropic in the plane perpendicular to the longitudinal axis (transverse plane). Shaft of the long bones like femur are usually aligned along the longitudinal axis. It is stronger and stiffer when loaded in the longitudinal axis and this structure enables the leg bones to resist uniaxial stresses that develop along the shaft (longitudinal axis) during walking, running, and jumping, etc. There are five independent material constants which describe the isotropic elastic properties of cortical tissue which are shown in the Table 1.2. The mean values of all human femoral bone samples tested by Reilly and Burstein. The cortical bone is stronger in compression than in tension, which is shown in Table $1.3[52,55,57]$.

\begin{tabular}{|lcc|}
\hline \multicolumn{1}{|c|}{ Cortical elastic properties } & Number of specimens & Mean Values \\
\hline Longitudinal elastic modulus & 170 & $17 \mathrm{GPa}$ \\
\hline Transverse elastic modulus & 31 & $11.5 \mathrm{GPa}$ \\
\hline Shear modulus & 166 & $3.28 \mathrm{GPa}$ \\
\hline Poisson's ratio, longitudinal & 147 & 0.46 \\
\hline Poisson's ratio, transverse & 26 & 0.58 \\
\hline
\end{tabular}

Table 1.2 Mean Anisotropic Elastic Properties of Femoral Cortical Bone [57]

\begin{tabular}{|l|lc|}
\hline \multicolumn{2}{|c|}{ Cortical Ultimate Strengths } & Mean Values (MPa) \\
\hline \multirow{2}{*}{ Ultimate longitudinal stress } & Tension & 133 \\
\cline { 2 - 3 } & Compression & 193 \\
\hline \multirow{2}{*}{ Ultimate transverse stress } & Tension & 51 \\
\cline { 2 - 3 } & Compression & 133 \\
\hline Ultimate shear stress & Torsion & 68 \\
\hline
\end{tabular}

Table 1.3 Mean Anisotropic Ultimate Properties of Femoral Cortical Bone [57]

Bone is essentially a heterogeneous (composed of different substances) structure due to variations in micro-structural parameters such as porosity. Different moduli and strengths of cortical tissue are dependent on the bone density. It is appropriate to assume average properties for cortical bone in the case of bone-implant stress analysis. It is observed that the modulus of metallic implants is much greater than that of cortical bone and about $\pm 20 \%$ of variations in the modulus of cortical bone will not affect implant stress calculations $[52,58]$. 


\subsubsection{Cancellous Bone}

Cancellous bone is less denser, softer, weaker, and less stiffer than the cortical bone. Typically, it occupies the interior region of the bones. It is highly vascular (related to blood vessels) and frequently contains red blood cells. It is a highly heterogeneous material. Its properties and density varies in the human body depending on the location. Researchers have written about the distribution of its properties from multiple locations in the human skeleton [59-62]. The proximal cancellous bone properties are shown in the Table 1.4.

\begin{tabular}{|c|c|c|c|c|c|c|c|}
\hline \multirow{2}{*}{ Study } & \multirow{2}{*}{ Year } & \multicolumn{2}{|c|}{$\begin{array}{l}\text { Apparent Density } \\
(\mathrm{g} / \mathrm{cc})\end{array}$} & \multicolumn{2}{|c|}{$\begin{array}{c}\text { Elastic Modulus } \\
\text { (MPa) }\end{array}$} & \multicolumn{2}{|c|}{$\begin{array}{c}\text { Ultimate Strength } \\
\text { (MPa) }\end{array}$} \\
\hline & & Mean & Range & Mean & Range & Mean & Range \\
\hline Behrens et al. [63] & 1974 & - & - & - & - & - & $1.8-63.6$ \\
\hline Lindahl [64] & 1976 & - & - & - & $1.4-79$ & - & $0.2-6.7$ \\
\hline Carter and Hayes [65] & 1977 & - & - & - & $10-500$ & - & $1.5-45$ \\
\hline Williams and Lewis [66] & 1982 & - & - & - & $8-457$ & - & $1.5-6.7$ \\
\hline Goldstein et al. [67] & 1983 & - & - & - & $4-430$ & - & $1-13$ \\
\hline Hvid and Hansen [68] & 1985 & - & - & - & - & - & $13.8-116.4$ \\
\hline Ciarelli et al. [69] & 1986 & - & - & - & $5-552$ & - & $0.52-11$ \\
\hline Linde et al. [70] & 1989 & 0.29 & $0.09-0.66$ & 445 & $61-1174$ & 5.33 & $0.68-14.1$ \\
\hline Ashman et al. [71] & 1989 & 0.26 & $0.13-0.75$ & 1107 & $340-3350$ & - & - \\
\hline
\end{tabular}

Table 1.4 Proximal Cancellous Bone Pproperties 


\section{CHAPTER 2}

\subsection{Hip Arthroplasty}

Total Hip Arthroplasty is a very common surgery for the treatment of end-stage arthritis. It leads to pain relief, improvement in function and quality of life. It is also recognized as "the operation of the century" [72]. Hip arthroplasty, also known as hip replacement procedures, are meant to relieve arthritis pain, and restore joint function by replacing the contact surfaces of the hip joint. The basic concept of a total hip arthroplasty is to replace the ball and socket joint with an artificial ball and socket. After the joint is replaced, there is no longer any arthritis in the joint, because the joint is entirely artificial [33].

\subsection{History of Total Hip Arthroplasty}

By the end of the eighteenth century, the progress in the field of operative orthopaedics was considerably advanced as a result of the improvement achieved in identifying the physiology of the skeletal tissues that occurred during the first half of that century. Liverpool, in the United Kingdom, had become famous for its skilled surgeons, where Henry Park (1744-1831) worked at The Royal Infirmary. Anthony White (1782-1849) of the Westminster Hospital in London is credited with the first excision arthroplasty in 1821 though he did not make a personal report of the operation and because of this surgery he gained recognition in the medical community [73]. In 1820, (White, 1822, and Barton, 1827) attempted to restore mobility to painful and deformed hip joints and centered on simply removing the affected femoral and acetabular bone involved. This evolved in the 1830-1880s into ghastly attempts to restore mobility using interpositional membranes between the femoral head and acetabulum, where materials such as wooden blocks and animal (e.g., pig) soft tissue were tried. The first prosthetic hip replacement dates to 1890 , which were carried out in Germany, and (Gluck T) used ivory to replace the femoral head (the ball on the femur) and published a description of a carved ivory femoral head replacement using bone cement like materials such as pumice and plaster of paris to secure the implants in place [3, 74].

Robert Jones, in 1895, and during the following years, interposed gold foil between the bone fragments in the course of the femur and the femoral shaft below the great trochanter [74]. In the early 1900s, Murphy and Erich Lexer (1867-1937) from Germany, had advocated the hip 
interposition of fascia lata which was a modification of the technique described in 1893 by another German surgeon, Heinrich Helferich (1851- 1945) [73].

Most popular was the interpositional membrane strategy that continued into the twentieth century with the use of new implant materials in the early 1900s, including organic materials (e.g., pig bladders and peri-implant soft tissues) and inorganic materials such as gold foil. The use of an individual's own soft tissues was the most popular method of inter-positional membrane hip surgery [3]. Sir Robert Jones (1855- 1933) used a strip of gold foil to cover reconstructed femoral heads. Twenty-one years later, he was able to report that the patient still retained effective motion at the joint. This was the longest follow-up report recorded, to that point, in the history of arthroplasty [73].

Later in 1923 Marius Smith-Peterson was credited with ushering in the modern era of total joint replacement with the development of mold arthroplasty, made of glass and inspired by a shard of glass found in a patient's back, surrounded in a benign, synovial membrane. This arthroplasty was designed as a cup that fit between the femoral head and the acetabular cup, and articulated on both surfaces using a cartilage like layer $[3,74]$. This arthroplasty was intended to facilitate bone-implant movement both at the femoral and the acetabular sides of the implant. This device, according to Smith-Petersen's reasoning, would "guide nature's repair" of the joint [73]. His desire was simply to develop a better interpositional membrane than had been in use for the previous 100 years. The efforts of Smith-Peterson and colleagues over the years 1923-1938 were spent improving the fracture resistance of the glass mold arthroplasty cup design, using materials such as early polymers (e.g., celluloid or phenolformeldehyde Bakelite or Formica) and improved glass (e.g., Pyrex) [3].

Also in 1938, Philip Wiles (1899-1966) of the Middelsex Hospital in London described the first THA using precisely fitted stainless steel components which were fixed to the bone with screws and bolts. In the early 1950s, McKee (1905-1991), who had trained with Wiles in London, started using the Thompson prosthesis on the femoral side that articulated with a three-claw type cup that was screwed into the acetabulum [73]. In 1939, E. J. Haboush converted the cup of Smith-Peterson into a hollow ball that made it fit on to and about the head and neck of the femur, so that the motion would be between the prosthesis and the acetabulum. He considered this to have the advantages, such as, to eliminate pain, by increasing the area of surface contact between 
the prosthesis and the bone which cause less bearing pressure and this also allow a more normal range of motion [74].

The modern total hip replacement (artrhroplasty) was also pioneered by Sir John Charnley in England in the early 1960's. He experimented with various designs of polytetrafluorethylene (p.t.f.e) acetabular cups combined with stainless steel femoral replacements. He found that (p.t.f.e) wore and the particulate material produced a tissue reaction similar to that found with other plastic materials. He reported on the use of a cold-curing acrylic resin for the stabilization of femoral head prostheses in the marrow cavity of the femur $[33,74]$.

In 1964, P. A. Ring showed a total hip replacement in which the cup was made of cobaltchormium alloy. The stem of the cup carried a screw thread and is inserted in the direction of maximum stress in the pelvic bone. Peter Ring working in parallel with the Russians, in Redhill, Surrey, started his clinical experience with cement-less components with a metal-on-metal articulation in 1964. Some of his early arthroplasties provided surprisingly good results with up to $97 \%$ of implants surviving at 17 years of follow up. Both the McKee and the Ring models were abandoned in the 1970s in favour of Sir John Charnley's model. These implants continued functioning extremely well and were "rediscovered" in the 1980s by Swiss and British surgeons $[73,74]$.

\subsection{Indications for the Replacement of Hip Joint}

Hip Joint replacement or Total Hip Replacement is surgery to replace all or part of the hip joint with an artificial device to restore joint movement (prosthesis). Hip joint replacement is a procedure that targets the older population as a result of increased fragility of the proximal femur due to osteoporosis. The operation is usually not recommended for younger people because of the strain they can put on the artificial hip [4, 30, 75, 76]. Many indications for the replacement of the hip joint include pain in the hip that has failed to respond to conservative therapy i.e. NonSteroidal Anti-Inflammatory Drug (NSAID medication for up to six months), and hip osteoarthritis or arthritis confirmed by X-ray. There is also the inability to work, sleep, or move because of the intense hip pain as well as a loose hip prosthesis. Various hip fractures as well as hip joint tumours can also be indications of the need for a Total Hip Replacement $[4,29,30]$. 
Total hip replacement surgery is usually recommended for patients showing symptoms such as current hip infections, poor skin coverage around the hip, Paralysis of the quadriceps muscles, disease of the blood vessels of the leg and foot (peripheral vascular disease) and severe limiting mental dysfunction, Figure 2.1 shows the difference in normal and diseased hip joint. The surgery can also be recommended if serious physical disease, terminal illness or morbid obesity (over $300 \mathrm{lb}$ ) is present in the patient $[3,4,30]$.
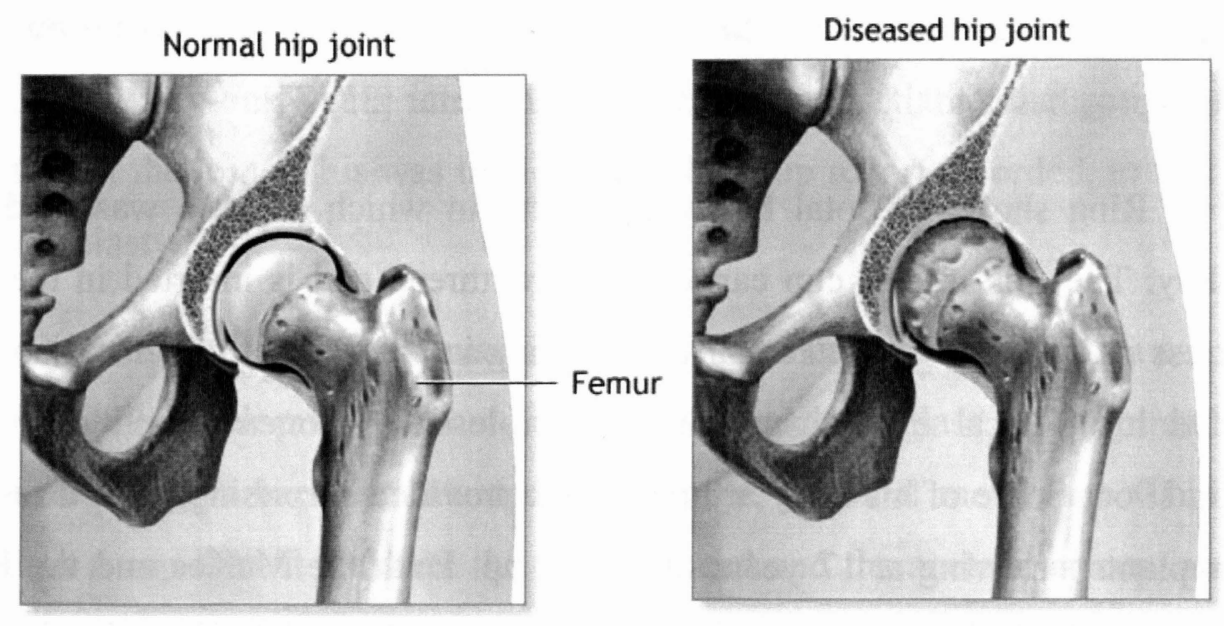

Figure 2.1 Normal Hip Joint (Left), and Diseased Hip Joint (Right) [3]

\subsubsection{Prosthesis Procedure}

The prosthetic hip is made of a ball as well as a socket joint, linking the dome at the head of the thigh bone (femur) and the cup in the pelvic bone. A total hip prosthesis is surgically implanted to replace the damaged bone within the hip joint. The total hip prosthesis consists of three parts. The first part is comprised of a plastic cup that replaces the hip socket (acetabulum), the second, a metal ball that will replace the fractured femoral head, and the third, a metal stem that is attached to the shaft of the bone to add stability to the prosthesis. If a hemi-arthroplasty is performed, either the femoral head or the hip socket (acetabulum) will be replaced with a prosthetic device. The patient will receive an extensive pre-operative evaluation of the hip to determine if there is a candidate for a hip replacement procedure. Evaluation will include assessment of the degree of disability and impact on patient's lifestyle, pre-existing medical conditions, and an evaluation of heart and lung function. The surgery will be performed using 
general or spinal anesthesia. The orthopedic surgeon makes an incision (a cut) along the affected hip joint, exposing the hip joint $[3,4,29]$. The head of the femur and the cup are cut out and removed shown in Figure 2.2.
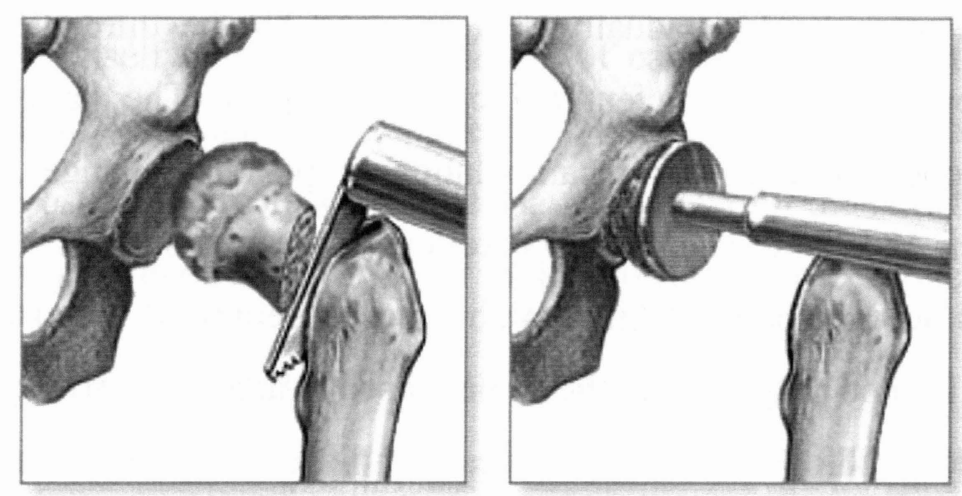

Figure 2.2 Head of Femur and Layer of Hip Socket are Removed [3]

Afterwards, a metal ball and a metal stem are inserted in the femur and a plastic socket is placed in the enlarged pelvis cup shown in Figure 2.3. The artificial components are fixed in place (sometimes special cement is used). The muscles and tendons are then replaced against the bones and the incision is closed. Usually, in most cases, patients return from surgery with large dressings along the hip area. A small discharge drainage tube will be placed during surgery and will help to successfully drain the excess fluids from the joint area $[4,29,77]$.
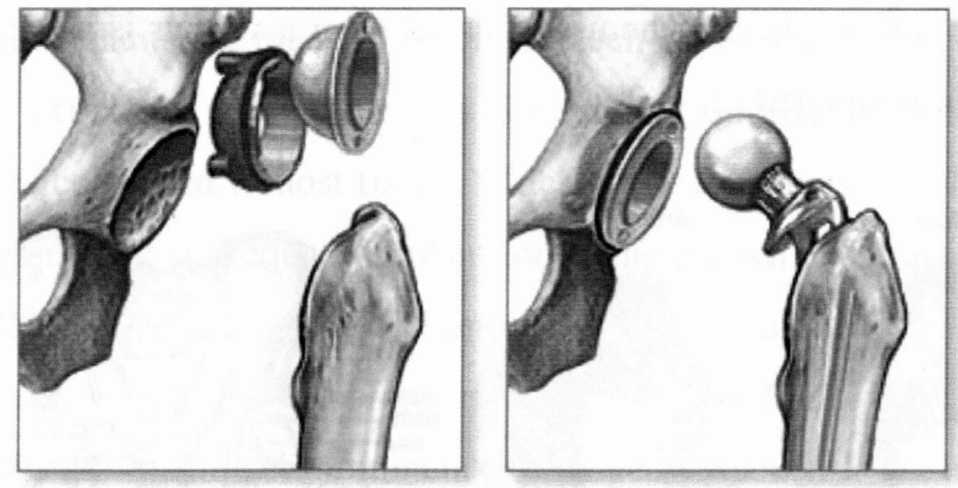

Figure 2.3 Ball and Stem Inserted into Femur [3] 


\subsubsection{Aftercare}

The patient will experience moderate to severe pain after surgery. However, patient-controlled analgesia (PCA), intravenous (IV), or epidural analgesics are effective in controlling postoperative pain. The pain should gradually decrease, and by the third day after surgery, oral analgesic medications may be sufficient to control the pain. The patient should take pain medications about one half hour before ambulation or position changes. Results with a hip prosthesis have been excellent. The operation relieves pain and stiffness symptoms, and most patients (over $80 \%$ ) need no help walking. With time, loosening of the artificial joint has been observed due to the limited properties of the cement used to attach the artificial parts to the bones $[3,4]$. Figure 2.4 shows before and after prosthesis, and it also shows the front view of a human pelvis with healthy and artificial hip joints.

The patient remains in the hospital for 5 to 8 days after surgery. However, some people may need further rehabilitation and assistance after hip replacement surgery. Temporary placement in a rehabilitation unit or long-term care centre may be necessary until mobility has improved and the person can safely live independently. These centres will provide intensive physical therapy to assist in regaining muscle strength and flexibility in the joint. Positioning is very important after surgery to reduce stress on the new joint and displacement of the joint. The new hip will not have the same range of movement of the original joint, although the patient should eventually be able to return to the previous level of activity. However, the patient should avoid vigorous sports such as tennis, skiing, or contact sports. The use of crutches or a walker is necessary for 3 months or more until healing is completed $[3,4,29]$.
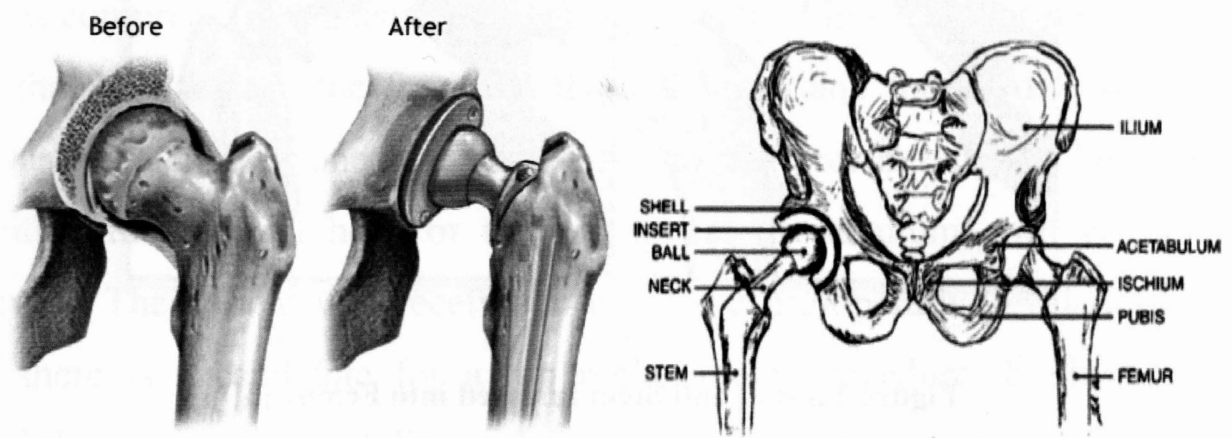

Figure 2.4 Before and After Prosthesis (Left), and an Illustration of Human Pelvis with a Healthy Hip Joint on the Right and an Artificial Hip Joint on the Left (Right) [3] 


\subsection{Failure of Prosthesis}

The new structure consists of both cancellous and cortical bone, the implant, and usually some sort of interface layer or cement, after arthroplasty. Cementless implants also give rise to interface layers. A combined structure of the bone-implant system is a composite structure replacing bone, that is itself a composite made out of cancellous and cortical bone [52]. This structure must be able to withstand forces applied to it due to the contact between the articulating surfaces of the hip prosthesis. Prosthetic failure may occur within the structure of the bone [7880], or in the bone-implant interface [81-84], or in the prosthesis structure itself [39, 85-87].

It is important that the implant materials are of adequate strength so that they could function properly for extended periods of usage $[15,88]$. Since cracks and flaws in the prosthetic materials do not heal on their own like biological tissue and consequently get worse under repeated loading therefore, fatigue behavior of metals and polymers used in implants is of important concern $[89,90]$. There are also other causes for the failure of the hip implants besides the fatigue of prosthetic mateirals which includes infection caused by the debris generated from worn surfaces [85, 91], wear in the hip joint surface [39, 86, 87], the stress shielding [79, 92-96], and implant loosening and migration. These causes of failure have their own detatiled study therefore the overal implant behavior could be predicted and improved, but this study is only concerned with the failure of the hip implant caused by the stress shielding.

\subsection{Stress Shielding}

Most common metal implants are made of stainless steel, cobalt-chromium alloys, and titanium based alloys. Major problems of these metals for implant applications are their mismatched mechanical properties compared to host tissue, which causes necrosis (death of cells or tissues) of the surrounding tissue and subsequent implant loosening known as 'stress shielding' effect [3, 97]. Loading applied to the bone tissue by the implant surfaces may be different from the loading originally applied on the same region before implantation. The living skeleton tissue remodels and adapts itself when the loading environment is changed. When loading on the bone tissue is increased, both the volume and mechanical properties of the bone may increase in response, and when femoral component of hip prostheses is implanted, the load will now be shared between the implant and the bone and will not be carried by the surrounding bone tissue alone as before. As a result, the amount of load carried by the bone tissue is reduced, and the bone tissue will adapt 
and remodel according to the new loading condition $[52,97]$. If the stresses on the metal femoral component, or at the interfaces, are excessive as compared to the strength of the materials, mechanical failure might occur. Stresses in bone should be moderate compared with its strength, so as not to generate cracks, but not too low in comparison with natural values, so as to prevent stress shielding and associated bone resorption. (Figure 2.5 a) illustrates the initial anteropsterior (AP) radiograph of the hip, showing dense cortical bone of the remnant of the medial femoral neck (indicated by the arrow symbol). (Figure $2.5 \mathrm{~b}$ ) illustrates the subsequent anteroposterior (AP) radiograph, shwoing advanced metaphyseal bone loss in the proximal femur $[29,52,79$, $80,97,98]$.

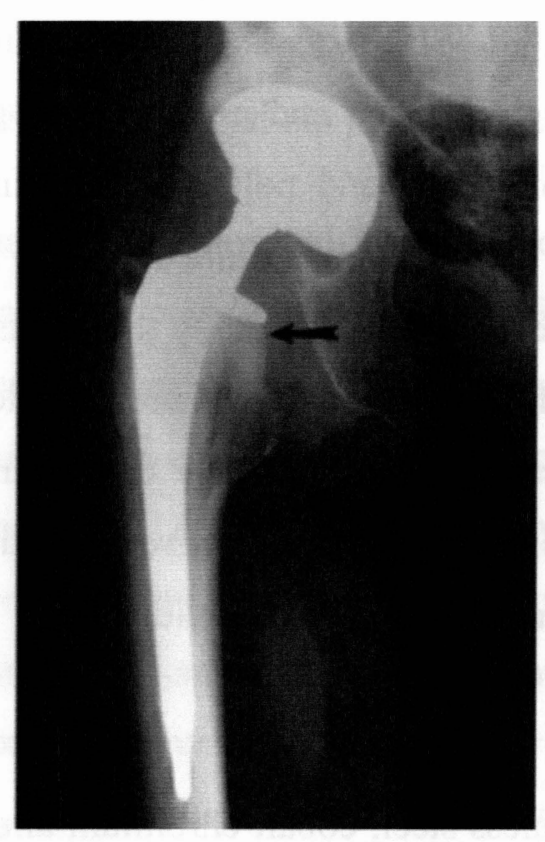

(a)

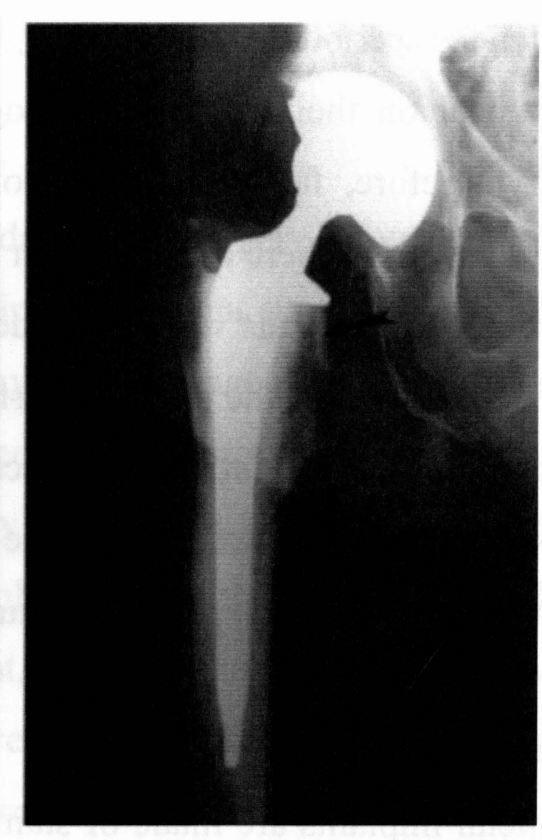

(b)

Figure 2.5 Stress Shielding [29]

\subsection{Bone Resorption}

Polyethylene debris is known to be particularly responsible for the inflammatory response that leads to bone resorption and loosening of implants over time. In bone-implant systems, there exist parallel paths among which the load is shared according to the relative stiffness of the components in the composite structure. The stiffness of the bone may decrease due to lesser load carried by the bone, after the prosthesis is implanted, and this will increase the relative stiffness 
of the implant with respect to the bone. As a result, the implant carries more load which in turn further reduces the load fraction carried by the bone that causes further decrease in bone stiffness. Ongoing decrease in bone stiffness is called osteolysis. If the modulus of the implant is much higher than bone, the load will be transmitted through the implant instead of the bone causing bone resorption rather than bone regeneration. Stress shielding causes bone resorption because the body is continually remodelling bone according to the stress to which the bone is subjected. Osteogenic cells lay down new bone matrix to strengthen bone under high loads. When bone is not loaded, other cells called osteoclasts resorb it. This is one of the most common reason for total hip replacement to fail [52, 79, 80, 97].

\subsection{Need of the Polymer Composites for Orthopaedic Implants}

The fabrication of bioactive particulate reinforced polymer composites for orthopaedic implants has been receiving considerable attention from biomedical sector. By using metallic components for orthopaedic applications does not overcome the requirement of high strength and low stiffness (low elastic modulus) to reduce stress shielding. This gave rise to the possibility of using polymer composites for orthopaedic applications. The benefits of using polymer composites include the convenience of controlling the volume fraction of the constituent materials, their overall arrangement in the macrostructure, the absence of corrosion, and the possibility of designing radio-transparent composites that do not interfere with $\mathrm{X}$-ray radiography [99-101]. CF/PA12 is a more recently innovated polymer composite that this study aims to incorporate into femoral components to reduce stress shielding in the hip joints.

\subsection{Carbon Fibre Reinforced Polyamide 12 (CF/PA12)}

First suggested as a prosthetic material for femoral stems in total hip arthroplasty (THA) by a team of researchers from the École Polytechnique de Montréal (Montreal, QC, Canada) and the Industrial Materials Institute (National Research Council, Boucherville, QC, Canada), Carbon fibre reinforced polymer (polyamide 12) or CF/PA12 is a recently proposed carbon-polymer composite $[24,25,102,103]$. Natural occuring polyamides include wool and silk, while synthetic polyamides include nylons and aramids ( polyamides capable of extrusion into fibers having resistance to high temperatures and great strength). These are polymers of amide (an organic compound) monomers joined by peptide bonds [1, 24, 102-104]. 
CF/PA12 has proven to be a highly suitable biomimetic material especially in hip implant stems. Campbell et al. first started the study on the structural properties of CF/PA12 [24, 102], which were published in 2006. Tests were conducted on hollow cylindrical geometries with $3 \mathrm{~mm}$ wall thickness manufactured using polyamide 12 (PA12) matrix reinforced with long discontinuous carbon fibres (CF). The composite material comes in the form of braided (band or ribbon) nonconsolidated strands with a fibre orientation varying between 20 and 45 degrees, in the beginning. The reason was to vary the orientation of each layer in the composite stem to control material properties in different directions. Inflatable bladder moulding was used to manufacture these femoral stems. It is a process which combines compression moulding and bladder moulding. Polyamide 12 strands and braided carbon fibres are placed onto an inflatable bladder and then inserted in a mould cavity, as shown in Figure 2.6. The mould is then closed and placed into an optimum manufacturing conditions, at which are those that produce the least void content or air pockets in the composite material. This composite has theoretical density of $1.45 \mathrm{~g} / \mathrm{cc}$, but the actual density of the moulded CF/PA12 material under optimum conditions was calculated to be $1.42 \mathrm{~g} / \mathrm{cc}$. The characteristics of the resulting CF/PA12 composite is illustrated in Table 2.1 $[1,24,102,103]$.
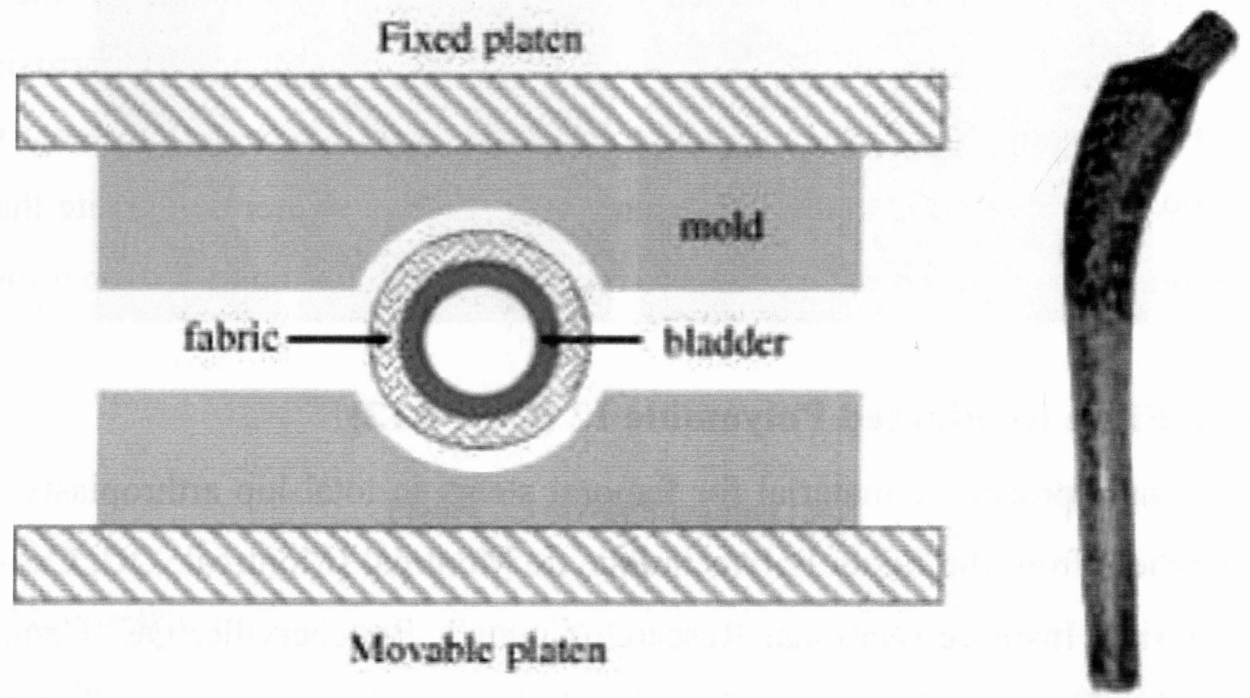

Figure 2.6 Inflatable Bladder Moulding to Manufacture CF/PA12 THA Femoral Stems [103] 


\begin{tabular}{|l|c|}
\hline CF Volume Fraction & 0.55 \\
\hline CF Weight Fraction & 0.68 \\
\hline Density of CF $(\mathrm{g} / \mathrm{cc})$ & 1.78 \\
\hline Density of PA12 $(\mathrm{g} / \mathrm{cc})$ & 1.03 \\
\hline Diameter of CF Fibres $(\boldsymbol{\mu m})$ & 10 \\
\hline
\end{tabular}

Table 2.1 CF/PA12 Composite Constituent Properties [103]

The modelled femoral stem resembles cortical bone in beharior. Five hollow cylindrical test specimens were tested, each having composite braided carbon fibre and PA12 strands with specific ply configuration. In the first two layers, the CF are oriented at $\pm 45^{\circ}$, followed by one layer with $0 / 90^{\circ}$ orientation, followed by three layers with $\pm 45^{\circ}$ orientation, respectively. The best consolidation quality (density closest to theoretical value of $1.448 \mathrm{~g} / \mathrm{cc}$ ) was reported to be manufactured at a temperature of $250^{\circ} \mathrm{C}$, and at a pressure between $50-90 \mathrm{psi}$, with a holding time of four minutes. Uniaxial force was applied on five $44 \mathrm{~mm}$ long samples with $3 \mathrm{~mm}$ thick walls, and outer diameter of $22 \mathrm{~mm}$. The compressive force was applied by an electromechanical machine by using $100 \mathrm{KN}$ load with parallel plates. Compressive stress and strain were calculated from the load deflection curves at the maximum load value, which are given in Table 2.2. These values showed that the hollow cylindrical test specimens have properties that matched cortical bone in the human femur. The compression stress-strain curve is shown in the Figure 2.7, which shows a typical linear elastic region ending when maximum strength is reached. Figure 2.8 shows that the failure can occur by barreling and buckling $[24,102]$.

\begin{tabular}{|c|c|c|c|c|}
\hline \multirow{2}{*}{ Stem Specimen } & \multicolumn{1}{c}{$\begin{array}{c}\text { Bulk Compressive } \\
\text { Modulus (GPa) }\end{array}$} & $\begin{array}{c}\text { Bulk Compressive } \\
\text { Sstrength (MPa) }\end{array}$ & $\begin{array}{c}\text { Strain at } \\
\text { Maximum } \\
\text { Strength (\%) }\end{array}$ & Density (g/ce) \\
\hline $\mathbf{1}$ & 15.5 & 167 & 1.94 & 1.39 \\
\hline $\mathbf{2}$ & 14.0 & 177 & 1.88 & 1.40 \\
\hline $\mathbf{3}$ & 14.5 & 179 & 1.83 & 1.40 \\
\hline $\mathbf{4}$ & 15.8 & 178 & 1.70 & 1.37 \\
\hline $\mathbf{5}$ & 15.4 & 217 & 1.85 & 1.40 \\
\hline Mean & $\mathbf{1 5 . 1}$ & $\mathbf{1 8 4}$ & $\mathbf{1 . 8 4}$ & $\mathbf{1 . 3 9}$ \\
\hline
\end{tabular}

Table 2.2 Compression Test Results of CF/PA12 Specimens by Campbell et al [24, 102] 


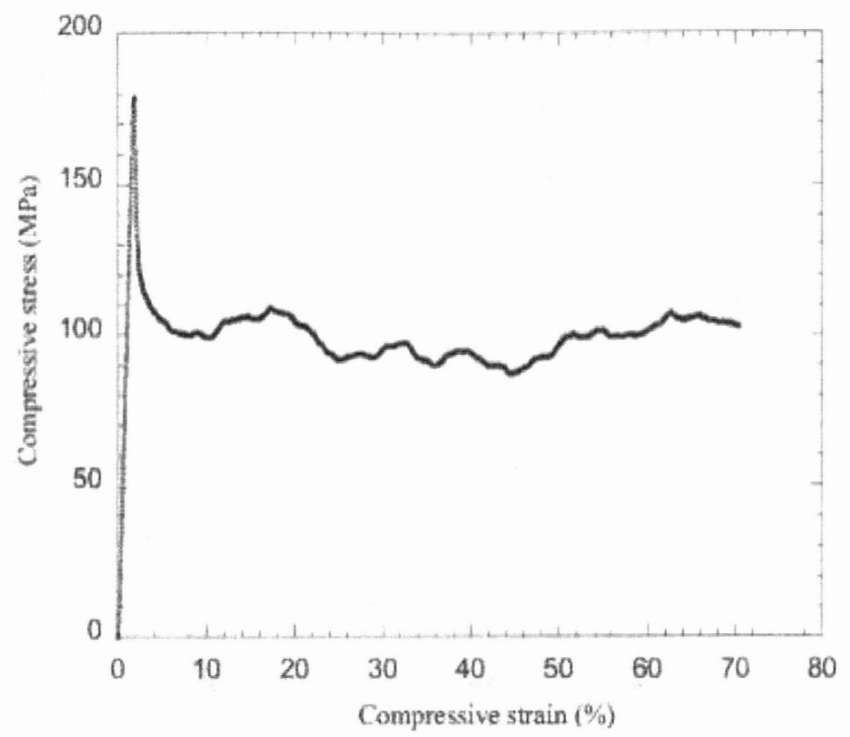

Figure 2.7 Compression Stress-Strain Curve of CF/PA12 Cylinders by Campbell et al [24, 102]

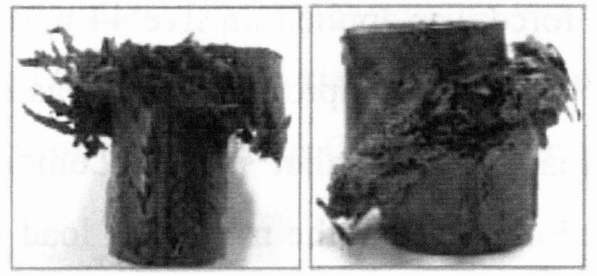

a b

Figure 2.8 Failed Stem Samples After Compression Testing: a) Barrelling, and b) Buckling Along the $4^{\circ}$ Shear Plane [24, 102]

Two studies were published by Campbell et al, in 2008. First on the manufacturing and properties of CF/PA12 hollow cylinders and hip implant femoral stems, and second on the performance of the femoral stems $[25,103]$.

In the first study, a more detailed analysis of the optimal manufacturing conditions for CF/PA12 to obtain a composite structure with the best consolidation quality possible and therefore the highest stiffness and rigidity, was published. CF/PA12 in the form of braided sleeves of comingled CF and PA12 strands were used in the study to manufacture actual hip implant femoral stems. The femoral stems were again manufacturing by inflatable bladder moulding, where six layers of braided sleeves of CF/PA12 yarns were placed around a silicone bladder mandrel [103]. Campbell et al. studied several manufacturing conditions. The optimal moulding conditions were 
setup at a temperature of $250^{\circ} \mathrm{C}$, compression pressure at $480 \mathrm{kpa}$, with a holding time of five minutes. The compression performance of femoral stems manufactured at different moulding conditions were compared. The stress-strain curves indicated that the femoral stems also undergo a linear stress-strain behaviour when subjected to compression, followed by yielding and abrupt softening until a plateau is reached, that resembled with the previous studies done in 2006 [24, 102]. Yielding occurred by shear deformation at $\pm 45^{\circ}$ with respect to the loading axis, i.e. along the orientation of the carbon fibres. The maximum load at failure $(28-32 \mathrm{kN})$ was reported to be roughly 10 times larger than normal physiological loads experienced during gait $(2.5-3 \mathrm{kN})$ [103].

In the second 2008 study, the fatigue performance of CF/PA12 material teste was exceeded, by far, the required fatigue performance for hip implant stems [25]. Hollow cylindrical configurations, and hip implant femoral stem configuratios were the two specimen configuratins used. Compression and flexural (short-term) tests were conducted on the hollow cylindrical specimens of CF/PA12 (22 mm outer diameter, $3 \mathrm{~mm}$ wall thickness), whereas cyclic fatigue (long-term) tests were performed on both cylindrical specimens and on actual geometry femoral stems. Under a maximum load of $28.6 \mathrm{kN}$, the compression tests showed a modulus of $12.2 \mathrm{Gpa}$, and the ultimate strength of $155 \mathrm{Mpa}$, which are close to the cortical bone tissue values of 11.517 Gpa and 133-139 Mpa, respectively, estimated by Reilly and Burstein [55, 57], and aslo close to the cortical bone tissue values of 7.0-18.7 GPa and 175-265 MPa, respectively, estimated by Wirtz et al. [58]. $16.4 \mathrm{GPa}$ and $188 \mathrm{Mpa}$ were the flexural modulus and ultimate strength of the $\mathrm{CF} / \mathrm{PA} 12$ cylinder, which are close to the cortical bone tissue properties of 14.3-21.1 GPa and 178-250 MPa, respectively, published by Synder and Schneider [105], Table 2.3 shows the compression test results of CF/PA12 cylinders compared to cortical tissue. The bending stiffness was calculated based on the product of the elastic modulus and moment of inertia. The bending stiffness of the composite cylinders (22 mm outer diameter) was $180-145 \mathrm{~N}-\mathrm{m}^{2}$, which is within range of the cortical bone (of 25-30 mm outer cortex diameter) bending stiffness of 170-500 N$\mathrm{m}^{2}[25]$. 


\begin{tabular}{|l|c|c|c|c|}
\hline \multicolumn{1}{|c|}{} & $\begin{array}{c}\text { Specimen } \\
\text { Material }\end{array}$ & $\begin{array}{c}\text { Maximum } \\
\text { Compressive } \\
\text { Load (kN) }\end{array}$ & Modulus (GPa) & $\begin{array}{c}\text { Ultimate } \\
\text { Strength (MPa) }\end{array}$ \\
\hline Campbell et al. [25] & CF/PA12 & $28.6 \pm 3.8$ & $12.2 \pm 1.3$ & $155 \pm 27$ \\
\hline Reilly and Burstein [55, 57] & Cortical bone & - & $11.5-17$ & $133-193$ \\
\hline Wirtz et al. $[58]$ & Cortical bone & - & $7.0-18.7$ & $178-250$ \\
\hline
\end{tabular}

Table 2.3 Compression Test Results of CF/PA12 Cylinders Compared to Cortical Tissue [25]

The cyclic fatigue tests indicated that the CF/PA12 cylinders failed at $10^{6}$ cycles at a maximum fatigue stress of $101 \mathrm{MPa}$ (load of $17 \mathrm{kN}$ ), and at $10^{7}$ cycles for $95 \mathrm{MPa}(18 \mathrm{kN})$. These results show fatigue limits of $10^{6}$ or more for loads that are at least six times more than the $3000 \mathrm{~N}$ recommended by ASTM standards for hip arthroplasty femoral components. In view of these results, all of these provide convincing evidence proving $\mathrm{CF} / \mathrm{PA} 12$ to be an excellent candidate material for orthopaedic appliances in general $[24,25,102,103]$. 


\section{CHAPTER 3}

\subsection{Current Study}

Carbon fibre reinforced polyamide-12 (CF/PA12) is a mouldable carbon-polymer composite that matches the properties of cortical bone tissue and because of that it has been selected to be used in orthopaedic implants. This study is about the validation of the finite element (FE) model to test stress characteristics in hip prosthesis and the stress shielding in the composite hip-implant and comparing them with the other two conventional hip-implants (i.e., Exeter and Omnifit Eon).

\subsection{Problem Statement}

Metallic hip implants (i.e., Exeter and Omnifit Eon) that have high stiffness of hip prostheses result in stress shielding, which changes the normal loading environment of the hip joint by preventing the transfer of loads from the implant to the bone tissue - resulting in bone resorption and eventual failure of the prosthesis.

\subsection{Research Question}

Can a polymer-composite $\mathrm{CF} / \mathrm{PA} 12$ hip implant be shown to reduce stress shielding observed in conventional metallic hip implants through finite element modelling and experimenal testing?

\subsection{Aims of This Study}

The distinct goals of this study are as follows:

1. Summarise relevant literature on hip joint anatomy, joint biomechanics, hip replacement procedures, and hip implants. Review literature on hip joint bone loss, the prevention of stress shielding, in vitro experimental studies and finite element studies of stress distribution in hip implant systems.

2. Conduct an experimental study of the stresses generated in the hip-implant systems under static axial loading using the Exeter hip stem, Omnifit Eon hip stem, and composite hip stem implant systems.

3. Develop a computer-aided, realistic geometry of the hip-implant prosthesis systems. 
4. Use the CAD geometry to generate a numerical model for static finite element analysis (FEA) of the hip-implant systems. Validate the model by comparing the FEA results with the experimental results obtained earlier, and using published literature.

5. Evaluate the performance of the composite prosthesis when compared with the conventional metallic hip implants.

\subsection{Experimental Study}

The purpose of the experimental study is to authenticate the finite element (FE) model developed to predict stresses in the hip-implant system. This experiment was conducted by measuring the surface strains at different locations on the hip implant of the synthetic femur model. The results of the strians measured on the hip implants during the experiment and the results from the FE model can be assumed a good confirmation of the FE model if the difference is within 25 percent [106-108]. In several studies in validation experiments, synthetic analogue bone models have been used, because there are problems with storage and preventing alterations in the skeletal material properties as the bone tissue ages and dries and therefore experimental confirmation using cadaveric bones are very rare $[23,109,110]$.

All studies in this thesis are based on observing a static axial loading of the hip-implant system. By considering the joint force during normal gait, this thesis is structured around applying a compressive force of $3000 \mathrm{~N}$, which is equivalent to 2 to 3 times a normal body mass of $87 \mathrm{~kg}$. The average body mass of an adult male (age 20-74 years) in the US is around $87 \mathrm{~kg}$ [111].

Applied loads of $2000 \mathrm{~N}$ and $3000 \mathrm{~N}$ compare well with previous FEA studies conducted on hipimplant systems. $2000 \mathrm{~N}$ was used by Pyburn et al. [112] in uniformly distributed compression, $2000 \mathrm{~N}$ maximum axial force was used by Grasa et al. [113], $2300 \mathrm{~N}$ was used by Campbell et al. [25], a maximum of $3000 \mathrm{~N}$ compressive force was used by Gross et al. [94], 2000-3000 N was used by Ohnishi et al. [75] and the total strain energy was calculated for each of the models, and 2000 N-3000 N was used by Pilliar et al. [114] on the head of the hip-implant in the hip joint. In the light of these studies, an axial compressive test load of $3000 \mathrm{~N}$ is reasonably typical. 


\subsection{Strain Gauge Selection}

To select a proper strain gauge depends upon two factors, the problem being studied and the nature of the test materials on which the gauge will be mounted. There are some factors that should be considered like temperature sensitivity, high strain sensitivity, and the electrical resistivity of the foil [115]. In this study, the in vitro experiments are conducted at room temperature, and the test materials have high enough moduli that large strains are not expected under the compressive loads applied (up to $3000 \mathrm{~N}$ ). Because of the poor thermal conductivity of bone material (including simulated bone), Szivek and Gharpuray [115] recommend the use of high resistance gauges (about $350 \Omega$ ). Uni-axial gauges were considered sufficient, as the mode of loading in the experimental study is mainly axial and the strain direction of interest lies in this direction. Furthermore, Vishay ${ }^{\circledR}$ 350-Ohms general-purpose uniaxial linear-pattern gauges (125UW, model CEA-06-125UW-350, Vishay Micro-Measurements \& SR-4, Raleigh, NC, USA) are employed in this study, are shown in Table 3.1 and Figure 3.1.

\begin{tabular}{|l|l|}
\hline Model & CEA-06-125UW-350 \\
\hline Description & Universal General Purpose Strain Gauges \\
\hline Resistance & $350.0 \Omega \pm 0.3 \%$ \\
\hline Overall Length and Width & $0.325 \times 0.180$ in $(8.26 \times 4.57 \mathrm{~mm})$ \\
\hline Strain Range & $\pm 3 \%$ \\
\hline Temperature Range & $-75^{\circ} \mathrm{C}$ to $175^{\circ} \mathrm{C}$ \\
\hline Gauge Factor, GF (at $\left.\mathbf{2 4}^{\circ} \mathrm{C}\right)$ & $2.120 \pm 0.5 \%$ \\
\hline GF Sensitivity & $(1.2 \pm 0.2) \% / 100^{\circ} \mathrm{C}$ \\
\hline Transverse Sensitivity & $(0.7 \pm 0.2) \%$ \\
\hline
\end{tabular}

Table 3.1 Vishay ${ }^{\circledR 350-O h m s ~ S t r a i n ~ G a u g e ~ S p e c i f i c a t i o n s ~[116] ~}$
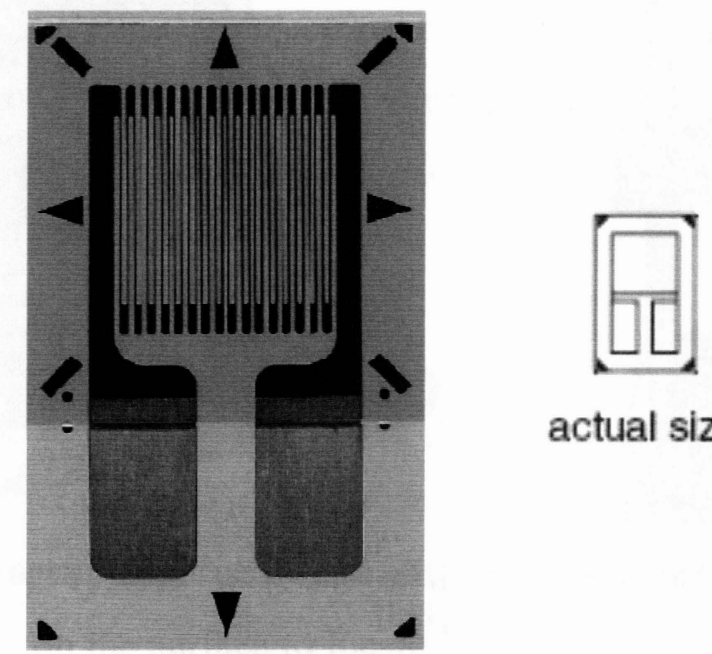

actual size

Figure 3.1 Vishay ${ }^{\circledR}$ 350-Ohms Uniaxial Linear-Pattern Strain Gauge Model CEA-06-125UW-350 [116] 


\subsection{Experiment Overview}

An Omnifit ${ }^{\circledR}$ hip implant made of titanium alloy which is manufactured by Stryker Corporation (Mahwah, NJ, USA), an Exeter ${ }^{\circledR}$ hip implant made of CoCrMo alloy which is also manufactured by Stryker Corporation (Mahwah, NJ, USA), and a composite hip stem which is manufactured from a single piece of carbon fibre-based polymer known as CF/PA12 (carbon fibres/polyamide 12) was used in the experiment.

Static axial compression was the mode of loading on the bone-implant system and $3000 \mathrm{~N}$ was the load, which was studied. By using a material testing instrument Instron ${ }^{\circledR} 8874$ (Canton, MA, USA), shown in the Figure 3.2, axial loading tests were performed. The Instron® 8874 consists of a capacity of $\pm 25 \mathrm{kN}$ with a load cell, resolution of $0.1 \mathrm{~N}$, and an accuracy of $\pm 0.5 \%$. Through FastTrack ${ }^{\mathrm{TM}} 8800$ servohydraulic controller unit (Instron, Illinois Tool Works, Norwood, MA, USA), compressive loading rate and maximum load were applied in conjunction with a desktop computer running the interface software FastTrack ${ }^{\mathrm{TM}} 2$ which is able to display a feedback at regular intervals on the actuator displacement.
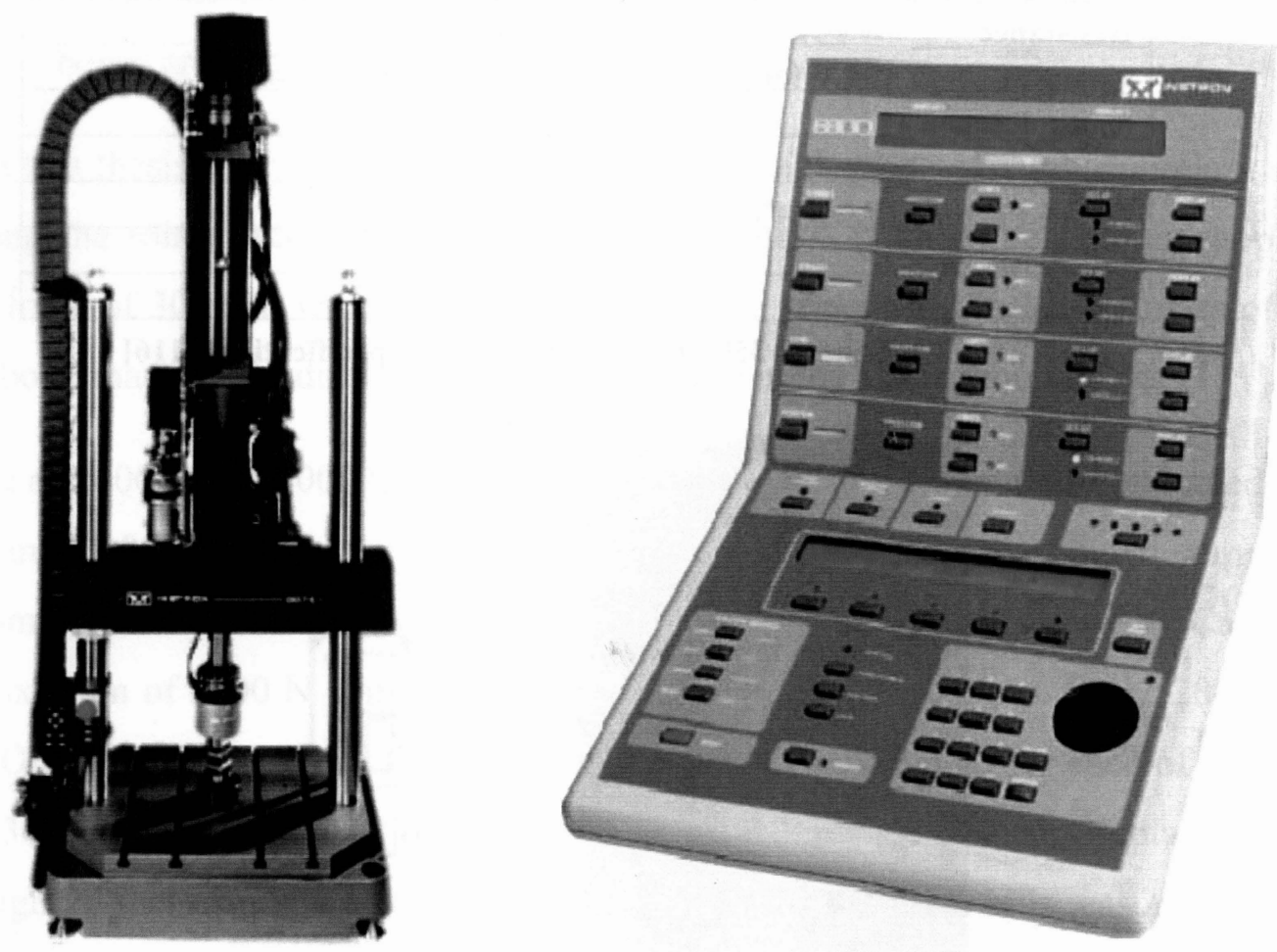

Figure 3.2 Instron ${ }^{\circledR}$ FastTrack ${ }^{\mathrm{TM}} 8874$ (Left) [117], Instron ${ }^{\circledR}$ FastTrack ${ }^{\mathrm{TM}} 8800$ Controller Panel (Right) [118] 
Vishay ${ }^{\circledR}$ 125UW 350-Ohms general-purpose uniaxial linear-pattern gauges [116] (model CEA06-125UW-350, Vishay Micro-Measurements, Raleigh, NC, USA) was used to measure the surface strain, that was attached to the femoral surface.

Each gauge was soldered by wire leads. The wires lead to a data acquisition unit CRONOS-PL2 (IMC Mess-Systeme GmbH, Berlin, Germany) through a UNI2-8 eight-channel all-purpose amplifier. The CRONOS-PL was connected to data collection notebook computer running signal analysis software FAMOS V5.0 (IMC Mess-Systeme GmbH, Berlin, Germany).

\subsection{Preparation}

\subsubsection{Hip Implant Preparation}

Square steel chambers were filled with commercially available anchoring cement and then distal ends of the hip arthroplasties were placed in them so that the implants were standing vertically. Carefully, the distal ends were kept to a depth into the potting chambers so that the working lengths of the devices from the top of the cement pot to the top of the femoral ball were at the same height $(115 \mathrm{~mm})$. The implants were subsequently instrumented with $350 \mathrm{Ohm}$ general purpose linear pattern strain gauges (Model CEA-06-125UW-350, Vishay Measurements Group, Raleigh, NC, USA) as per gauge manufacturer's protocol. Each prosthesis had 6 gauges (3 medial side, 3 lateral side) fixed at key points along their surfaces as can be seen from the Figure 3.8. The strain gauge locations could only be placed approximately at corresponding points, due to the differing geometries and surface texturing of the implants. Wire leads were soldered to the gauges, secured to the implants using electrical tape, and attached to an 8-channel CRONOS-PL data acquisition system (IMC Mess-Systeme GmbH, Berlin, Germany). This system was linked to a dedicated laptop computer for data storage and analysis using FAMOS V5.0 software (IMC Mess-Systeme GmbH, Berlin, Germany).

\subsubsection{Strain Gauge Installation}

There are some specific rules in preparing the gauge and test surface to have proper bonding. Surface preparation is required (1) to ensure a chemically clean surface having an ideal roughness for strain gauge application, (2) to obtain a neutral surface $\mathrm{pH}$ of around 7 , and (3) to draw visible layout lines on the surface to locate and orient the strain gauge. Surface preparation was done as per the strain gauge manufacturer's instructions [119]. 
There are five basic steps to follow. First step is solvent degreasing; it was performed to remove oils, organic contaminants, and soluble chemical residues from each test location. CSM-1A Degreaser [119] was used to degrease the implant surfaces. To ensure contaminants could not enter the degreaser container, the aerosol type applicator was used. Wiping was done in one direction only with the sterilised cotton so that contaminants are not re-applied

Second step is the surface abrading, in which the surfaces were abraded to remove any loosely bonded adherents (scale, rust, paint, galvanized coatings, oxides, etc), and to develop a surface texture suitable for bonding. Final abrading was applied on the implant surfaces by using 320grit silicon carbide paper on surfaces thoroughly wetted with M-Prep Conditioner A [119].

Third step is the gauge-location layout lines. By using a ballpoint pen layout lines were burnished on the hip implants. Layout lines are ordinarily applied following the abrading operation and before final cleaning [119].

Fourth step is the surface conditioning, in which M-Prep Conditioner-A was applied again on the surfaces, repeatedly with cotton tipped applicators until a fresh tip no longer showed any traces on it. Once again, wiping is done with gauze in one direction only, to dry the surface. Cleaning solutions should never be allowed to dry on the surface. While cleaning, the surface should be dried by wiping through the cleaning area with a single slow stroke of gauze sponge. The stroke should begin inside the cleaning area to avoid dragging contaminants in from the boundary of the area [119].

The fifth step is the neutralizing, in which the surface condition is brought back to an optimum alkalinity of 7.0 to $7.5 \mathrm{pH}$, which is suitable for all Micro-Measurements strain gauge adhesive systems. This is done by applying M-Prep Neutralizer 5A to the cleaned surface, and by scrubbing the surface with a clean cotton tipped applicator. The cleaned surface was kept completely wet with Neutralizer 5A. When neutralized, the surface was dried by wiping through the cleaned area with a single slow stroke of a clean gauze sponge [119].

After the instructions were followed properly, the surface is now prepared for gauge bonding. With the help of tweezers, the gauges were removed from their envelopes. With the outsidefacing sides of the gauges taped on, the gauges were then entered on 100-150 mm pieces of PCT$2 \mathrm{~A}$ cellophane tape. Care was taken when positioning the taped gauges on the test surface so that 
the triangular alignment marks on the gauge coincided with the layout lines. For all gauges, one end of the tape was allowed to remain stuck to the surface, while another end was slowly pulled back to expose the bonding side of the gauge. As per the manufacturer's instructions, M-Bond 200 catalyst was applied to the bonding side of the gauge, followed by a careful application of a few drops of M-Bond 200 at the junction of the tape and the test surface. By holding the tape firmly, it was then rotated back and the gauge was carefully replaced over the layout lines by one straight stroke on the outer surface using gauze to attach the gauge/tape assembly on the test surface. To ensure that the M-Bond 200 adhesive bonded properly, firm thumb pressure was applied on the gauge for about a minute [119].

\subsubsection{Data Acquisition and Signal Analysis}

To connect the strain gauges to the CRONOS-PL data acquisition unit (IMC Mess-Systeme $\mathrm{GmbH}$, Berlin, Germany), insulated, three-conductor, stranded tinned-copper lead wiring was used. Black, white, and red were the three wiring colours for the three conductors. Each conductor was stripped of at least half an inch of isulation and they were all seperated. For all six strain guages, the red part of the wiring was soldered onto one strain gauge terminal and the black and white parts of the wiring were twisted together onto the other terminal. Figure 3.3 shows a three lead wire conductor.

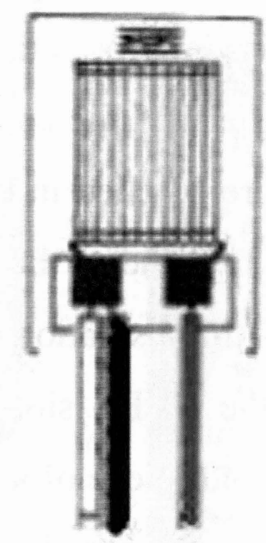

Figure 3.3 Three Lead Wire Conductors Separated and Soldered to a Strain Gauge

By attaching the three wires to the strain gauge it has become the part of the quarter bridge circuit which is shown in the Figure $3.4 \mathrm{~b}$. By comparing a two-wire connection shown in Figure 3.4 a, and three-wire connection Figure 3.4 b, it is obvious that in a three-wire connection there is 
a reduction in the resistance $\left(R_{L}\right)$ in the static strain gauge reading and that is why it is recommended for static experiments [120].

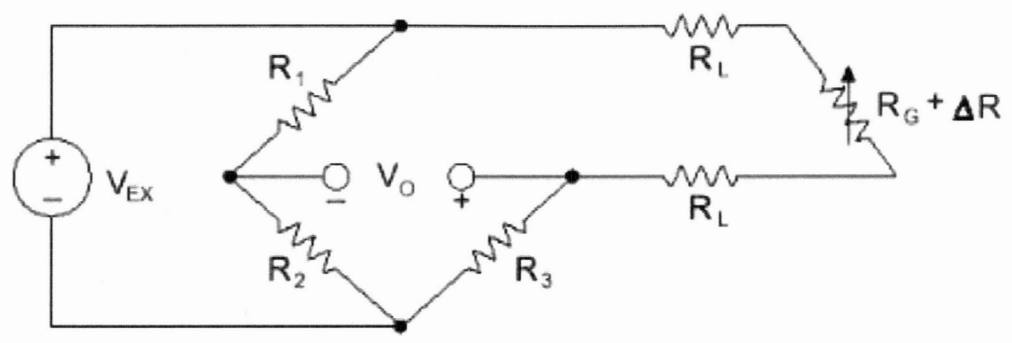

a) Two-Wire Connection

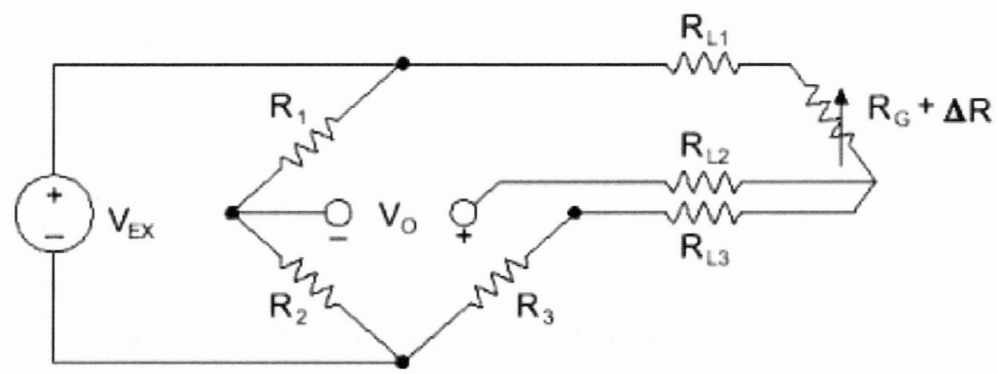

b) Three-Wire Connection

Figure 3.4 Illustration of Circuit Options to Connect a Strain Gauge to the Quarter Bridge Circuit [120]

From every two strain gauges, wiring was connected to one DSub-15-pin connector (ACC/DSUB-UNI2, IMC Mess-Systeme GmbH, Berlin, Germany) which is shown in the Figure 6.11, that completes the Wheatstone bridge for strain measurements. The supplier of the CRONO-PL unit has provided the amplifier and the connector. The wiring from the gauges can be inserted into the several slots which are labelled in the DSub-15-pin connector shown in the Figure 3.5. First, from a strain gauge, the free end of the colour-coded lead wire is seperated into three seperate wires and by stripping off the insulation around half an inch from each coloured wire, the red wire was connected to the +VB1 slot and the black wire was connected to I1_1/4B1. Not from the strain gauge, a small piece of a free wire is inserted to the SENSE1 slot and the white wire from the strain gauge was twisted with the other end of this small wire, and inserted into $+\mathrm{IN} 1$ slot which finishes the quarter bridge for one strain gauge. 


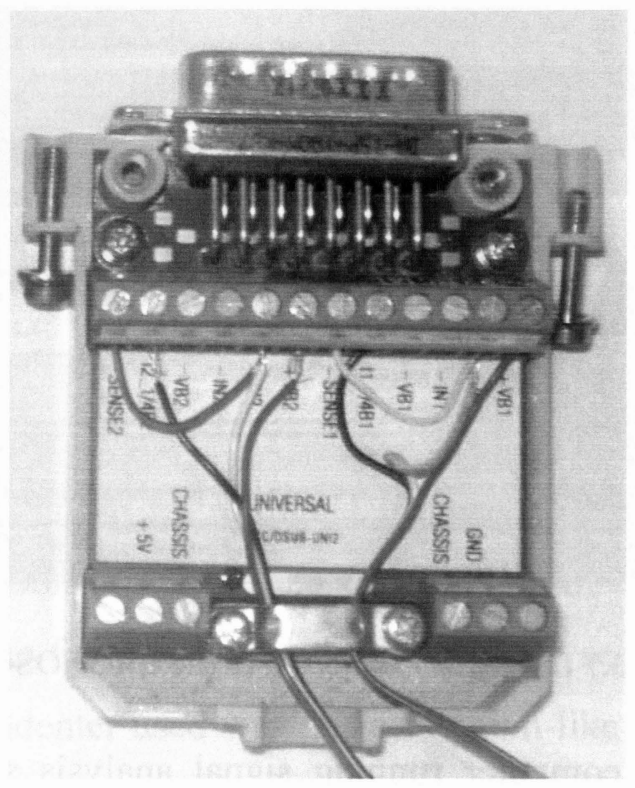

Figure 3.5 A Two-Channel DSub-15-Pin Connector can be attached to Wiring from Two Strain Gauges

In the same way all strain gauges were connected to one DSub-15 connector. The CRONOS-PL (Figure 3.7) is outfitted with a UNI2-8 eight-channel amplifier (IMC Mess-Systeme GmbH, Berlin, Germany) (Figure 3.6 left) installed in one of its posterior slots, which serves as the interface to connect the four DSub-15 connectors.
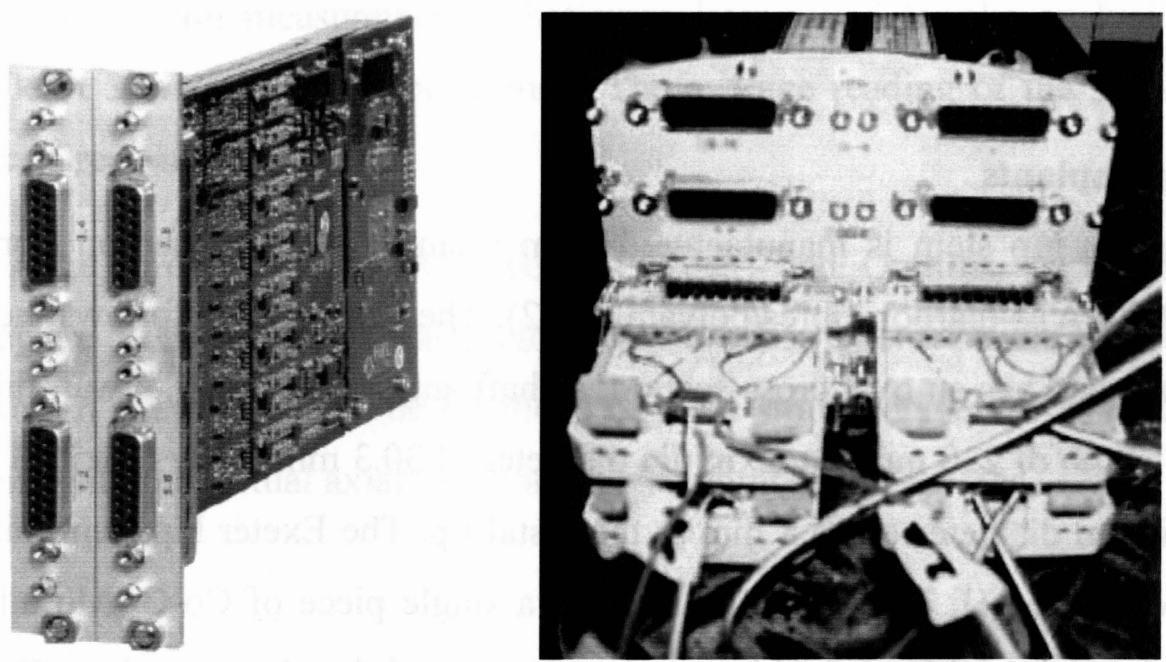

Figure 3.6 UNI2-8 All-Purpose Eight-Channel Amplifier (Left) [119] is Installed in the CRONOS-PL Unit to Accept the Four DSub-15 Connectors (Right) 


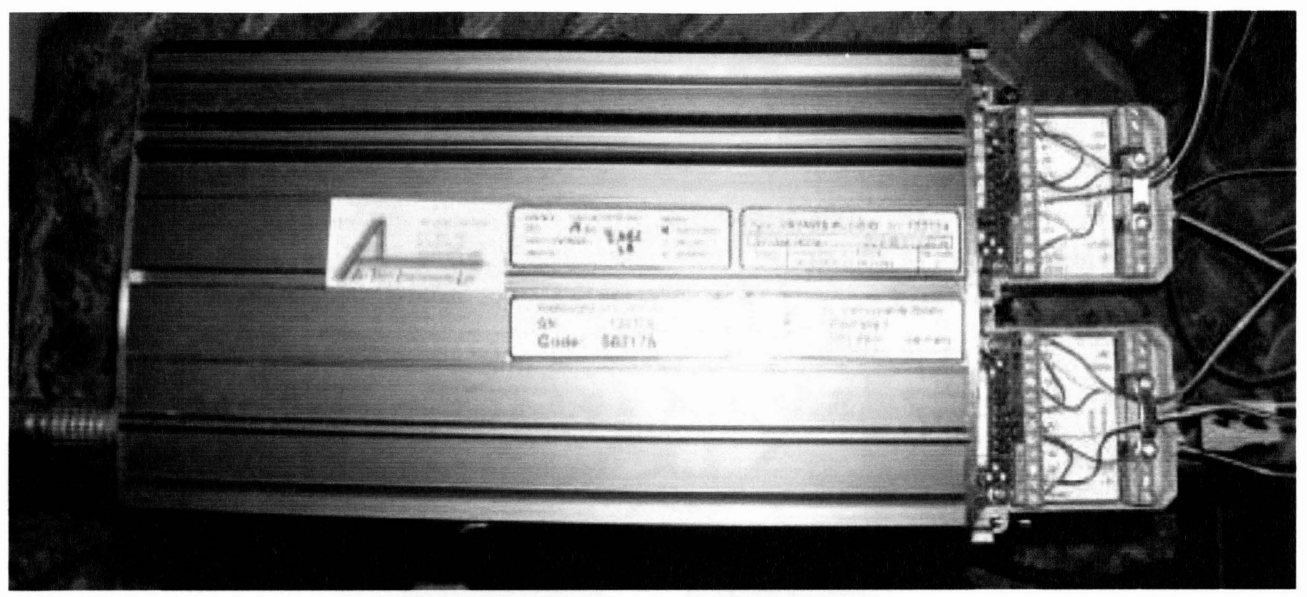

Figure 3.7 DSub-15s Connected to the CRONOS-PL Unit

A data collection notebook computer running signal analysis software FAMOS V5.0 (IMC Mess-Systeme GmbH, Berlin, Germany) was connected to the CRONOS-PL unit through a LAN network. A supply of 5 Volts was selected when the strain gauge setting in FAMOS V5.0 was configured to the quarter bridge option. As per the manufacturer's specifications, the gauge factor and resistance were set to 2.12 and $350 \Omega$, respectively and sampling frequency was set to 1.0 millisecond. By using a built-in option that is provided in FAMOS V5.0, all strain gauge circuits were balanced. The measured strains from all strain gauges as displayed in microstrain $(\mu \varepsilon)$ plotted against time.

\subsection{Methodology}

\subsubsection{Hip Implants}

The Composite hip stem is manufactured from a single piece of carbon fibre-based polymer known as CF/PA12 (carbon fibres/polyamide 12). The hollow stem follows the natural curve of femoral bone and has an oval cross-section, a shaft angle of $135 \mathrm{deg}$, a wall thickness of $3 \mathrm{~mm}$, an overall length of $230 \mathrm{~mm}$, a maximum diameter of $30.3 \mathrm{~mm}$ at the proximal base of the neck, and a minimum diameter of $15.8 \mathrm{~mm}$ at the distal tip. The Exeter hip stem (size 2, offset 37.5) (Stryker, Mahwah, NJ, USA) is comprised of a single piece of Co-Cr-Mo alloy material. The stem was characterized by a double-taper geometry and the absence of a collar with a polished surface, which allows gradual subsidence of the stem into the cement mantle [121]. Dimensions include total length $(150 \mathrm{~mm})$ and the distal tip diameter $(4 \mathrm{~mm})$. The Omnifit Eon hip stem (Size 
7, offset 41mm) (Stryker, Mahwah, NJ, USA) is comprised of a single piece of titanium alloy material [121]. The implant has a collar at the neck base to assist seating in the intramedullary canal. The outer surface is multi-sided to enhance bony ongrowth around the implant and increase rotational stability. Dimensions included total length $(165 \mathrm{~mm})$ and distal tip diameter $(10.4 \mathrm{~mm})$.

\subsubsection{Mechanical Testing}

All experiments were done using an Instron 8874 mechanical tester. The axial load cell had a capacity of $\pm 25 \mathrm{kN}$, a resolution of $0.1 \mathrm{~N}$, and an accuracy of $\pm 0.5 \%$. All hip implants were equipped with a cobalt-chrome femoral ball and were distally secured to the base of the tester with an industrial vice. The indenter used was an acetabulum-like cup made from stainless steel that was fixed to the machine. A vertical axial force of $3000 \mathrm{~N}$ was applied to each femoral head. Loading rate was set to $100 \mathrm{~N} / \mathrm{s}$ by using the software interface of the FastTrack 8800 . The FastTrack 2 software also obtained feedback from the actuator on its displacement every 0.01 seconds besides controlling the loading rate and maximum load. The data of actual applied load over time on the test specimens could then be plotted. Maximum of $3000 \mathrm{~N}$ of compressive load that was applied by the actuator, and then kept in place for about 90 seconds so that strain and stiffness measurements could be obtained under maximum loading. Actuator was then lifted and the pressure was released from the test assembly. At the same time, the FAMOS V5.0 software generated plots of the strain measurements, that were later saved for the analysis. For each loading case, at least 3 test runs were performed. The average reading of the 3 test runs was taken for each strain reading.

Figure 3.8 shows the three hip stems Composite, Exeter, and Omnifit, from left to right, respectively. They are all fixed in the cement blocks and are instrumented with $350 \mathrm{Ohm}$ general purpose linear pattern strain gauges. The locations of these strain gauges are also illustrated in the Figure 3.8 along with the virtual axial force on their femoral heads. 


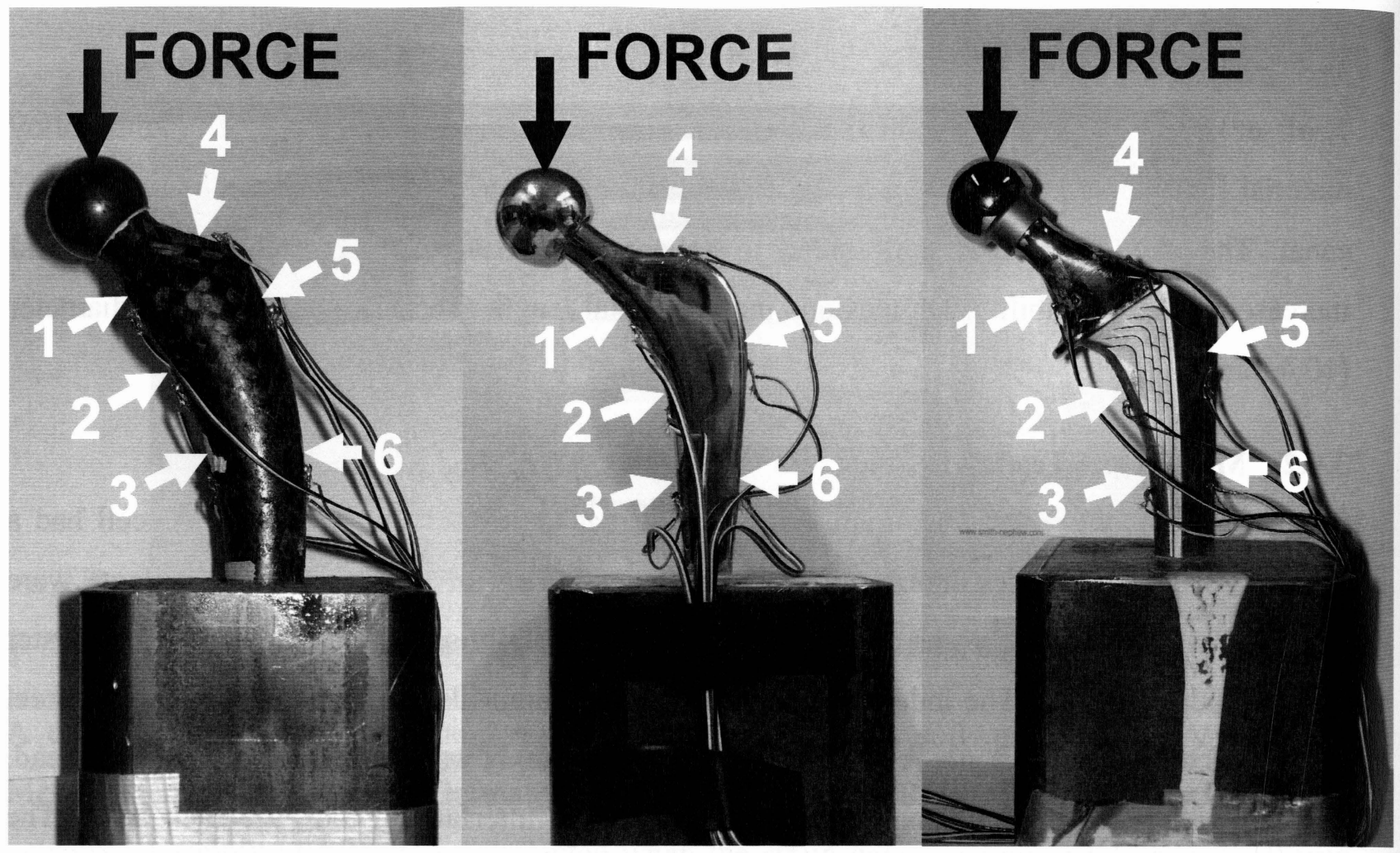

Figure 3.8 Locations of the Six Strain Gauges on All Three Hip Stems and the Virtual Axial Force on Their Femoral Heads 


\section{CHAPTER 4}

\subsection{Geometric Modelling}

The implant components were developed via the CAD software SolidWorks ${ }^{\circledR} 2008$ (SolidWorks Corporation, Dassault Systemes, Concord, MA, USA) to create a solid model of the Composite and the Exeter hip stems along with their femoral heads, acetabular cup indenters and the concrete blocks which were used in the experimental portion of this study. To generate the complex geometry of the Omnifit Eon stem, NextEngine 3D scanner (NextEngine, Inc, Santa Monica, CA, USA) was employed. This scanner can quickly create highly detailed, full colour, digital models measuring at a speed of 50,000 points per second. After scanning and modelling individual components, the file could be saved in the Parasolid or IGES format, as these formats are mostly used in the SolidWorks and Ansys softwares.

The models of the hip implants and their components are assembled exactly as in the experimental setup. The images in the following sections show the hip implants along with their components.

\subsubsection{Composite (CF/PA12) Hip Stem and Components}

The following figures show the Composite (CF/PA12) hip stem and its components. The hollow stem follows the natural curve of femoral bone and has an oval cross-section, a shaft angle of $135 \mathrm{deg}$, a wall thickness of $3 \mathrm{~mm}$, an overall length of $230 \mathrm{~mm}$, a maximum diameter of 30.3 $\mathrm{mm}$ at the proximal base of the neck, and a minimum diameter of $15.8 \mathrm{~mm}$ at the distal tip (Figure $4.1 \mathrm{a}$ ). The femoral head (Figure $4.1 \mathrm{~b}$ ) was made of cobalt-chrome, the acetabular cup indetnter (Figure $4.1 \mathrm{~d}$ ) was made of stainless steel that simulates vertical loading on the femoral head, and the block was made of cement (Figure $4.1 \mathrm{c}$ ). 


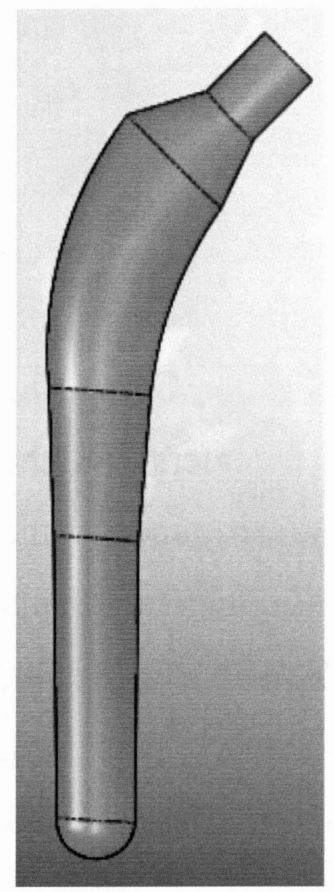

a

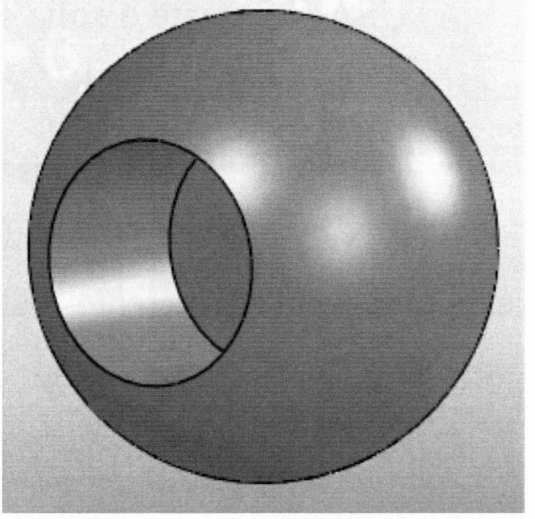

b

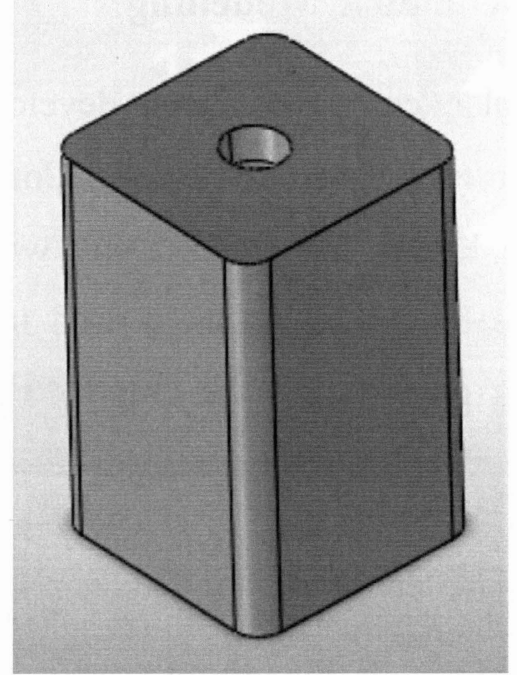

c

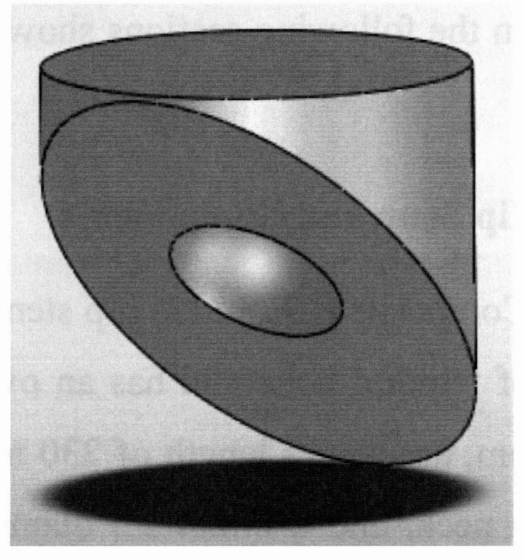

d

Figure 4.1 Composite (CF/PA12) Hip Stem and its components. (a). Hip Stem, (b). Femoral Head, (c). Cement Block, and (d). Acetabular Cup Indenter

\subsubsection{Stryker Exeter Hip Stem and Components}

The following figures show the Stryker Exeter hip stem and its components. The Stryker Exeter hip stem (size 2, offset 37.5mm) (Stryker, Mahwah, NJ, USA) (Figure 4.2 a) was comprised of a single piece of cobalt-chromium-molybdenum (CoCrMo) alloy material. The femoral head (Figure 4.2 b) was made of cobalt-chrome, the acetabular cup indetnter (Figure $4.2 \mathrm{~d}$ ) was made of 
stainless steel that simulates vertical loading on the femoral head, and the block was made of cement (Figure $4.2 \mathrm{c}$ ).

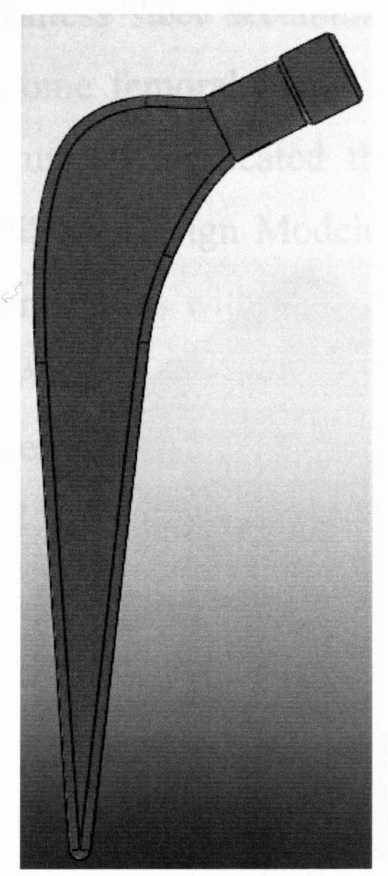

a

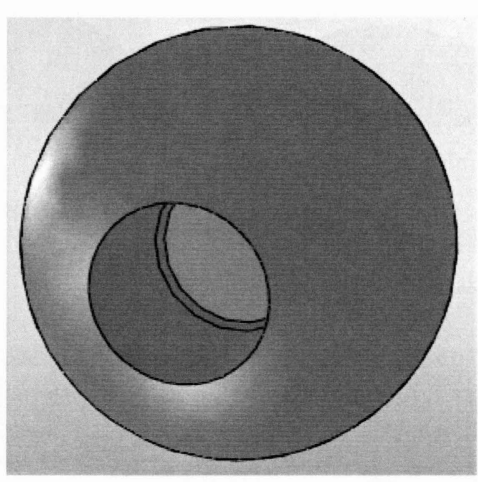

$\mathrm{b}$

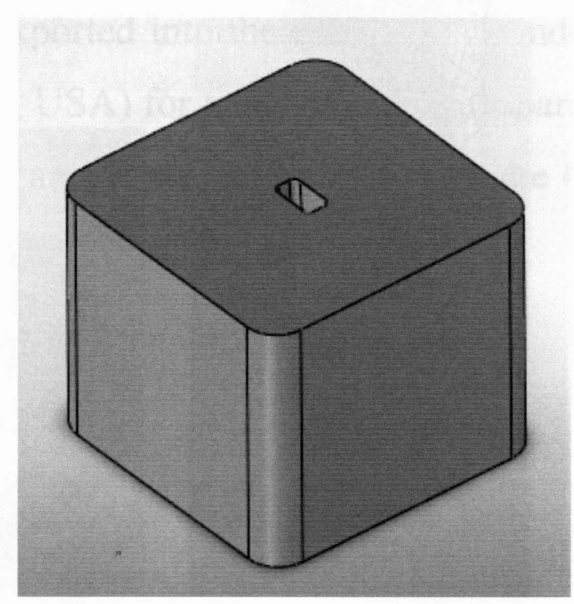

C

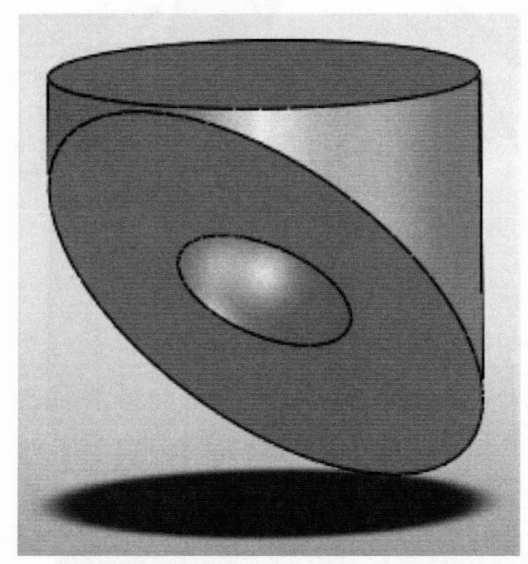

d

Figure 4.2 Stryker Exeter Hip Stem and its Components. (a). Hip Stem, (b). Femoral Head, (c). Cement Block, and (d). Acetabular Cup Indenter

\subsubsection{Stryker Omnifit Eon Hip Implant and Components}

The following figures show the Stryker Omnifit Eon hip stem and its components. The Stryker Omnifit Eon hip stem (Size 7, offset 41mm) (Stryker, Mahwah, NJ, USA) (Figure 4.3 a) is 
comprised of a single piece of titanium alloy material. The femoral head (Figure $4.3 \mathrm{~b}$ ) was made of cobalt-chrome, the acetabular cup indetnter (Figure $4.3 \mathrm{~d}$ ) was made of stainless steel that simulates vertical loading on the femoral head, and the block was made of cement (Figure $4.3 \mathrm{c}$ ).

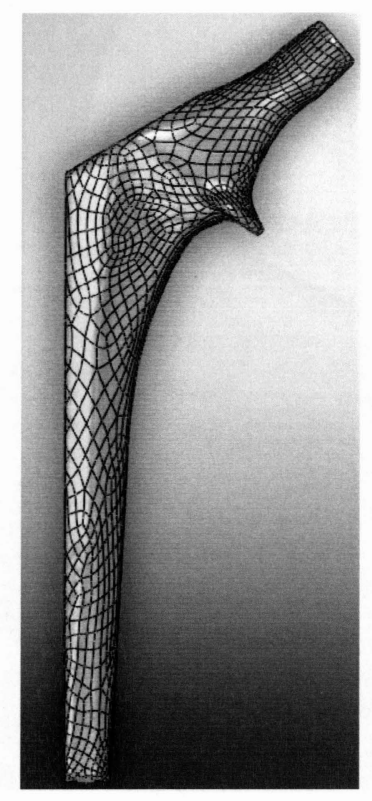

a

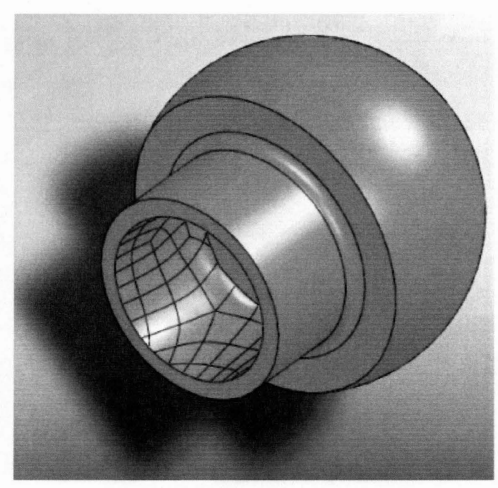

$\mathrm{b}$

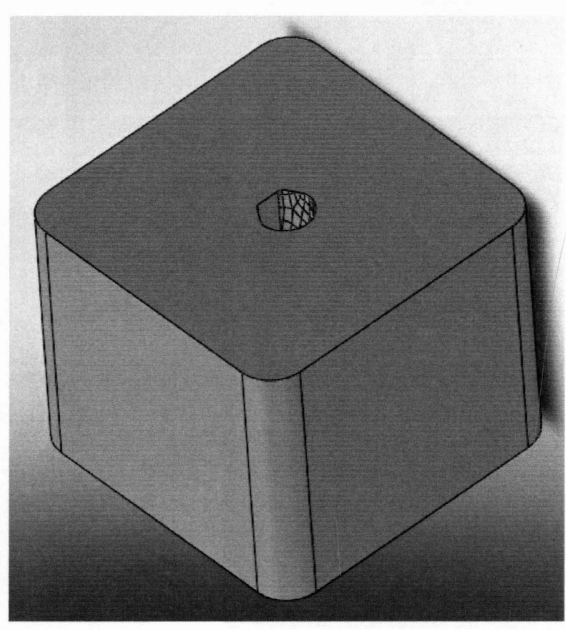

c

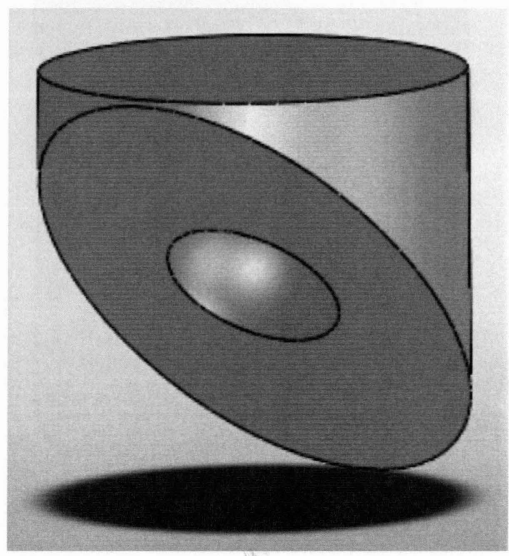

d

Figure 4.3 Stryker Omnifit Eon Hip Implant and its Components. (a). Hip Stem, (b). Femoral Head, (c). Cement Block, (d). Acetabular Cup Indenter 


\subsection{Assemblies}

All hip stems were positioned in a fixed distal base replicating the experimental setup. A stainless steel acetabular cup indenter was added to simulate vertical loading on the cobaltchrome femoral balls. This was done within Solidworks 2008 to ensure that the CAD model accurately replicated the experiments. The geometry was exported as a parasolid file into ANSYS Design Modeler, where Body Operations were performed to guarantee no overlap of components within the assembly. This geometry was then exported into the Simulation window of ANSYS Workbench 11.0 (ANSYS, Inc., Canonsburg, PA, USA) for analysis. The transparent assemblies of the Composite, Exeter and Omnifit hip stems are shown in Figure 4.4, Figure 4.5, and Figure 4.6.

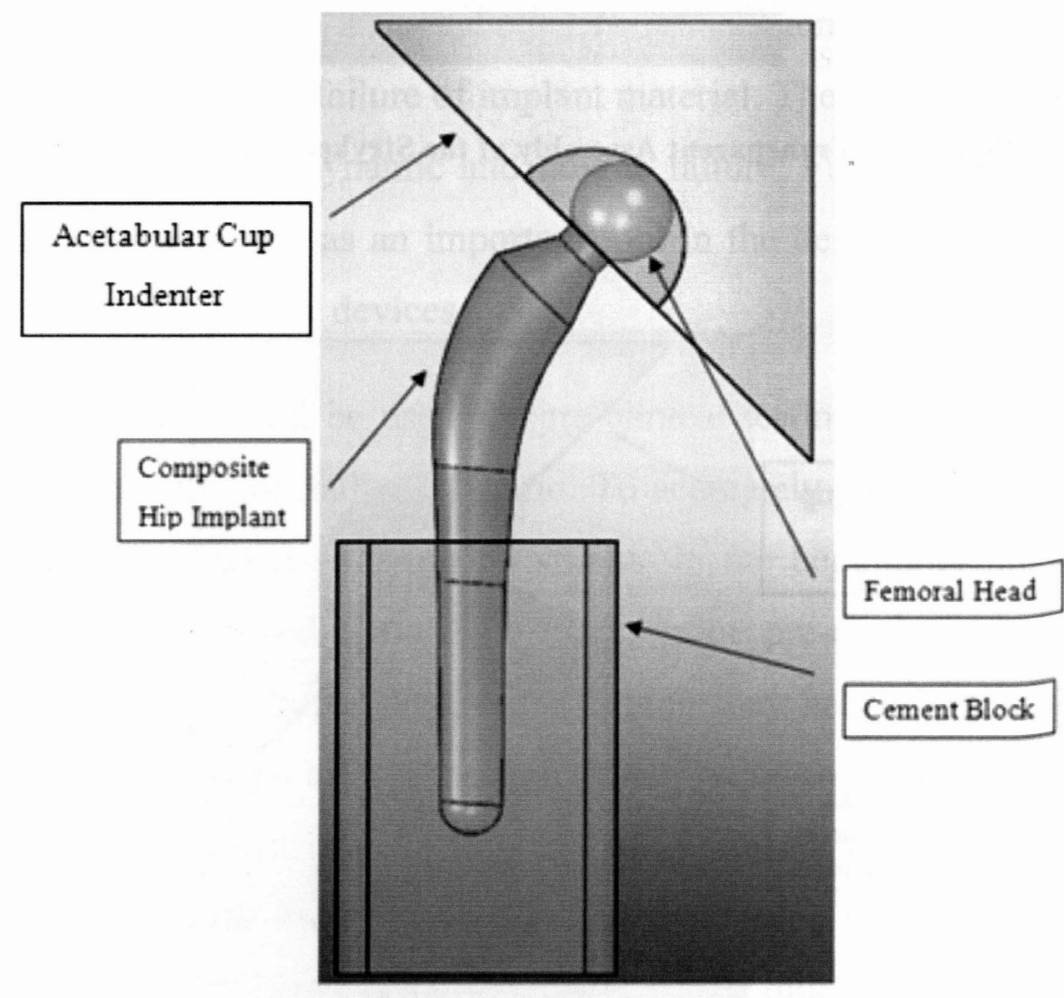

Figure 4.4 Transparent Assembly of the Composite Hip Stem 


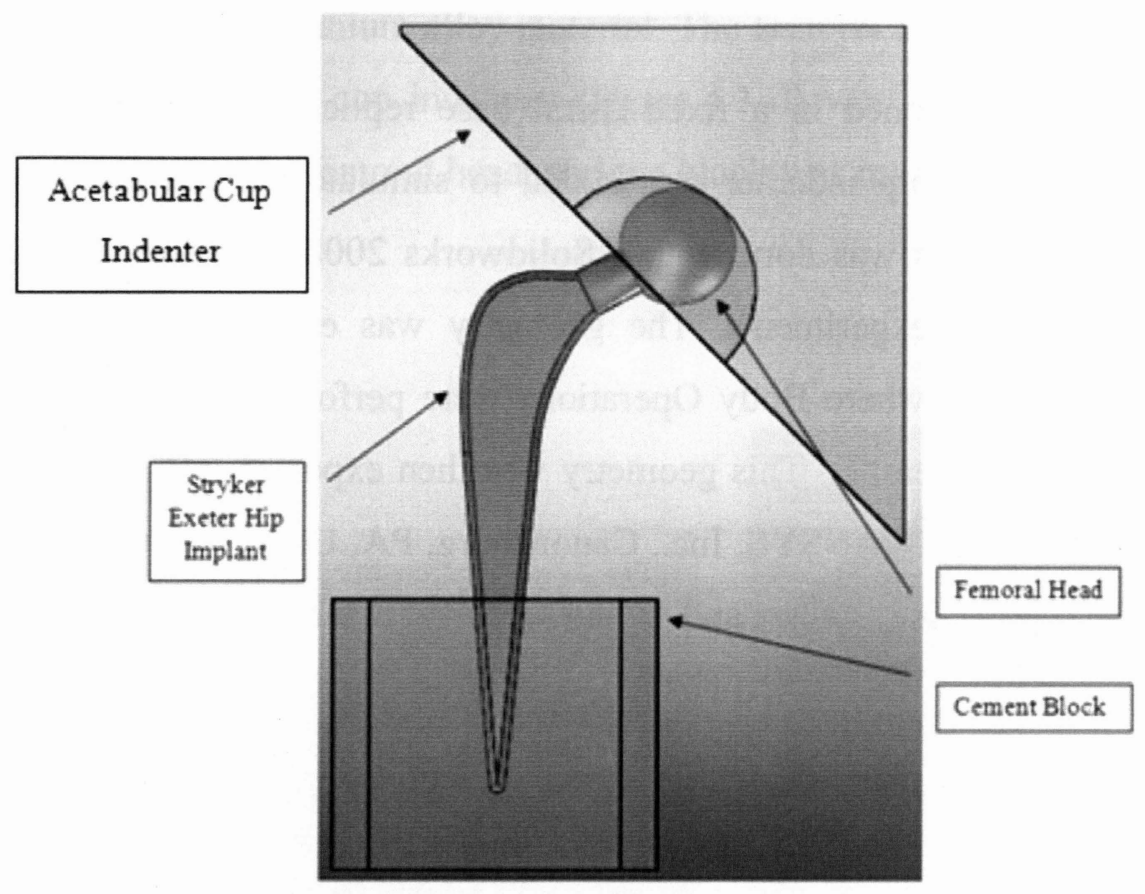

Figure 4.5 Transparent Assembly of the Stryker Exeter Hip Stem

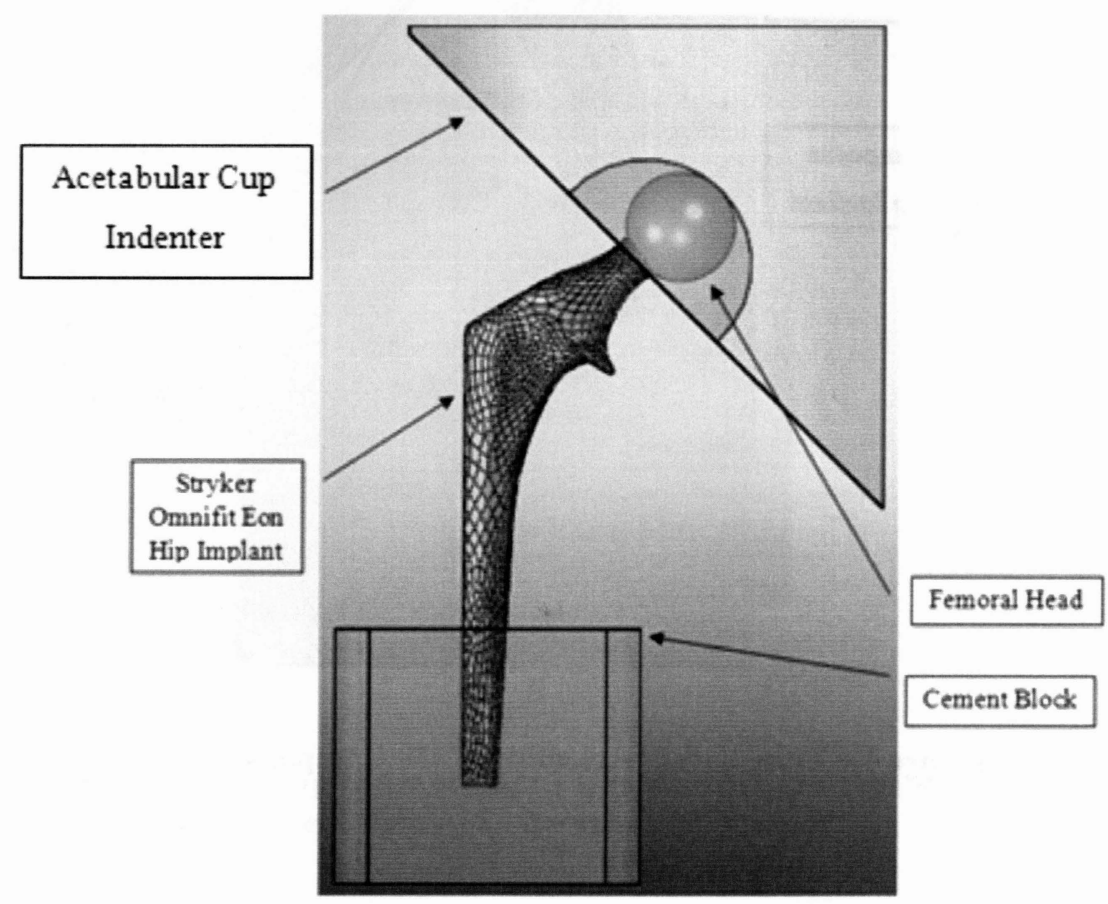

Figure 4.6 Transparent Assembly of the Stryker Omnifit Eon Hip Stem 


\subsection{Finite Element Modelling}

\subsubsection{Overview}

The geometry modelled and assembled as described in the previous section was used to develop a finite element (FE) model, described in this chapter. In following chapter, the FE model is validated by comparing the strains generated on the implant surfaces with those measured in the experimental study. Once validated, the FE model is used to study the implant-bone stress transfer characterisitics of the composite model with that of the conventional models. The following section provides a review of relevant published studies concerning FE modelling of the hip joint.

\subsubsection{Importance and Need of Finite Element Analysis}

Forces applied to the hip implant due to the human activities generate dynamic stresses varying in time and resulting in the fatigue failure of implant material. Therefore, it is important to ensure the hip prostheses against static, dynamic and fatigue failure. Finite element method has been used in orthopaedic biomechanics as an important tool in the design and analysis of total joint replacements and other orthopaedic devices.

Finite element (FE) models could be used for pre-clinical testing of hip replacement implants against the damage accumulation failure scenario. To accurately predict mechanical failure, the models should accurately predict stresses and strains. In the beginning, the new hip implants were introduced on the orthopedic market without prior pre-clinical testing, which led to unsatisfactory clinical results. Proper pre-clinical testing may help to reduce the frequency of implant loosening. FE simulation allows the stress distribution to be determined throughout the entire reconstruction and not just in discrete points. They do not require the physical copies of the implant and in that case the testing can already be proceeded from the design specifications and the effects of the design changes can be analyzed very quickly. They also allow hip joint reconstructions to be tested under complex, realistic loading configurations.

Finite element models in designing and improving hip prostheses have been developed for a long time. Previous studies have employed representative 2D models [75, 122, 123], more realistic 3D models $[23,75,103,124-128]$, simplified static analysis [25, 113, 129-133], and more complex dynamic analysis $[15,25,133-135]$. The literature on finite element (FE) modelling of the hip 
joint is quite vast, and only selected relevant static analysis studies will be discussed in this section.

\subsection{Material Properties}

A material property is an intensive (not depending on the size or the amount of material), often quantitative property of a material, usually with a unit that may be used as a metric of value to compare the benefits of one material versus another to aid in material selection. The material properties for the hip stem FE models which were used in the analysis are as follows: Composite CF/PA12 hip stem $(E=16.4 \mathrm{GPa}, \mathrm{v}=0.3)$, Stryker Exeter hip stem $(\mathrm{E}=210 \mathrm{GPa}, \mathrm{v}=0.3)$, and Stryker Omnifit Eon hip stem $(\mathrm{E}=114 \mathrm{GPa}, \mathrm{v}=0.3)$. The femoral balls or heads were set at values for cobalt-chrome with properties $(E=200 \mathrm{GPa}, \mathrm{v}=0.3)$.

\subsubsection{CoCrMo Alloy}

The Exeter hip stem (Stryer, Mahwah, NJ, USA) (size 2, offset $37.5 \mathrm{~mm}$ ) is made of cobaltchromium-molybdenum (CoCrMo) alloy [121]. CoCrMo alloys are cobalt based metal alloys which are frequently used in the medical grade alloys in joint arthroplasty containing around 27$30 \%$ chrome and 5-7\& molybdenum. The specifications for CoCrMo medical grade alloys (cast, wrought, and forged) are covered in the American Society for Testing and Materials (ASTM) standards F75, F799, and F1537, as reported by Kurtz [81].

This study will use ASTM F1537 minimum specifications for wrought and warm worked CoCrMo medical grade alloys with a tensile yield strength of $827 \mathrm{MPa}$, and ultimate tensile strength of $1172 \mathrm{MPa}$ (ultimate elongation of 12\%), as reported by Kurtz [81]. The alloy density used is $8.28 \mathrm{~g} / \mathrm{cc}$, which is of the commercially available CoCrMo alloy manufactured as per ASTM F1537 ( $28 \%$ chromium and 6\% molybdenum). The Poisson's ratio used is 0.30 , which is the same for all the individual constituent metals (cobalt, chromium, and molybdenum). Table 4.1 shows the properties of Cobalt-Chrome alloy. 


\begin{tabular}{|l|c|}
\hline Density & $8.28 \mathrm{~g} / \mathrm{cc}$ \\
\hline Elastic modulus [136] & $210 \mathrm{GPa}$ \\
\hline Yield strength [81] & $827 \mathrm{MPa}$ \\
\hline Ultimate strength [81] & $1172 \mathrm{MPa}$ \\
\hline Ultimate elongation (tensile) [81] & $12 \%$ \\
\hline Poisson's ratio & 0.30 \\
\hline Isotropy & Isotropic \\
\hline
\end{tabular}

Table 4.1 Cobalt-Chromium Alloy Properties

\subsubsection{Ti Alloy}

Ti-6Al-4V alloy is currently used for the fabrication of most stems for total hip joint replacements. Because of its high mechanical strength, corrosion resistance, and excellent biocompatibility, it has got the preference to be used in many orthopaedic applications. However, this alloy has two main drawbacks, significant stress shielding and important migration. First, due to its young's modulus of $114 \mathrm{GPa}$, which is much higher than that for the contiguous bone, the stiff implant will sustain greater part of the load and results in the stress shielding. The second is the consequence of large micro-motions at the bone-implant interface resulting from non-optimal surface conditions. These weaknesses lead to implant loosening and bone resorption in the surrounding femoral bone. To overcome these problems, low modulus Ti-based alloys (Ti$13 \mathrm{Nb}-13 \mathrm{Zr}$ and $\mathrm{Ti}-29 \mathrm{Nb}-13 \mathrm{Ta}-4.6 \mathrm{Zr}$ ) with an elastic modulus between 60 and $80 \mathrm{GPa}$ are used, which provide sufficient strength and corrosion resistance. They reduce stress shielding enhance bone remodelling although their modulus is still 4-5 times higher than that of the contiguous bone. These materials have high cost, inferior wear properties [23].

\subsubsection{CF/PA12}

The manufacturing and compression testing of CF/PA12 was conducted by Campbell and colleagues $[24,25,102,103]$. Using the compressive properties as tested and published by Campbell et al. [25], the CF/PA12 is modelled to be isotropic for FE modelling. Table 4.2 outlines the properties of $\mathrm{CF} / \mathrm{PA} 12$. 


\begin{tabular}{|l|c|}
\hline Density [24, 102] & $1.43 \mathrm{~g} / \mathrm{cc}$ \\
\hline Bulk compressive modulus [25] & $12.2 \mathrm{GPa}$ \\
\hline Bulk compressive ultimate strength [25] & $155 \mathrm{MPa}$ \\
\hline Bulk flexural modulus (not used in FEA) [25] & $16.4 \mathrm{GPa}$ \\
\hline Bulk flexural ultimate strength [25] & $188 \mathrm{GPa}$ \\
\hline Poisson's ratio [23] & 0.3 \\
\hline Elasticity model & Linear elastic \\
\hline Isotropy & $\begin{array}{c}\text { Isotropic, using bulk } \\
\text { compressive modulus as } \\
\text { elastic modulus }\end{array}$ \\
\hline
\end{tabular}

Table 4.2 CF/PA12 Properties

\subsubsection{Cement Block}

The hip implants used in the experiment were osteotomised and rigidly fixed in a block of cement/concrete. While it is convenient to model the base of the hip implants to be rigidly constrained, such models may not be able to reproduce the experimental measurements. The cement block was also modelled to be flexible with properties provided by the material library in the ANSYS Workbench software package itself. Concrete properties are shown in Table 4.3.

\begin{tabular}{|l|c|}
\hline Density & $2.3 \mathrm{~g} / \mathrm{cc}$ \\
\hline Elastic Modulus & $30 \mathrm{GPa}$ \\
\hline Yield Strength & $0 \mathrm{MPa}$ \\
\hline Ultimate Uompressive Strength & $41 \mathrm{MPa}$ \\
\hline Poisson's Ratio & 0.18 \\
\hline Elasticity Model & Linear elastic \\
\hline Isotropy & Isotropic \\
\hline
\end{tabular}

Table 4.3 Concrete Properties

\subsection{Finite Element (FE) Analysis}

\subsubsection{SOLID187 3-D 10-Node Tetrahedral Structural Solid}

SOLID187 is included in ANSYS Workbench which has a higher order 3D tetrahedral solid element. All the solid bodies were modelled with this element. This element has three degrees of freedom at each node, having 10 nodes, in the nodal $\mathrm{x}, \mathrm{y}$, and $\mathrm{z}$ directions. Its behaviour is quadratic displacement, and is quite suited to modelling irregular meshes like those imported from CAD software, and because of this quality SOLID187 has been used to model the highly 
curvaceous geometry of the implant components. This element has plasticity, hyper elasticity, creep, stress stiffening, large deflection, and large strain capabilities. Moreover, it has mixed formulation capability for simulating deformations of nearly incompressible elastoplastic materials, and fully incompressible hyper elastic materials. This element would be ideal if used for further analysis, in future, for FE model of this study including the more complex material behaviour. This element input data includes the orthotropic or anisotropic material properties, which correspond to the element coordinate directions. Figure 4.7 shows the node locations, the coordinate system, and the geometry for this element. Figure 4.8 illustrates the element stress directions which are parallel to the element coordinate system, and the surface stress outputs are in the surface coordinate system [137].

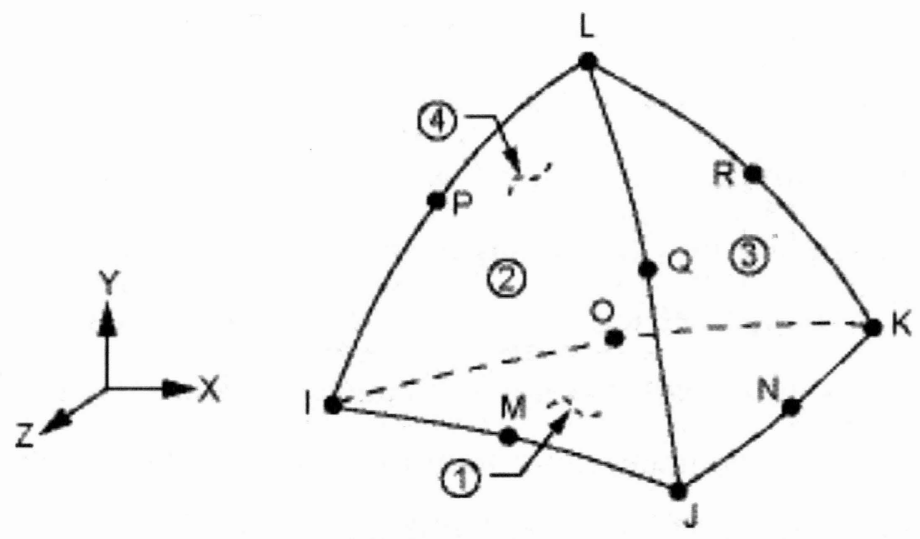

Figure 4.7 SOLID187 Element Description [137]

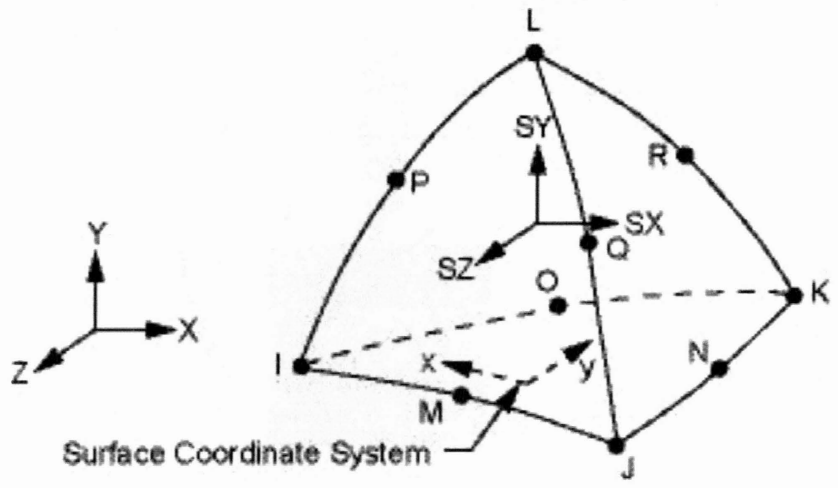

Figure 4.8 SOLID187 Stress Output Directions [137] 


\subsubsection{TARGE170 3D Target Segment}

To represent various 3-D "target" surfaces for the associated elements, TARGE170 is used. The contact elements themselves overlay the solid, shell, or line elements describing the boundary of a deformable body and are potentially in contact with the target surface, defined by TARGE170. The target surface is discretized by a set of target segment elements (TARGE170) and is paired with its associated contact surface via a shared real constant set. For rigid target surfaces, these elements can easily model complex target shapes. For flexible targets, these elements will overlay the solid, shell, or line elements describing the boundary of the deformable target body [138].

Each target surface can be associated with only one contact surface, and vice-versa. However, several contact elements could make up the contact surface and thus come in contact with the same target surface. In the same way, several target elements could make up the target surface and thus come in contact with the same contact surface. For either the target or contact surfaces, many elements may be applied in a single target or contact surface, but doing so may increase computational cost. For a more efficient model, localize the contact and target surfaces by splitting the large surfaces into smaller target and contact surfaces, each of which contain fewer elements. If a contact surface contacts more than one target surface, duplicate contact surfaces must be defined that share the same geometry but relate to separate targets that have separate real constant set numbers [138]. Figure 4.9 shows the element description for TARGE170.

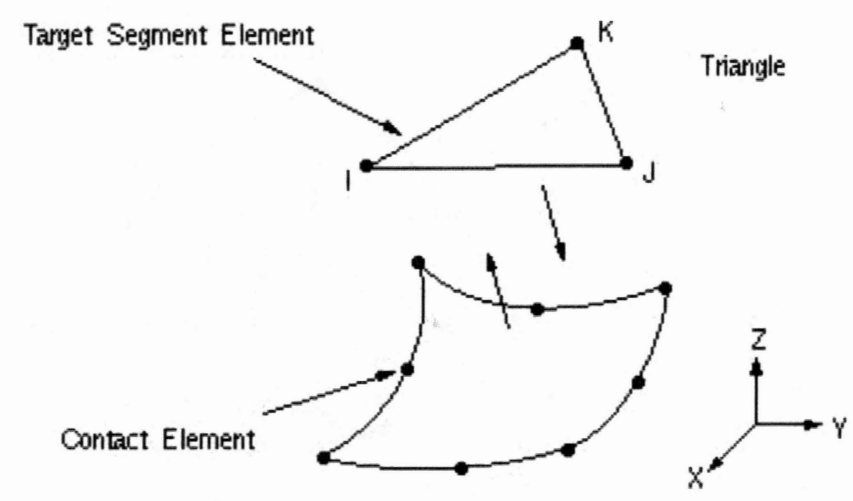

Figure 4.9 TARGE170 Element Description [138] 


\subsubsection{Simulation Using ANSYS}

The Finite Element (FE) analysis was performed in the simulation window of ANSYS Workbench 11 suite. A slice operation was performed so that the working length from the distal end of each hip implant to the top of the femoral ball were identical $(115 \mathrm{~mm})$ for all three hip stems in order to model the experimental setup. The isolated distal material was restrained in the simulation utility. A vertical load of $3000 \mathrm{~N}$ was then applied at the face of the indenter with motion permitted in a two-dimensional plane, i.e. the proximal-distal and medial-lateral directions. Bonded contact was assumed between all contact surfaces, except that the contact region between the vertical acetabular indenter and cobalt-chrome femoral ball was set to no separation to avoid slipping.

\subsection{Boundary Conditions}

The cement block is placed under fixed support (dark blue in Figure 4.10) and acetabular cup indenter of all three hip implants was constrained to move in the axial direction only (yellow surfaces in Figure 4.10). The applied axial force in all cases was applied on the acetabular cup indenters to replicate the experimental study where the actuator press down on the hip stem setups.
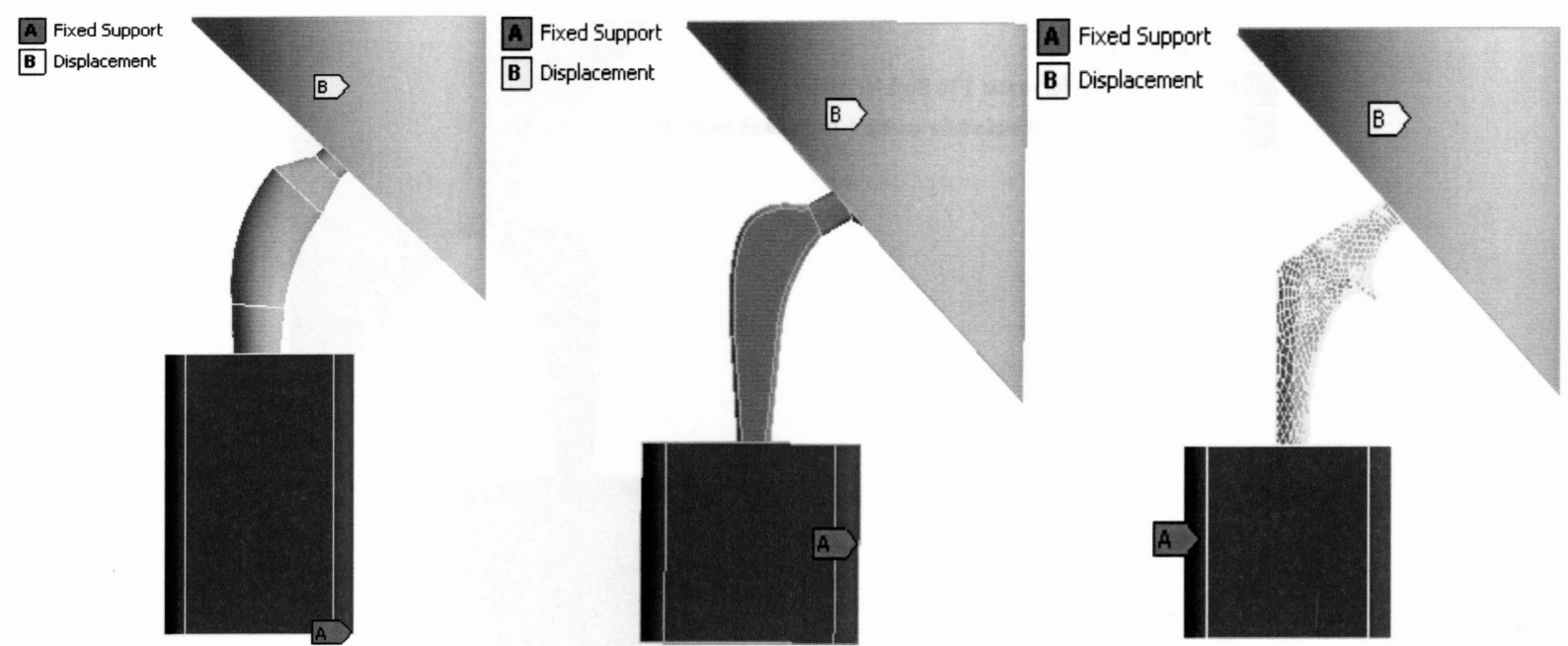

Figure 4.10 Boundary Conditions on the Assembly for the 3000 N Load 


\subsection{Contacts}

Bonded contact was assumed between all contact surfaces, except that the contact region between the vertical acetabular indenter and cobalt-chrome femoral ball was set to no separation to avoid slipping. Figure 4.11, Figure 4.12, and Figure 4.13 are showing the precise models created in the ANSYS software for the finite element analysis (FEA).

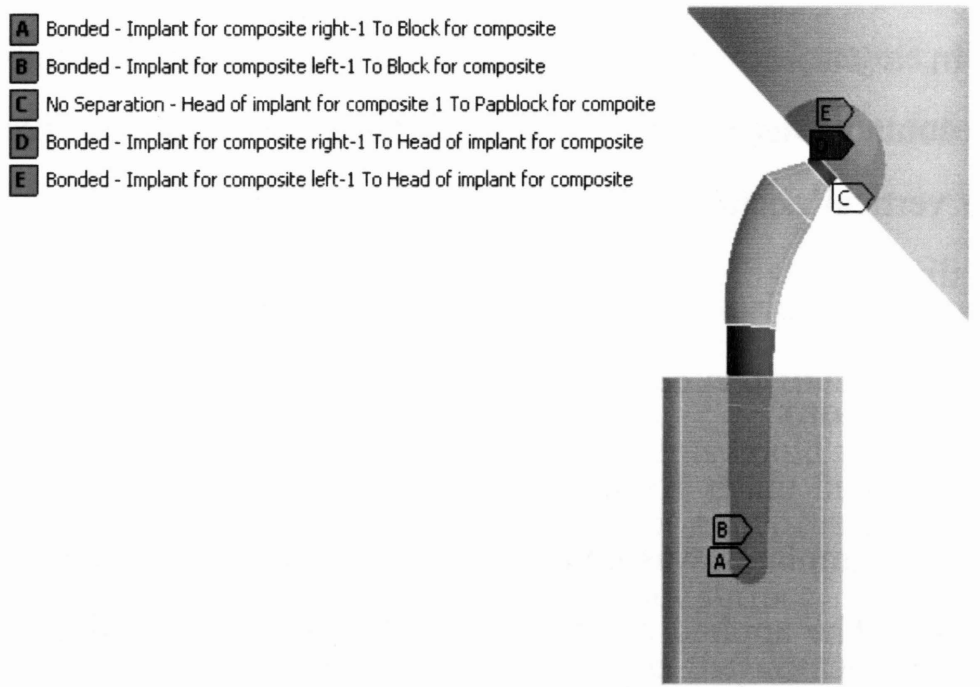

Figure 4.11 Contact Locations in the Composite Hip Stem Assembly

A Contact Region

B Bonded - IMPLANT for exeter 1 To Block for exeter

No Separation - Head of implant for exeter 1 To Papblock for exeter

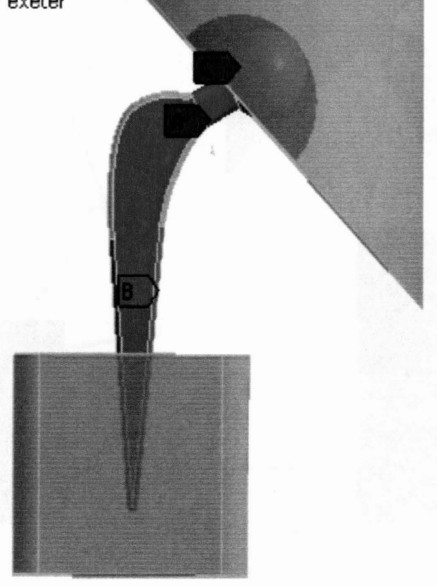

Figure 4.12 Contact Locations in the Exeter Hip Stem Assembly 
A Bonded - Scanned Stryker To Block for scanned stryker

B Bonded - Scanned Stryker To Head of implant for scanned stryker

[C. No Separation - Papblock for scanned stryker To Head of implant for scanned stryker

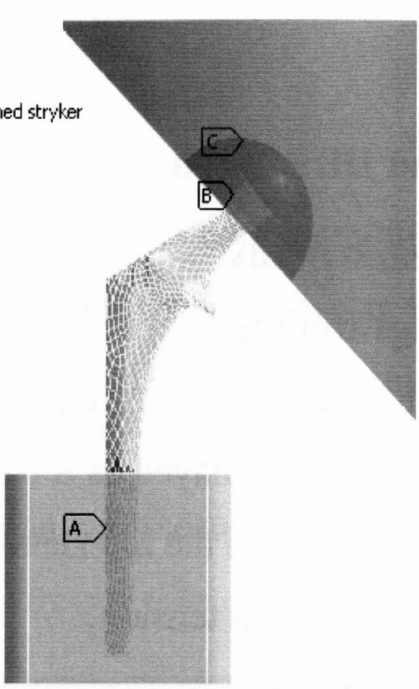

Figure 4.13 Contact Locations in the Omnifit Eon Hip Stem Assembly 


\section{CHAPTER 5}

\subsection{Results and Discussion}

\subsubsection{Experimental Study}

The gauge readings from the experimental study of the three hip implants for an axial load of $3000 \mathrm{~N}$ are tabulated in Table 5.1. The gauge locations and their sides are also identified. The measured microstrain is displayed as a bar chart in Figure 5.1. The results indicate that the strain gauges on the medial side of the hip stems experienced compression and those on the lateral side of the hip stems experienced tension.

\begin{tabular}{|c|c|c|c|c|c|}
\hline $\begin{array}{c}\text { Gauge } \\
\text { Side }\end{array}$ & Gauge & \multicolumn{3}{c|}{ Calculated strain $(\boldsymbol{\mu} \varepsilon)$ for Exp } & State of Load \\
\cline { 3 - 6 } & Location & Composite & Exeter & Omnifit & Experienced \\
\hline \multirow{3}{*}{\begin{tabular}{c} 
Medial \\
\cline { 2 - 6 }
\end{tabular}} & 1 & -2352 & -713 & -704 & Compression \\
\cline { 2 - 6 } & 2 & -4178 & -608 & -643 & Compression \\
\cline { 2 - 6 } & 3 & -4157 & -1103 & -1660 & Compression \\
\hline \multirow{3}{*}{ Lateral } & 4 & 1070 & 452 & 357 & Tension \\
\cline { 2 - 6 } & 5 & 1017 & 366 & 222 & Tension \\
\cline { 2 - 6 } & 6 & 1274 & 988 & 727 & Tension \\
\hline
\end{tabular}

Table 5.1 Gauge Locations and Their Corresponding Experimentally Measured Microstrain Values for Each Hip Stem

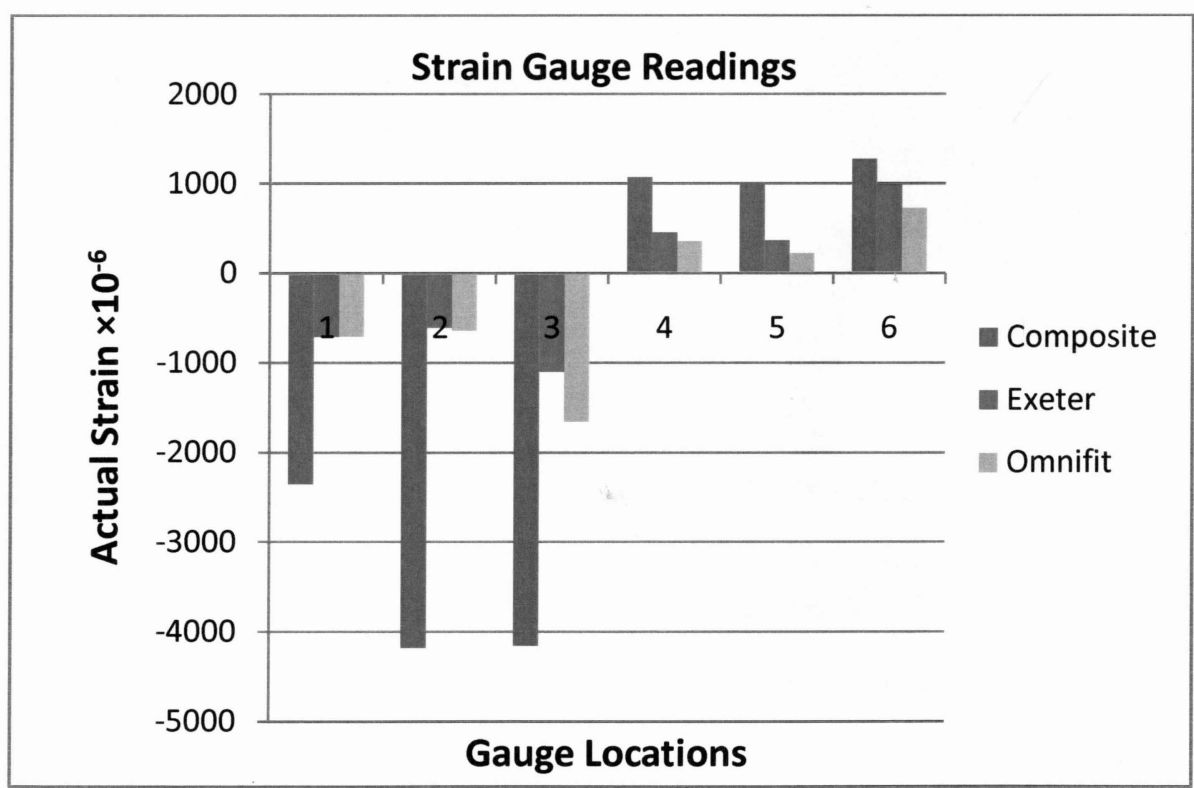

Figure 5.1 Column Chart Showing Gauge Locations and Their Corresponding Experimentally Measured Microstrain Values for Each Hip Stem 


\subsection{Finite Element Study}

\subsubsection{FEA Calculated Surface Strains}

The calculated microstrains for an axial load of $3000 \mathrm{~N}$ from the corresponding gauge locations on the FE models are tabulated against the experimental results as shown in the Table 5.2. The gauge locations and their sides are also identified. The calculated microstrain is displayed as a bar chart in Figure 5.2. As in the experimental case, the results indicate that the strain gauges on the medial side of the hip stems experienced compression and those on the lateral side of the hip stems experienced tension.

\begin{tabular}{c|cc|c|c|c|}
$\begin{array}{c}\text { Gauge } \\
\text { Side }\end{array}$ & $\begin{array}{c}\text { Gauge } \\
\text { Location }\end{array}$ & \multicolumn{3}{c|}{ Calculated strain $(\mu \varepsilon)$ for FEA } & $\begin{array}{c}\text { State of Load } \\
\text { Experienced }\end{array}$ \\
\cline { 3 - 6 } & & Composite & Exeter & Omnifit & \\
\hline \multirow{3}{*}{ Medial } & 1 & -2164 & -847 & -792 & Compression \\
\cline { 2 - 6 } & 2 & -4285 & -624 & -528 & Compression \\
\cline { 2 - 6 } & 3 & -2031 & -509 & -503 & Compression \\
\hline \multirow{2}{*}{ Lateral } & 4 & 1081 & 418 & 298 & Tension \\
\cline { 2 - 6 } & 5 & 862 & 295 & 235 & Tension \\
\cline { 2 - 6 } & 6 & 158 & 251 & 213 & Tension \\
\hline
\end{tabular}

Table 5.2 Gauge Locations and Their Corresponding Microstrain Values for Each Hip Stem by FEA

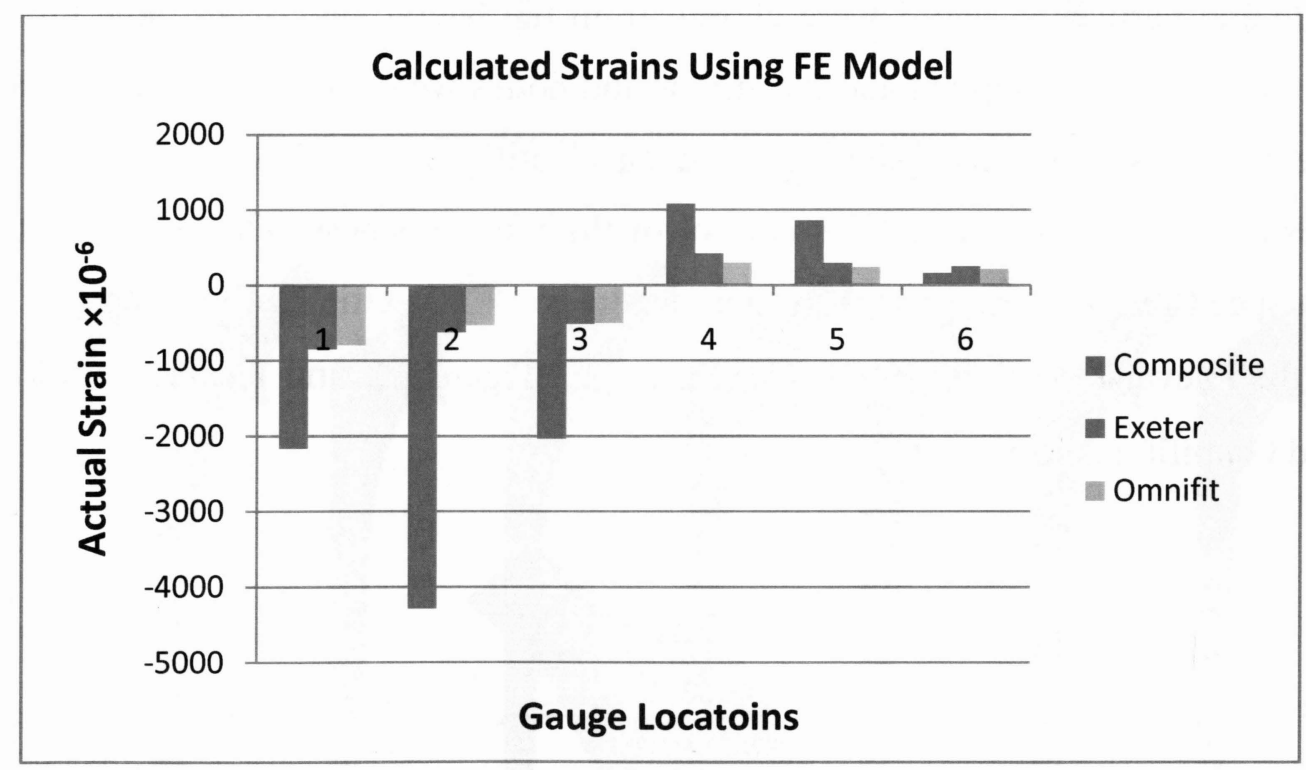

Figure 5.2 Column Chart Showing Gauge Locations and Their Corresponding Microstrains Values for Each Hip Stem by FEA 


\subsection{Meshing Properties}

ANSYS Workbench 11.0 was employed to generate meshes. The number of nodes and elements, respectively, were 171,531 and 134,769 for the composite hip stem, 314,658 and 240,272 for the Exeter hip stem, and 149,972 and 106,940 for the Omnifit Eon hip stem. The mesh was adjusted as required to compensate for problematic geometries. Structural elements used were a 10-node quadratic tetrahedron for all implants. This element has three degrees of freedom at each node translations in the nodal $\mathrm{x}, \mathrm{y}$, and $\mathrm{z}$ directions and a quadratic displacement behaviour well suited to modelling irregular and highly curvaceous geometries - such as those imported from CAD software.

\subsection{Mesh Sensitivity and Convergence}

A 10-node quadratic tetrahedron mesh has been used for all hip implants for the structural elements. This element has three degrees of freedom at each node, translation in the $\mathrm{x}, \mathrm{y}$, and $\mathrm{z}$ directions and a quadratic displacement behaviour well suited to modelling irregular and highly curvaceous geometries, such as those imported from CAD software. Four vertices were chosen from the all three hip stems as shown in the Figure 5.3. Vertices 1 , and 2 were chosen from the medial side and vertices 4 , and 5 were chosen from the lateral side of all three hip stems. An axial load of $3000 \mathrm{~N}$ was applied and the strains and nodes were recorded after each refinement. The refinement was performed using the 'relevance' utility in ANSYS Workbench, which is a global mesh control utility that allows control of the mesh fineness. The control options range from high speed mesh (-100 setting) to high accuracy (+100 setting). Eight meshes created by changing the relevance setting were tested (Figure 5.4, Figure 5.5, and Figure 5.6) for composite, Exeter and Omnifit, respectively.

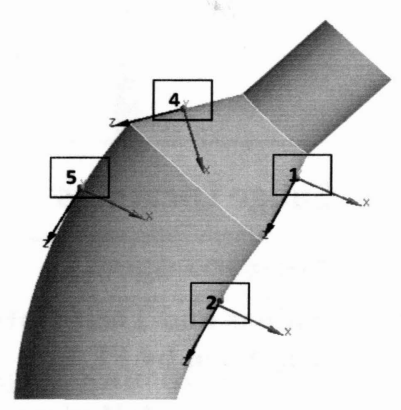

Figure 5.3 Locations of the Vertices Used to Test for Mesh Sensitivity 


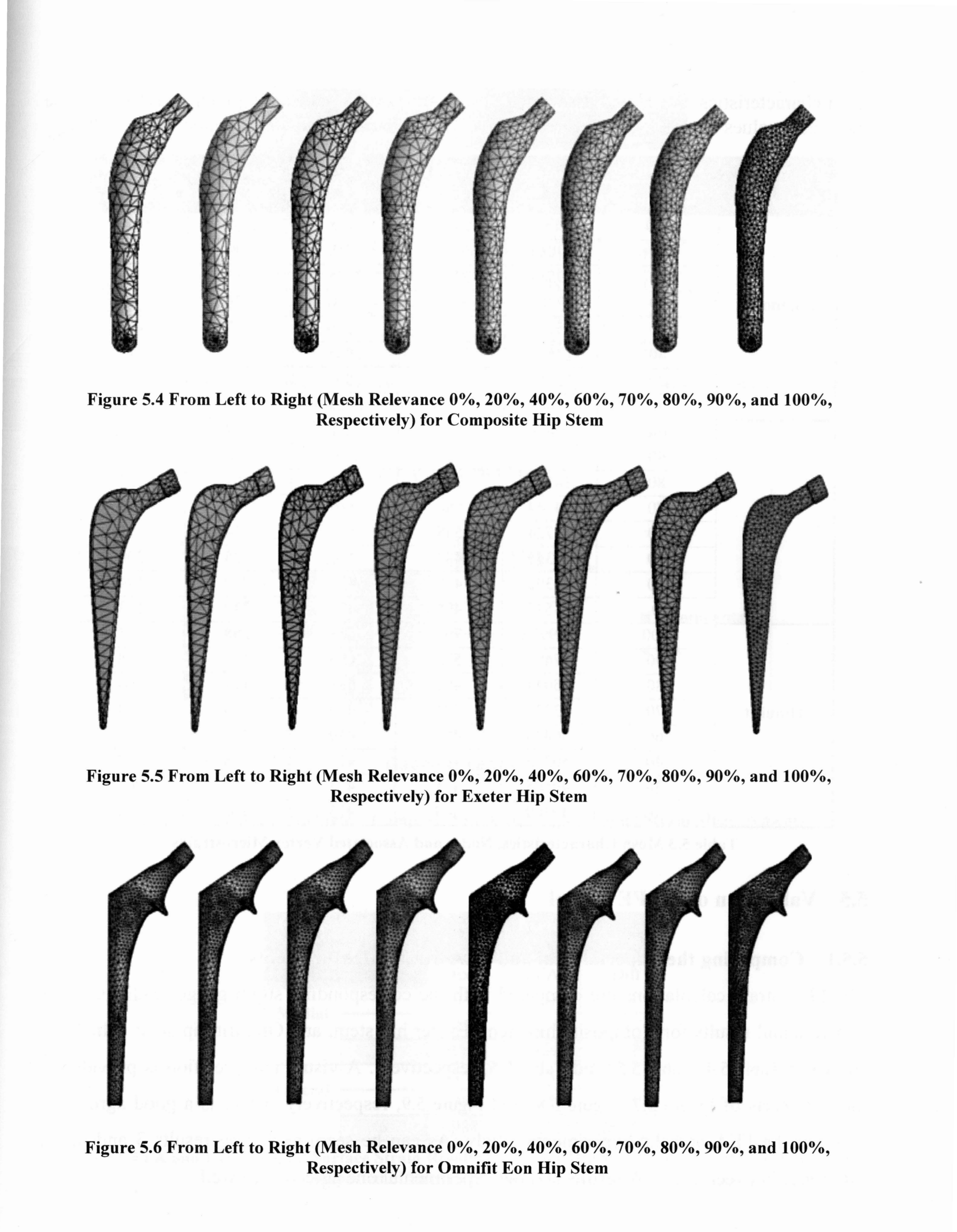


Mesh characteristics, nodes and associated vertex microstrain values are given in Table 5.3. The Microstrain values at vertex 1 and 2 are negative as they experienced compression.

\begin{tabular}{|c|c|c|c|c|c|c|}
\hline & $\begin{array}{c}\text { Mesh } \\
\text { Relevanc }\end{array}$ & Nodes & Vertex 1 & Vertex 2 & Vertex 4 & Vertex 5 \\
\hline \multirow{8}{*}{ Composite } & 100 & 171531 & 2164 & 4178 & 1070 & 1017 \\
\hline & 90 & 23085 & 3168 & 3768 & 309 & 455 \\
\hline & 80 & 19517 & 3171 & 3725 & 283 & 474 \\
\hline & 70 & 17300 & 3082 & 3700 & 258 & 442 \\
\hline & 60 & 15751 & 2957 & 3660 & 163 & 454 \\
\hline & 40 & 13690 & 3656 & 3953 & 536 & 585 \\
\hline & 20 & 12882 & 3439 & 3803 & 463 & 518 \\
\hline & 0 & 12859 & 3274 & 3721 & 298 & 435 \\
\hline \multirow{8}{*}{ Exeter } & 100 & 314658 & 847 & 624 & 418 & 295 \\
\hline & 90 & 43859 & 620 & 536 & 296 & 234 \\
\hline & 80 & 38187 & 591 & 520 & 262 & 223 \\
\hline & 70 & 34144 & 560 & 516 & 275 & 219 \\
\hline & 60 & 31724 & 548 & 510 & 254 & 215 \\
\hline & 40 & 29351 & 483 & 490 & 225 & 200 \\
\hline & 20 & 26392 & 478 & 476 & 220 & 194 \\
\hline & 0 & 24547 & 496 & 475 & 219 & 193 \\
\hline \multirow{8}{*}{ Omnifit } & 100 & 149972 & 792 & 528 & 298 & 235 \\
\hline & 90 & 57497 & 522 & 486 & 124 & 208 \\
\hline & 80 & 55044 & 492 & 481 & 111 & 204 \\
\hline & 70 & 53331 & 481 & 479 & 109 & 204 \\
\hline & 60 & 50428 & 483 & 479 & 111 & 204 \\
\hline & 40 & 50235 & 461 & 475 & 108 & 202 \\
\hline & 20 & 49505 & 451 & 473 & 102 & 201 \\
\hline & 0 & 49369 & 449 & 475 & 102 & 201 \\
\hline
\end{tabular}

Table 5.3 Mesh Characteristics, Nodes and Associated Vertex Microstrains

\subsection{Validation of the FE Model}

\subsubsection{Comparing the Experimental and FEA Strain Measurements}

The FEA strain calculations are compared with the corresponding strain gauge readings of the experimental results for Composite hip stem, Exeter hip stem, and Omnifit hip stem, which are shown in Table 5.4, Table 5.5, and Table 5.6, respectively. A visual interpretation is provided in the bar charts of Figure 5.7, Figure 5.8, and Figure 5.9, respectively. There is a good agreement between the FEA and the experimental study. As can be seen, excluding results 3 and 6 , the difference between the FEA results and the experimental one agreed very well. 


\begin{tabular}{c|cc|c|c|}
\hline $\begin{array}{c}\text { Gauge } \\
\text { Side }\end{array}$ & $\begin{array}{c}\text { Gauge } \\
\text { Location }\end{array}$ & \multicolumn{3}{c|}{ Composite } \\
\cline { 3 - 5 } & & Exp & FEA & $\%$ Diff \\
\hline \multirow{3}{*}{ Medial } & 1 & -2352 & -2164 & 8.7 \\
\cline { 2 - 5 } & 2 & -4178 & -4285 & 2.5 \\
\cline { 2 - 5 } & 3 & -4157 & -2031 & 104.7 \\
\hline \multirow{3}{*}{ Lateral } & 4 & 1070 & 1081 & 1.0 \\
\cline { 2 - 5 } & 5 & 1017 & 862 & 18.0 \\
\cline { 2 - 5 } & 6 & 1274 & 158 & 706.3 \\
\hline
\end{tabular}

Table 5.4 FEA and Experimental Surface Strain Results for Composite Hip Stem (Location of Gauge Readings Suspected of Error are Shaded in Grey)

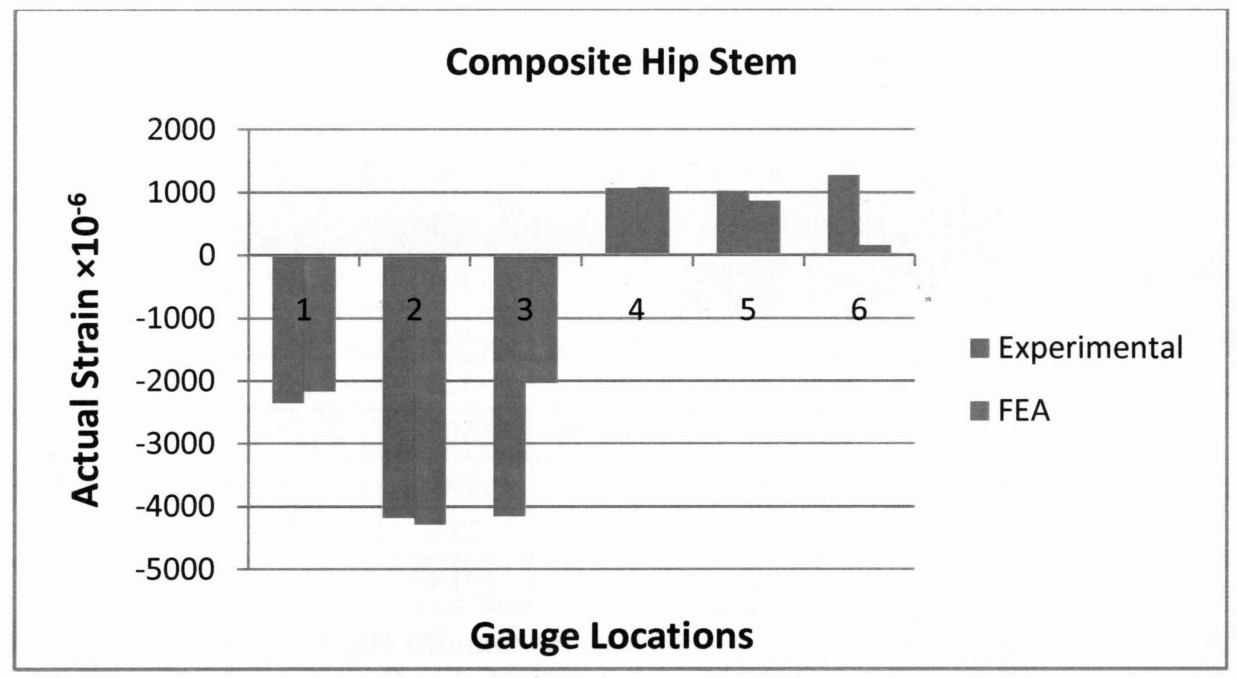

Figure 5.7 Composite Hip Stem - Comparing FEA and Experimental Strain Measurements

\begin{tabular}{c|cc|c|c|}
\hline $\begin{array}{c}\text { Gauge } \\
\text { Side }\end{array}$ & $\begin{array}{c}\text { Gauge } \\
\text { Location }\end{array}$ & \multicolumn{3}{c|}{ Exeter } \\
\cline { 3 - 5 } & & Exp & FEA & $\%$ Diff \\
\hline \multirow{3}{*}{ Medial } & 1 & -713 & -847 & 15.8 \\
\cline { 2 - 5 } & 2 & -608 & -624 & 2.6 \\
\cline { 2 - 5 } & 3 & -1103 & -509 & 116.7 \\
\hline \multirow{2}{*}{ Lateral } & 4 & 452 & 418 & 8.1 \\
\cline { 2 - 5 } & 5 & 366 & 295 & 24.1 \\
\cline { 2 - 5 } & 6 & 988 & 251 & 293.6 \\
\hline
\end{tabular}

Table 5.5 FEA and Experimental Surface Strain Results for Exeter Hip Stem (Location of Gauge Readings Suspected of Error are Shaded in Grey) 


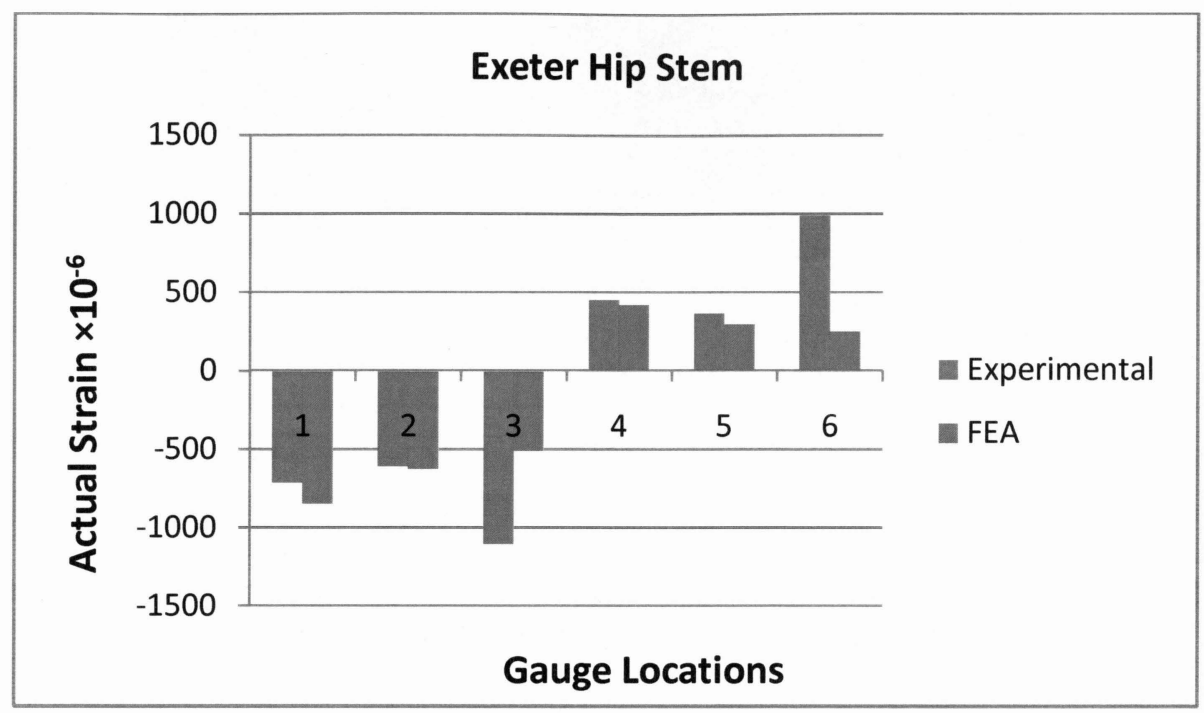

Figure 5.8 Composite Hip Stem - Comparing FEA and Experimental Strain Measurements

\begin{tabular}{c|c|c|c|c|}
\hline $\begin{array}{c}\text { Gauge } \\
\text { Side }\end{array}$ & $\begin{array}{c}\text { Gauge } \\
\text { Location }\end{array}$ & \multicolumn{3}{c|}{ Omnifit Eon } \\
\cline { 3 - 5 } & & Exp & FEA & \%Diff \\
\hline \multirow{3}{*}{ Medial } & 1 & -704 & -792 & 11.1 \\
\cline { 2 - 5 } & 2 & -643 & -528 & 21.8 \\
\cline { 2 - 5 } & 3 & -1660 & -503 & 230.0 \\
\hline \multirow{2}{*}{ Lateral } & 4 & 357 & 298 & 19.8 \\
\cline { 2 - 5 } & 5 & 222 & 235 & 5.5 \\
\cline { 2 - 5 } & 6 & 727 & 213 & 241.3 \\
\hline
\end{tabular}

Table 5.6 FEA and Experimental Surface Strain Results for Omnifit Hip Stem (Location of Gauge Readings Suspected of Error are Shaded in Grey)

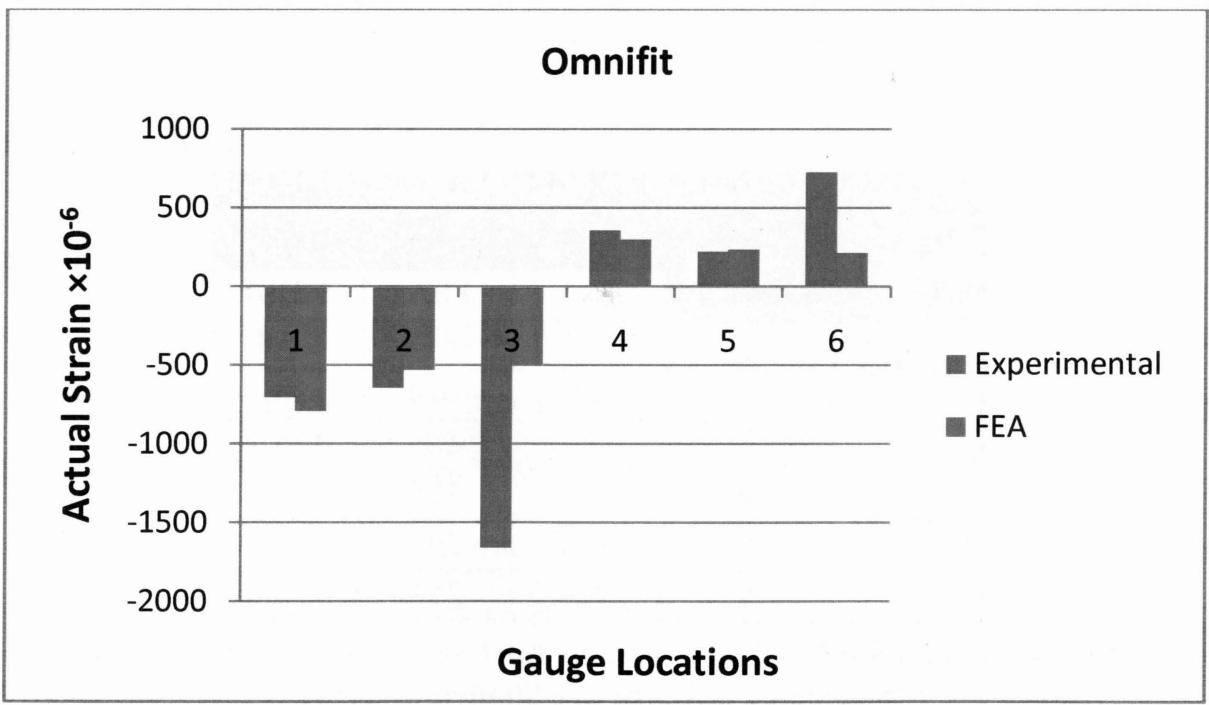

Figure 5.9 Composite Hip Stem - Comparing FEA and Experimental Strain Measurements 
Four of the six gauge readings from the experimental results agree well with the FEA calculated results that are within $1-25 \%$ for the strain gauges at locations $1,2,4$, and 5 on all three hip implants. The readings for strain gauges at locations 3 and 6 on all three hip implants have unusually high disagreement between the FEA and the experimental results and are shown in grey colour.

The results can be explained for the four gauge locations 1, 2, 4, and 5 which have up to $25 \%$ difference in FEA calculation as follows:

1. The strain gauges used in the experiment are relatively large enough that they only sense an average strain over the area they cover as compared to selecting the same point on the FE model provides the precise and accurate calculated nodal strain value at the particular location.

2. A careful attempt was made to ensure that all gauges would be oriented along the vertical axis. The strain gauge orientation on the surface plane, however carefully applied, may still slightly be off-axis with respect to the vertical and therefore differ from the FEA calculated measurements.

3. There is always some curvature on the surface covered by any of the strain gauges. This introduces the possibility of gauge reading error increasing with the degree of surface curvature.

4. In the experimental study, the femoral heads (balls) of all implants were covered with a tape to ensure that there is no slipping between the Acetabular Cup Indenter (Pap-Block) and the femoral head. On the other hand, in the FEA model there was a contact command for no separation between femoral head and Pap-Block, that can bring a significant change or difference in the results.

Except for locations 3 and 6, all FEA results can be considered to represent the experimental study. At the level of microstrains, a similarity within $25 \%$ is a convincing validation of the FEA model [106-108].

By dividing microstrain values of corresponding FE locations 1 to 6 , the average microstrain ratios; for composite/Exeter is 3.26; for composite/Omnifit is 3.82; and for Exeter/Omnifit is 
1.18, showing that the composite implant was far less stiff than the standard metallic hip implants.

\subsection{Results}

\subsubsection{FE Results}

The FE microstrain distribution maps at $3000 \mathrm{~N}$ are shown for all three hip implants in Figure 5.10. Microstrain distributions obtained from FE analysis on the hip prostheses are shown in Table 5.7. By dividing the microstrain values of corresponding FE locations 1 to 6 , the average microstrain ratios are: composite/Exeter $=3.26$; composite $/$ Omnifit $=3.82$; and Exeter $/$ Omnifit $=$ 1.18, which shows that the composite hip stem is far less stiff than the standard metallic hip stems given in appendix, Table 12, Table 13, and Table 14.

\begin{tabular}{|c|c|c|c|c|c|c|c|c|c|c|}
\hline Gauge & Gauge & \multicolumn{3}{|c|}{ Composite } & \multicolumn{3}{c|}{ Exeter } & \multicolumn{3}{c|}{ Omnifit } \\
\cline { 2 - 11 } Side & Location & EXP & FEA & \%Diff & EXP & FEA & \%Diff & EXP & FEA & \%Diff \\
\hline \multirow{3}{*}{ Medial } & $\mathbf{1}$ & -2352 & -2164 & 8.7 & -713 & -847 & 15.8 & -704 & -792 & 11.1 \\
\cline { 2 - 11 } & $\mathbf{2}$ & -4178 & -4285 & 2.5 & -608 & -624 & 2.6 & -643 & -528 & 21.8 \\
\cline { 2 - 11 } & $\mathbf{3}$ & -4157 & -2031 & 104.7 & -1103 & -509 & 116.7 & -1660 & -503 & 230.0 \\
\hline \multirow{3}{*}{ Lateral } & $\mathbf{4}$ & 1070 & 1081 & 1.0 & 452 & 418 & 8.1 & 357 & 298 & 19.8 \\
\cline { 2 - 11 } & $\mathbf{5}$ & 1017 & 862 & 17.9 & 366 & 295 & 24.1 & 222 & 235 & 5.5 \\
\cline { 2 - 11 } & $\mathbf{6}$ & 1274 & 158 & 706.3 & 988 & 251 & 293.6 & 727 & 213 & 241.3 \\
\hline
\end{tabular}

Table 5.7 Microstrain Distribution Obtained From FE Analysis on the Hip Prostheses
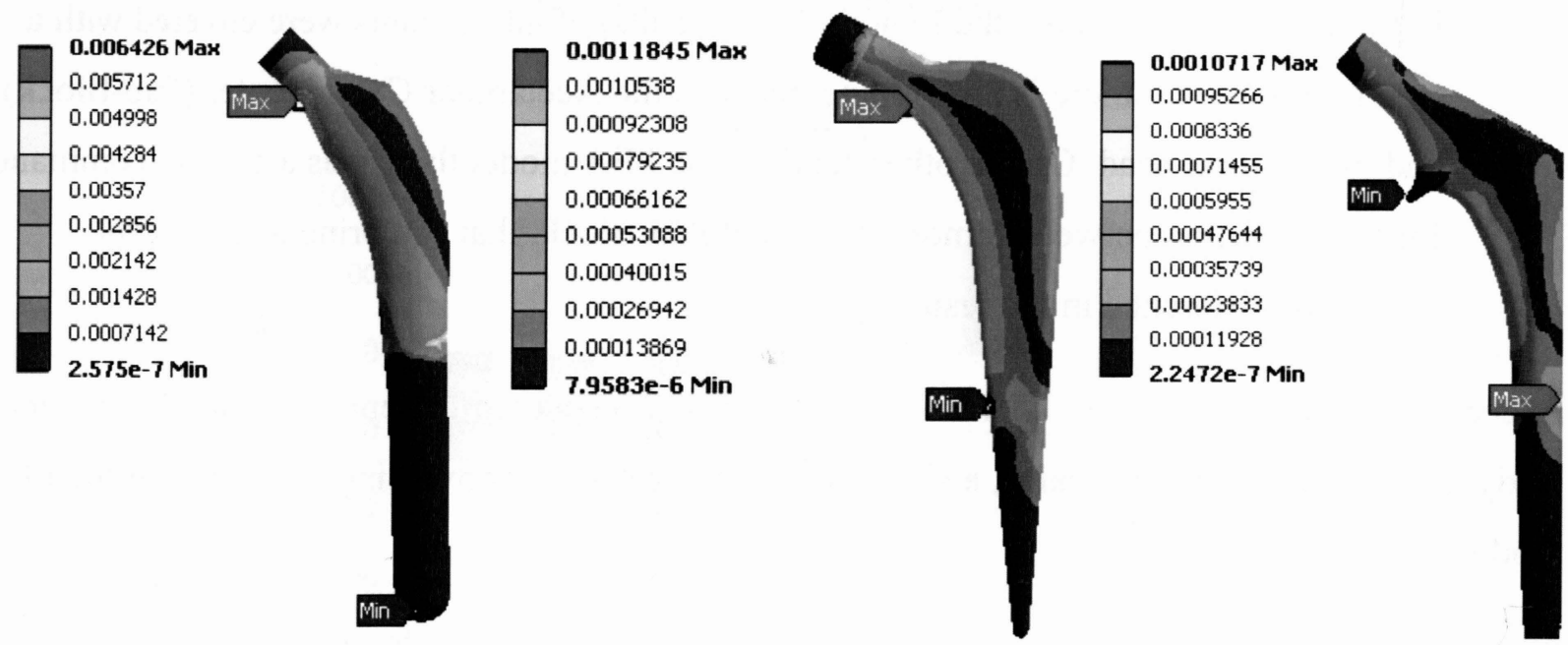

Figure 5.10 Equivalent (Von-Mises) Elastic Microstrains for Composite, Exeter, and Omnifit Hip Stems, Respectively (From Left to Right) 
The FE stress distributions at $3000 \mathrm{~N}$ of load are shown for all three hip stems in Figure 5.11. The metallic hip stems, i.e., Exeter and Omnifit, experienced peak stresses which exceeded that of the composite implant by more than $250 \%$ and $75 \%$, respectively. Peak implant stresses were situated in the neck region for the composite and the Exeter hip stems, whereas, the Omnifit showed peak stress in the lateral side near the fixation block. Implant stresses, excluding the peaks, ranged approximately from 0-55 $\mathrm{MPa}$ in the composite, 0-165 $\mathrm{MPa}$ in the Exeter, and 0$80 \mathrm{MPa}$ in the Omnifit. In the same way, the metallic hip stems, i.e., Exeter and Omnifit, yielded stress ranges which exceeded the composite hip stem by more than $200 \%$ and $45 \%$, respectively.
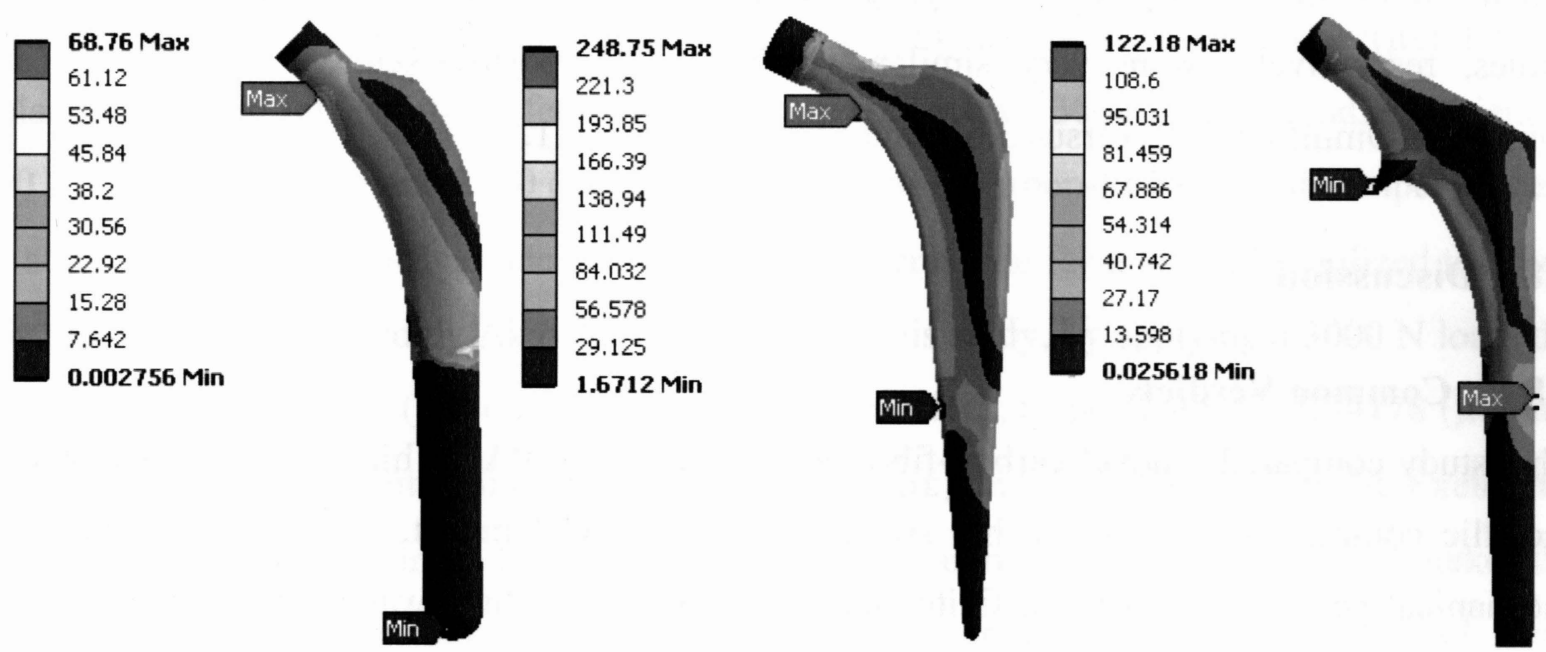

Figure 5.11 Equivalent (Von-Mises) Elastic Stresses for Composite, Exeter, and Omnifit Hip Stems, Respectively (From Left to Right)

\subsubsection{Experimental Results}

Axial stiffnesses for the hip implants were $1982 \mathrm{~N} / \mathrm{mm}, 2460 \mathrm{~N} / \mathrm{mm}$, and $2543 \mathrm{~N} / \mathrm{mm}$ for the composite, the Exeter, and the Omnifit, respectively. Microstrains distributions obtained from experiments on the hip stems are shown in the Table 5.7. By dividing the microstrain values of corresponding gauges 1 to 6 , the average microstrain ratios are: composite/Exeter $=3.40$; composite/Omnifit $=3.61$; and Exeter/Omnifit $=1.15$ given in the appendix Table 15, Table 16, and Table 17; which shows the similar relative trends to corresponding ratios of the inverse of the axial stiffness which are: Exeter/composite $=1.24 ;$ Omnifit $/$ composite $=1.28$; and Omnifit/Exeter $=1.03$. The linearity of the force deflection data shows that the specimens remained within the linear elastic region, incurring no permanent damage during mechanical stiffness tests, i.e., $\mathrm{R}^{2}=0.99$ for the composite, the Exeter, and the Omnifit. 


\subsection{Validating the FE Model Using Experimental Results}

The percentage difference between the FE model and the experimental strain at corresponding locations 1 to 6 were calculated as $\%$ difference $=($ Experimental Strain - FE Strain $) /$ FE Strain $\times 100$, which are shown in Table 5.7Table 5.7. The four most proximal gauge readings which are gauges 1, 2, 4, and 5, agreed quite well with the FEA calculated results, yielding aggregate average of $7.5 \%$, $11.5 \%$, and $14.6 \%$ for the composite, the Exeter, and the Omnifit, respectively, given in the appendix, Table 18, Table 19, and Table 20. The two most distal gauges which are gauges 3 and 6, had unusually high disagreement with FE analysis shown in the Table 5.7. Moreover, the calculated FE microstrain ratios for gauge locations 1 to 6 versus to the experimental gauge values, respectively, were very similar which are: composite/Exeter $=3.26$ versus 3.40 ; composite/Omnifit $=3.82$ versus 3.61 ; and Exeter $/$ Omnifit $=1.18$ versus 1.15 .

\subsection{Discussion}

\subsubsection{Common Verdicts}

This study compared a novel carbon-fibre polyamide12 (CF/PA12) hip stem with two standard metallic commercially available hip stems i.e. Exeter and Omnifit, and tried to predict their mechanical performance using a finite element (FE) model which was validated by a series of experiments. Particularly, the hip prostheses were mechanically assessed for stiffness, strain, and stress. Results disclose that the composite hip stem was less mechanically stiff as compared to the metallic hip stems. This is the first experimental report appearing in the literature which has evaluated the surface strain characteristics of this particular composite material for use as a hip stem in comparison to standard hip stems. In the experimental study, the concrete block of the femoral stem setup was held fixed to the Instron 8874 base plate using a vice which, in reality, applied rigid constraints to only small areas of two faces, whereas, in the FE model, a fixed support constraint was applied on all side faces of the concrete block. Therefore, the FE model included more constraints on the implant system than in the experimental setup.

\subsubsection{Composite Versus Standard Hip Implants}

From Table 12 and Table 13, it is evident that the Composite stem was between 3.26 and 3.82 times less mechanically stiff than the Exeter and the Omnifit stems. Implants with higher stiffness might potentially create an implant-femur system with an increased stiffness that 
provides better mechanical stability in the immediate post-operative scenario, at the same time, it might also lead to femur stress shielding, bone resorption, and eventual implant loosening. On the other hand, implants with lower stiffness could result in an increased load transfer to the host femur, therefore stimulating bone on-growth around the implant, reducing surrounding bone resorption, and improving mechanical stability for longer period of time [80, 139-142].

\subsubsection{Comparison with the Previous Studies}

To date, no other studies have examined the mechanical characteristics of the carbon-fibre polyemide12 (CF/PA12) composite for use as a hip stem material and compared it to commercially available metallic hip stems. The experimental peak microstrains $(\mu \varepsilon)$ for hip implants cemented into synthetic femurs and compressed with a $3000 \mathrm{~N}$ axial load, experienced $4000(\mu \varepsilon)$ on medial side and $2500(\mu \varepsilon)$ on lateral side for a Carbon-PEEK based composite stem and about $1200(\mu \varepsilon)$ on medial side and $900(\mu \varepsilon)$ on lateral side for a clinically utilized titanium alloy prosthesis determined by Akay M. et al [143]. In this study, by applying a $3000 \mathrm{~N}$ load, the hip stems experienced the $(\mu \varepsilon)$ on the medial and lateral sides, respectively; 2352-4178 $(\mu \varepsilon)$ and 1017-1274 $(\mu \varepsilon)$ for the composite hip stem, 608-1103 $(\mu \varepsilon)$ and 366-988 $(\mu \varepsilon)$ for the Exeter hip stem, and 643-1660 $(\mu \varepsilon)$ for the Omnifit hip stem, which can be seen from Table 5.7. It makes the comparison difficult, even though, the implant geometry, orientation and material, load level, interface conditions, and configuration type have been examined carefully.

\subsubsection{Clinical Implications}

The composite hip implant has shown promising results that replicates the performance of the natural femur better than the standard metallic hip implants. A previous study on a hip stem made from a similar composite CF/PEEK (Carbon Fibre-Reinforced Polyether-Ether-Ketone) and a previous investigation on the same composite hip stem examined currently [23, 143, 144] showed that these materials can potentially reduce stress shielding by increasing the load transfer to the host femur in comparison to metallic hip implants. This also confirmed that the composite hip stems absorbed less stress than the metallic hip stems (Figure 5.11), as a result, more load would be expected to be transfered to the host femur, which can obviously reduce bone resorption and subsequent implant loosening. 


\subsection{Concluding Statement and Future Considerations}

This study compared the mechanical behaviour of a novel carbon-fibre polyamide12 (CF/PA12) composite hip stem with two standard metallic commercially available hip stems, namely, the Exeter and the Omnifit. Exclusively, its mechanical performance was assessed using a finite element (FE) model, which was validated by a series of experiments, using measures of axial stiffness, strain and stress distributions. The study disclosed that the composite hip stem was less mechanically stiff as compared to the standard metallic hip stems; therefore, it might potentially be more optimal in reducing bone stress shielding, bone resorption, and implant loosening. This is the first report that has experimentally assessed the microstrain distribution of this composite hip stem and compared it directly to standard available metallic hip stems.

The excellent work done by Campbell et al $[24,25,102,103]$, has given the inspiration for this innovation for the hip implant designed entirely out of $\mathrm{CF} / \mathrm{PA} 12$ that has outstanding biomimetic properties. These implants have only been tested in vitro and have not been introduced into mainstream orthopaedic care yet: clinical proof of this material's viability is still to be obtained. Even now, the fabrication of such an implant has to be seen and whether its practical use will result in improved implant performance and durability. It has come into view that the proposed composite implant offers perceptible benefits in transforming more stress to the adjacent bone tissue. The FE model used in this study has overconstrained the constraints on the implants when compared to the experimental setup. A possible result of this would be an undestimation of surface microstrain by the FE model, which is what the results have indicated. Since, the FE model consistently underestimates the results of experimental results, it follows that comparative studies conducted by the FE model still able to indicate any improvement in stress shielding.

Several observable limitations are recognised by this study. First, only static axial compression tests were done experimentally and modelled using FE analysis. The hip stems, once implanted in vivo, might potentially be exposed to dynamic forces during activities of daily living that exceed $3000 \mathrm{~N}[145,146]$. However, it is still expected that the relative performance of the composite compared to the Exeter and Omnifit hip prostheses would be similar in 'real life'. Second, the FE model assumed that the composite stem had linear isotropic properties which simplified the analysis considerably. However, nonlinearity and anisotropy can influence bulk mechanical behaviour of composite materials [147]. It was still determined that the comparison 
of FE analysis and the experimental measurements was a good approximation for composites undergoing axial compression. Third, the hip stems were not implanted into femurs experimentally and during FE analysis, so this should be the work of future studies. Nonetheless, this study does provide the first step in understanding the mechanical characteristics of the composite hip implant relative to standard metallic hip implants. Fourth, the FE model was successful in predicting proximal microstrain values at gauges numbered 1,2, 4, and 5 in Figure 3.8, but it failed to predict distal strains at gauges numbered 3 and 6 in Figure 3.8. This happened because the FE model in general has difficulty in simulating the displacement of elements that are adjacent to rigidity constrained bodies, such as the distal locations on the hip stems that are close to the rigidly mounted cement block [148]. Fifth, because of the different geometries and surface textures of the three hip stems, the experimental placement of strain gauges could not be done in exact correspondence between them. 


\section{Appendix}

From Table 5.3, the graphs are drawn between the microstrain values and their corresponding number of nodes for all three hip implants. The graphs show the converging behaviour in all hip stems.

\begin{tabular}{|cc|c|c|}
\hline \multirow{2}{*}{$\begin{array}{c}\text { For } \\
\text { Composite }\end{array}$} & $\begin{array}{c}\text { Mesh } \\
\text { Relevance }\end{array}$ & Nodes & Vertex 1 \\
\cline { 2 - 4 } Hip Stem & 90 & 23085 & 3168 \\
\cline { 2 - 4 } & 80 & 19517 & 3171 \\
\cline { 2 - 4 } & 70 & 17300 & 3082 \\
\cline { 2 - 4 } & 60 & 15751 & 2957 \\
\hline
\end{tabular}

Table 1 Mesh Relevance, Nodes, and Microstrain Values at Vertex 1 in the Composite Hip Stem

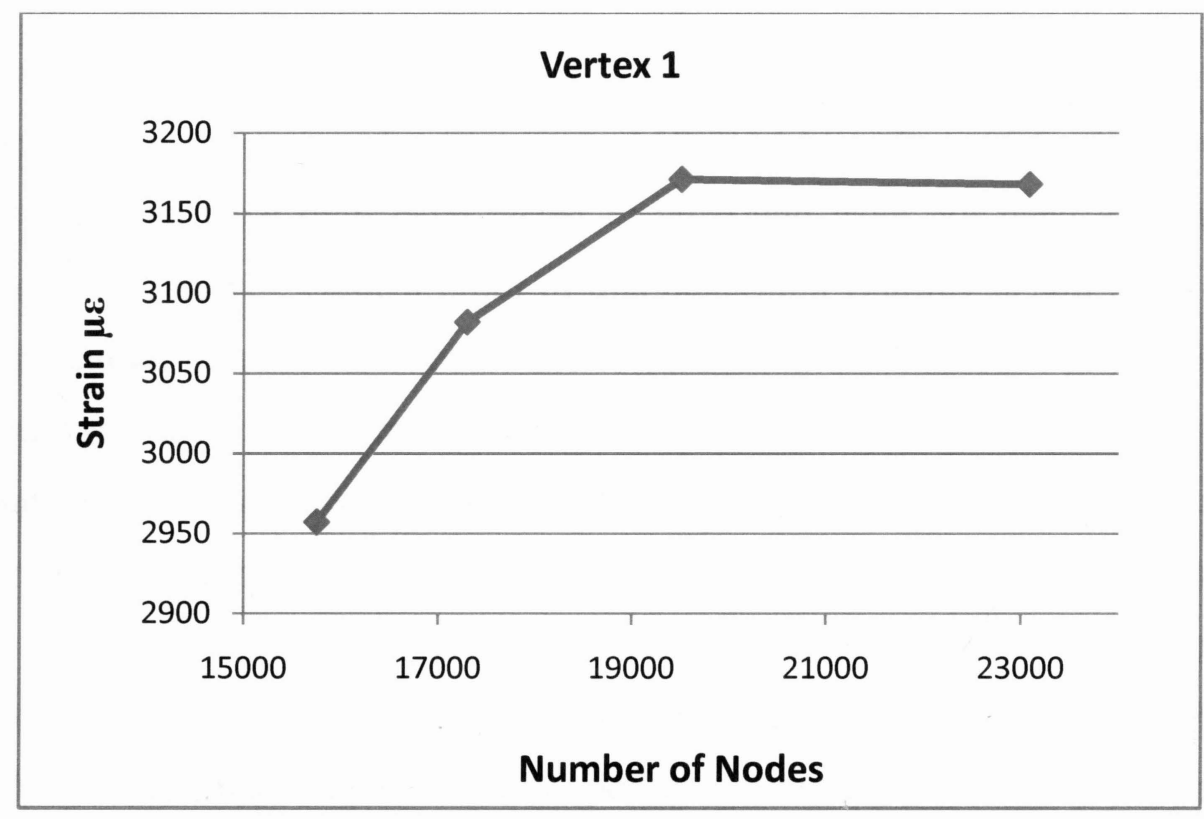

Figure 1 Change in Microstrain Values at Vertex 1 in the Composite Hip Stem

\begin{tabular}{cc|c|c|}
\multirow{2}{*}{$\begin{array}{c}\text { For } \\
\text { Composite }\end{array}$} & $\begin{array}{c}\text { Mesh } \\
\text { Relevance }\end{array}$ & Nodes & Vertex 2 \\
\cline { 2 - 4 } Hip Stem & 90 & 23085 & 3768 \\
\cline { 2 - 4 } & 80 & 19517 & 3725 \\
\cline { 2 - 4 } & 70 & 17300 & 3700 \\
\cline { 2 - 4 } & 60 & 15751 & 3660 \\
\hline
\end{tabular}

Table 2 Mesh Relevance, Nodes, and Microstrain Values at Vertex 2 in the Composite Hip Stem 


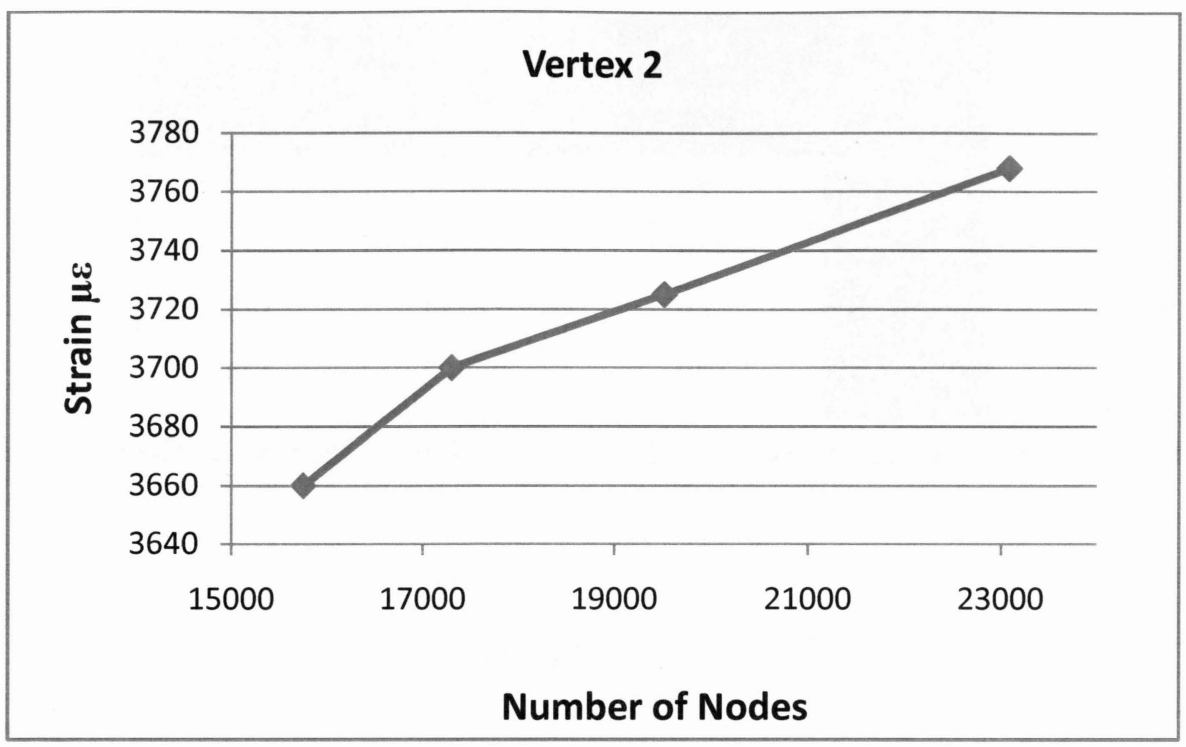

Figure 2 Change in Microstrain Values at Vertex 2 in the Composite Hip Stem

\begin{tabular}{|cc|c|c|}
\hline \multirow{2}{*}{$\begin{array}{c}\text { For } \\
\text { Composite }\end{array}$} & $\begin{array}{c}\text { Mesh } \\
\text { Relevance }\end{array}$ & Nodes & Vertex 4 \\
\cline { 2 - 4 } Hip Stem & 90 & 23085 & 309 \\
\cline { 2 - 4 } & 80 & 19517 & 283 \\
\cline { 2 - 4 } & 70 & 17300 & 258 \\
\cline { 2 - 4 } & 60 & 15751 & 163 \\
\hline
\end{tabular}

Table 3 Mesh Relevance, Nodes, and Microstrain Values at Vertex 4 in the Composite Hip Stem

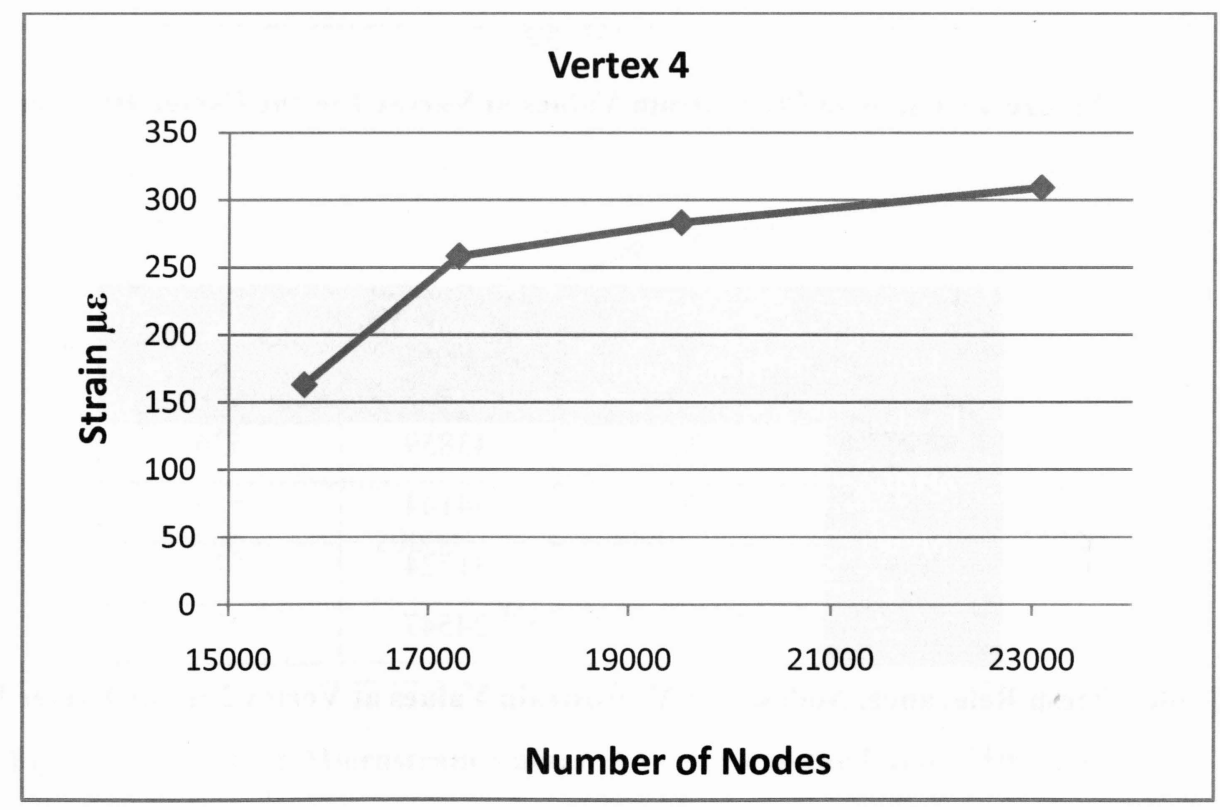

Figure 3 Change in Microstrain Values at Vertex 4 in the Composite Hip Stem 


\begin{tabular}{|c|c|c|c|}
\hline \multirow{2}{*}{$\begin{array}{c}\text { For } \\
\text { Exeter }\end{array}$} & $\begin{array}{c}\text { Mesh } \\
\text { Relevance }\end{array}$ & Nodes & Vertex 1 \\
\hline & 90 & 43859 & 620 \\
\hline नाр & 80 & 38187 & 591 \\
\hline Dtem & 60 & 31724 & 548 \\
\hline & 20 & 26392 & 478 \\
\hline
\end{tabular}

Table 4 Mesh Relevance, Nodes, and Microstrain Values at Vertex 1 in the Exeter Hip Stem

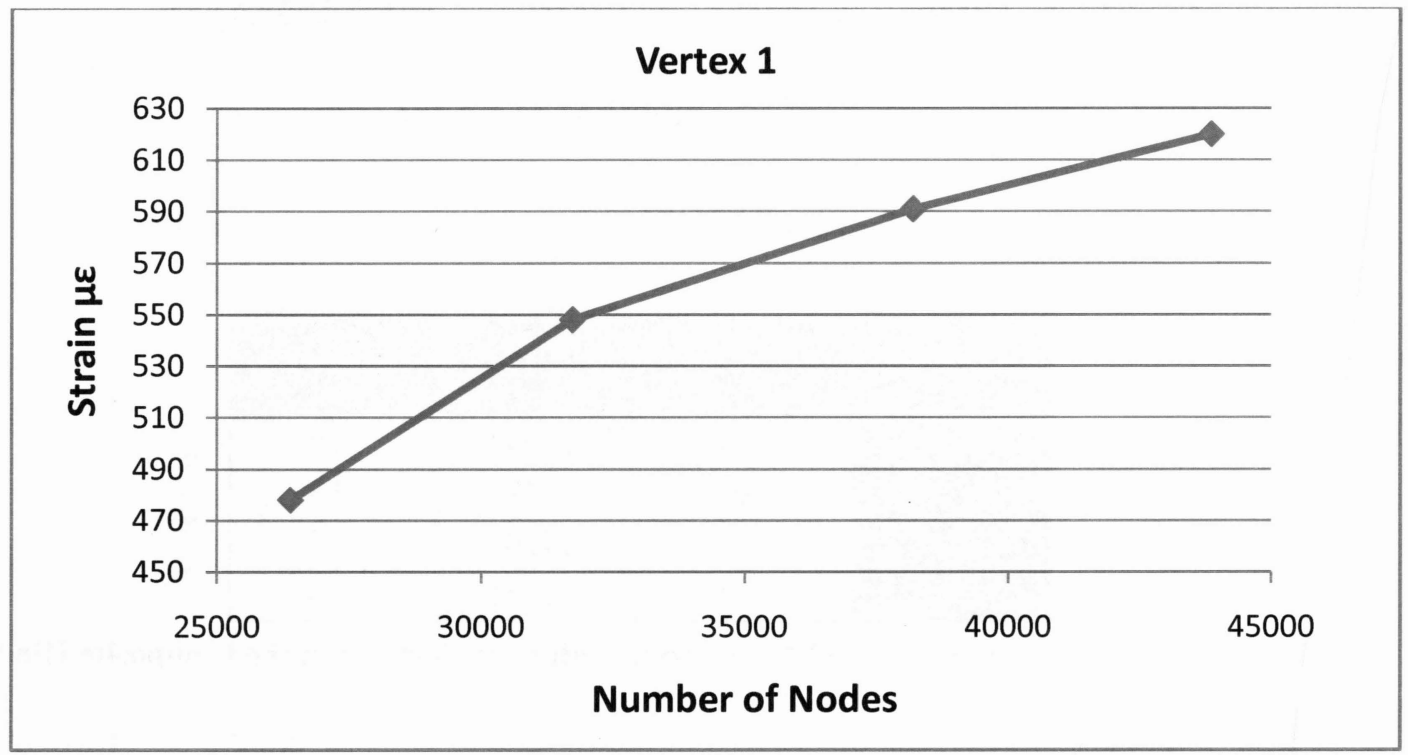

Figure 4 Change in Microstrain Values at Vertex 1 in the Exeter Hip Stem

\begin{tabular}{|cc|c|c|}
\hline \multirow{2}{*}{ For } & \multicolumn{1}{c}{$\begin{array}{c}\text { Mesh } \\
\text { Relevance }\end{array}$} & Nodes & Vertex 2 \\
Exeter & 90 & 43859 & 536 \\
\cline { 2 - 4 } Hip & 70 & 34144 & 516 \\
\cline { 2 - 4 } Stem & 60 & 31724 & 510 \\
\cline { 2 - 4 } & 0 & 24547 & 475 \\
\hline
\end{tabular}

Table 5 Mesh Relevance, Nodes, and Microstrain Values at Vertex 2 in the Exeter Hip Stem 


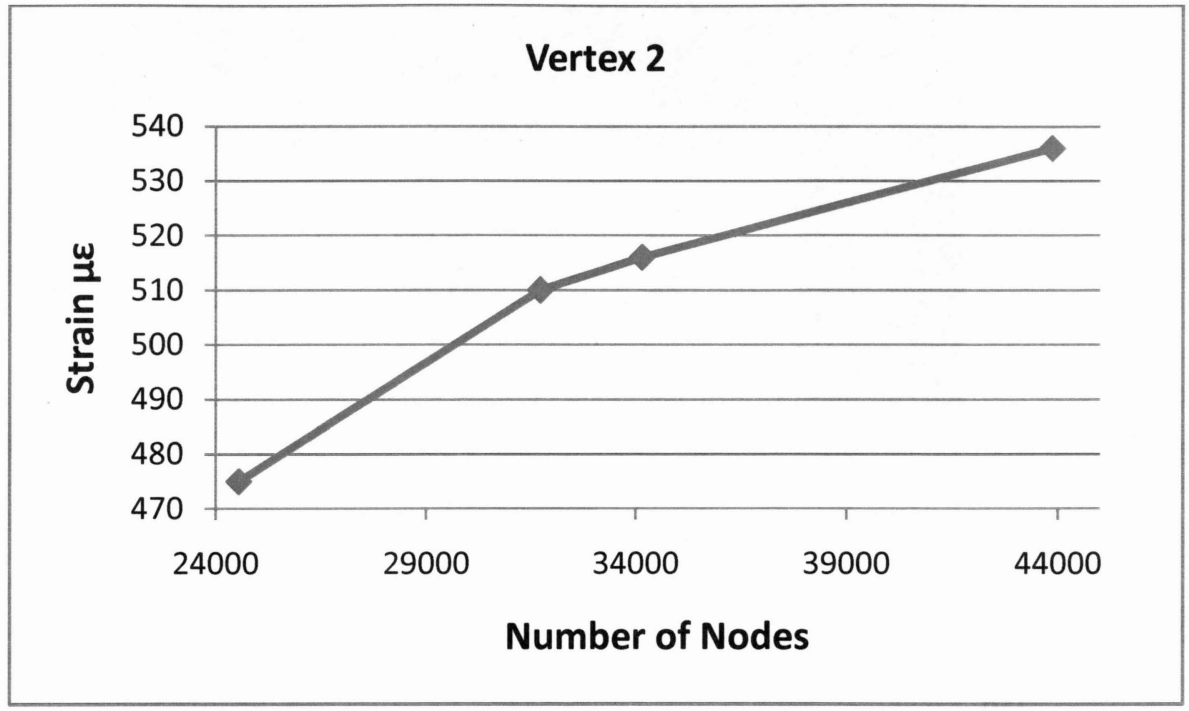

Figure 5 Change in Microstrain Values at Vertex 2 in the Exeter Hip Stem

\begin{tabular}{|cc|c|c|}
\hline $\begin{array}{c}\text { For } \\
\text { Exeter }\end{array}$ & $\begin{array}{c}\text { Mesh } \\
\text { Relevance }\end{array}$ & Nodes & Vertex 4 \\
\cline { 2 - 4 } Hip & 90 & 43859 & 296 \\
\cline { 2 - 4 } Stem & 70 & 34144 & 275 \\
\cline { 2 - 4 } & 60 & 31724 & 254 \\
\cline { 2 - 4 } & 0 & 24547 & 219 \\
\hline
\end{tabular}

Table 6 Mesh Relevance, Nodes, and Microstrain Values at Vertex 4 in the Exeter Hip Stem

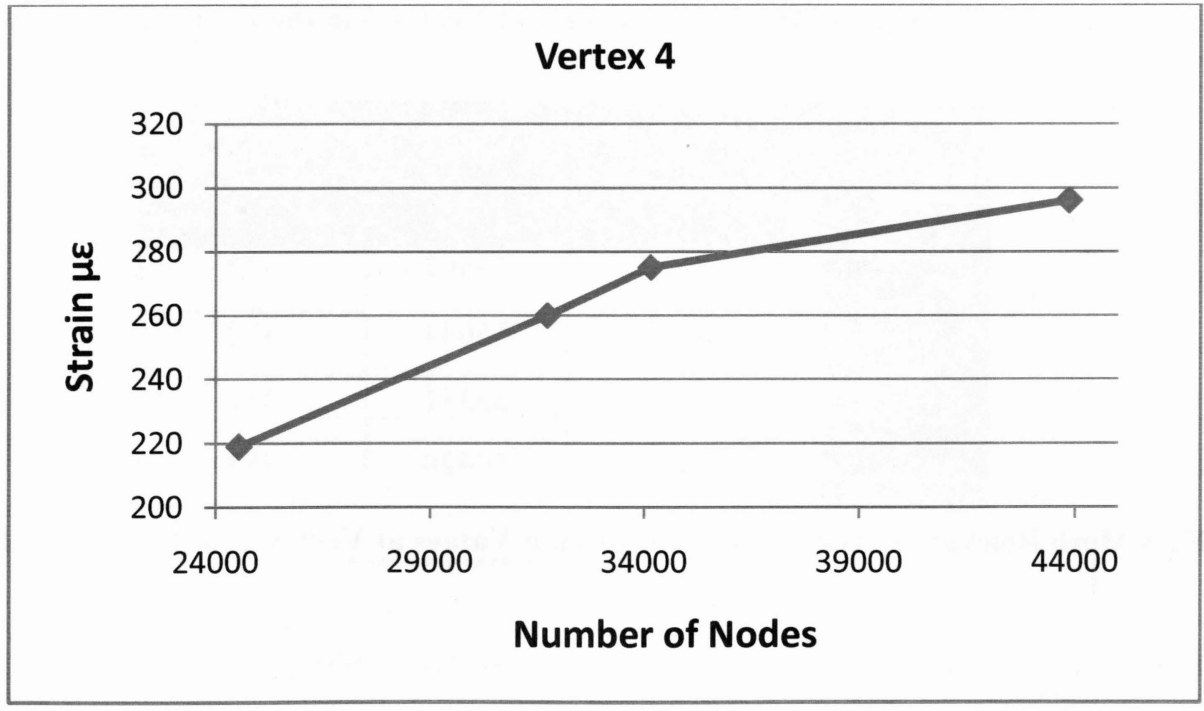

Figure 6 Change in Microstrain Values at Vertex 4 in the Exeter Hip Stem 


\begin{tabular}{|c|c|c|c|}
\hline \multirow{3}{*}{$\begin{array}{c}\text { For } \\
\text { Exeter }\end{array}$} & $\begin{array}{c}\text { Mesh } \\
\text { Relevance }\end{array}$ & Nodes & Vertex 5 \\
\cline { 2 - 4 } Hip & 90 & 43859 & 234 \\
\cline { 2 - 4 } Stem & 70 & 34144 & 219 \\
\cline { 2 - 4 } & 60 & 31724 & 215 \\
\cline { 2 - 4 } & 0 & 24547 & 193 \\
\hline
\end{tabular}

Table 7 Mesh Relevance, Nodes, and Microstrain Values at Vertex 5 in the Exeter Hip Stem

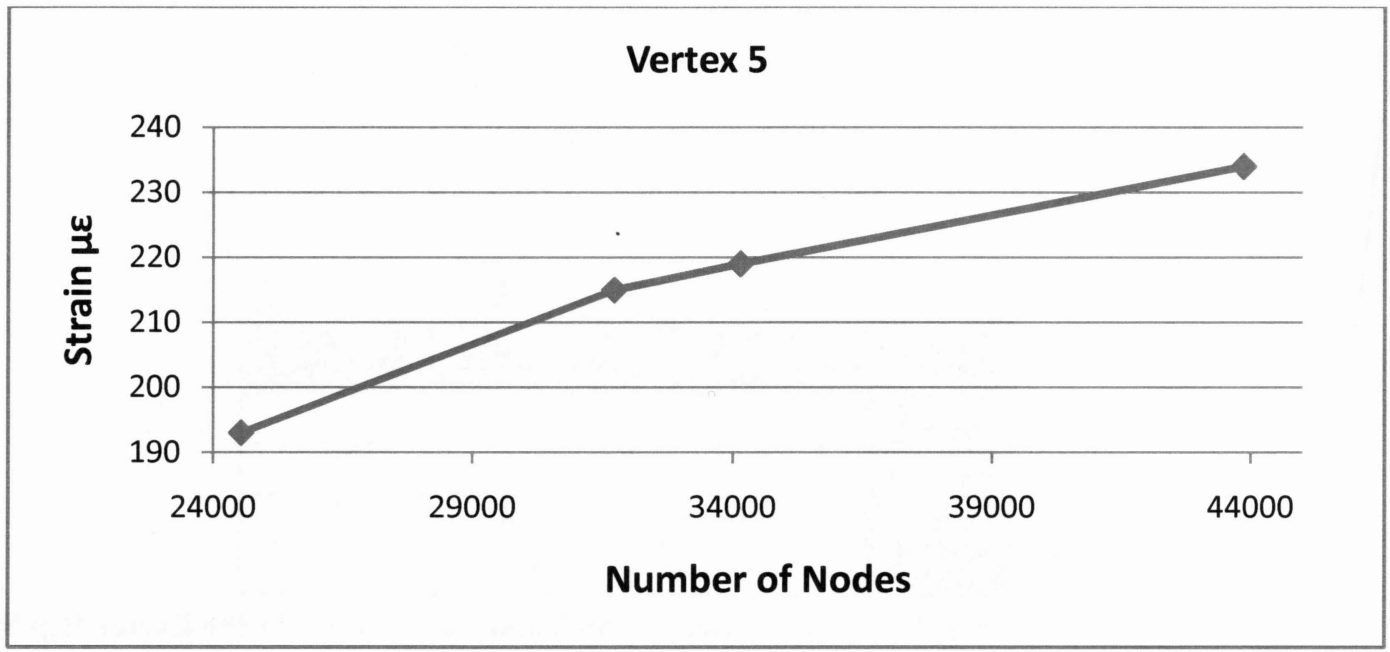

Figure 7 Change in Microstrain Values at Vertex 5 in the Exeter Hip Stem

\begin{tabular}{|cc|c|c|}
\hline \multirow{2}{*}{$\begin{array}{c}\text { Mesh } \\
\text { Ror }\end{array}$} & Nelevance & \multicolumn{2}{c|}{ Vertex 1 } \\
Omnift & 90 & 57497 & 522 \\
\hline Hip & 80 & 55044 & 492 \\
\cline { 2 - 4 } Stem & 70 & 53331 & 481 \\
\cline { 2 - 4 } & 60 & 50428 & 483 \\
\hline
\end{tabular}

Table 8 Mesh Relevance, Nodes, and Microstrain Values at Vertex 1 in the Omnifit Hip Stem 


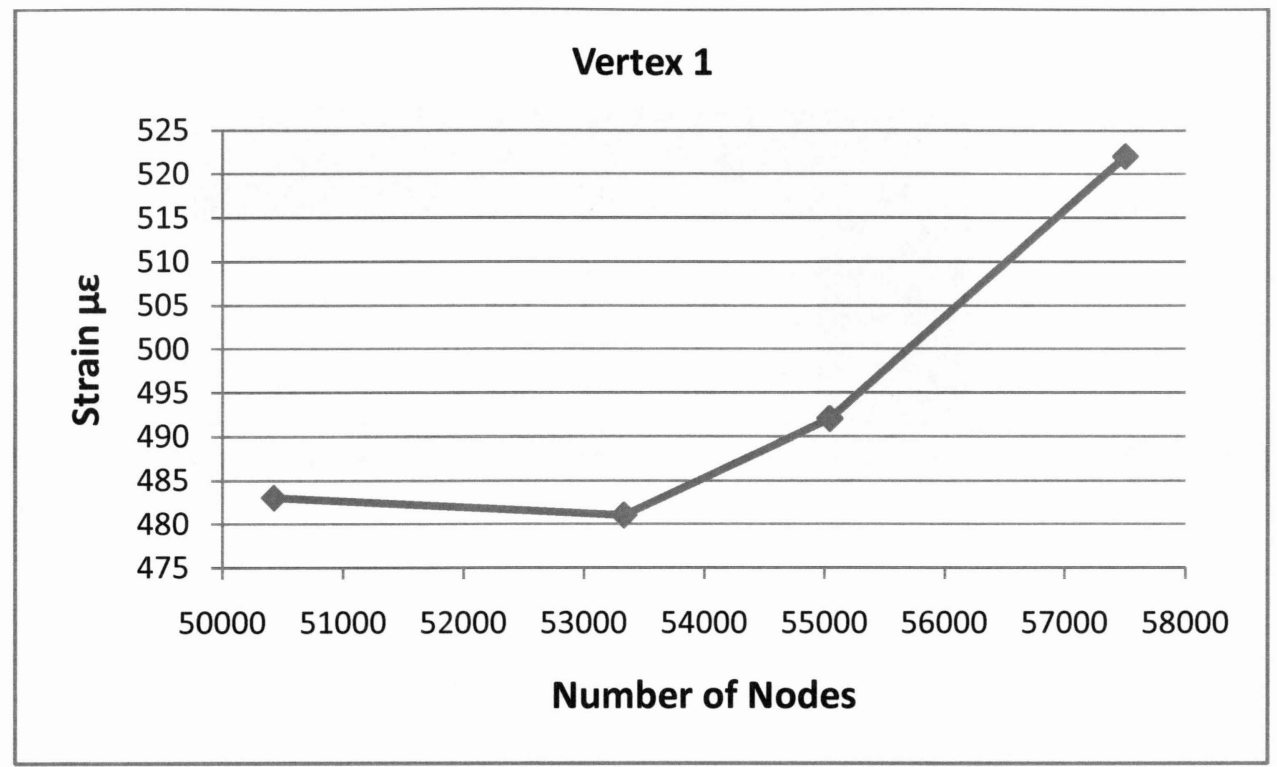

Figure 8 Change in Microstrain Values at Vertex 1 in the Omnifit Hip Stem

\begin{tabular}{cccc|c|}
$\begin{array}{c}\text { For } \\
\text { Omnift }\end{array}$ & $\begin{array}{c}\text { Mesh } \\
\text { Relevance }\end{array}$ & Nodes & Vertex 2 \\
\cline { 2 - 4 } Hip & 90 & 57497 & 486 \\
\cline { 2 - 4 } Stem & 80 & 55044 & 481 \\
\cline { 2 - 4 } & 70 & 53331 & 479 \\
\cline { 2 - 4 } & 60 & 50428 & 479 \\
\hline
\end{tabular}

Table 9 Mesh Relevance, Nodes, and Microstrain Values at Vertex 2 in the Omnifit Hip Stem

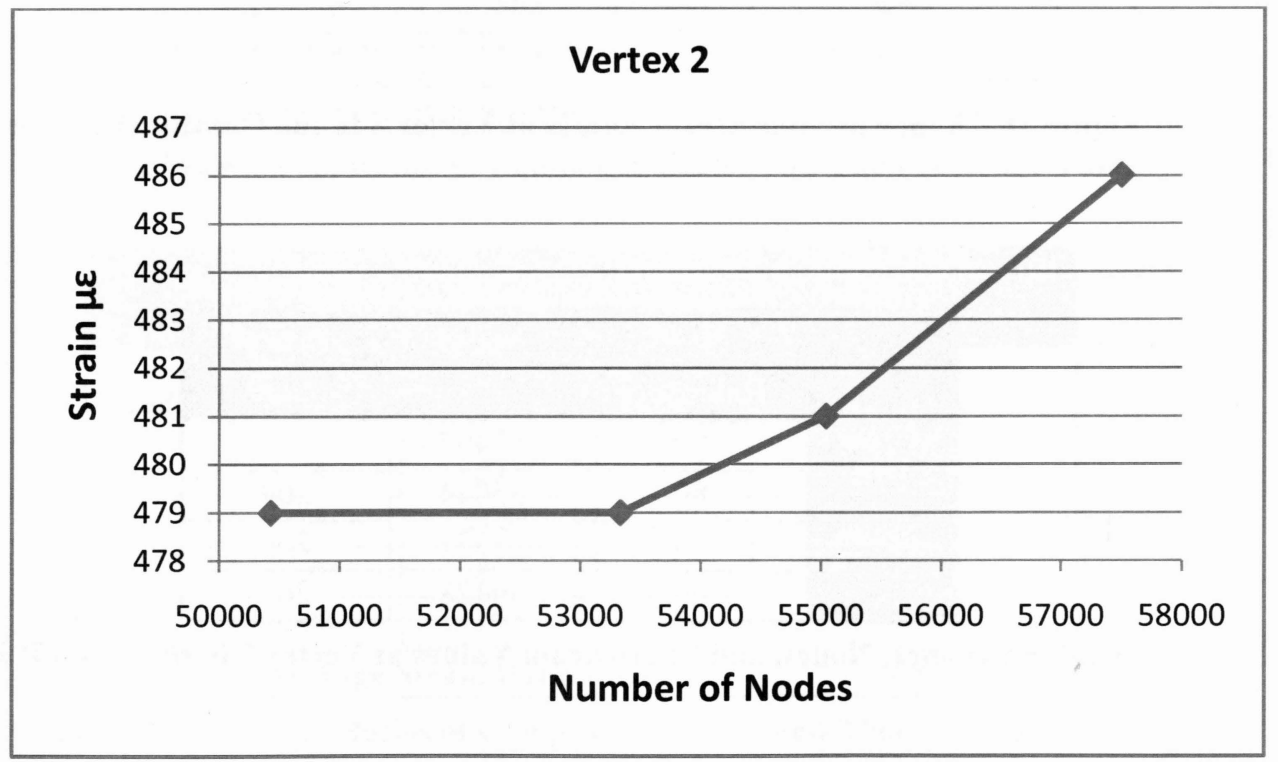

Figure 9 Change in Microstrain Values at Vertex 2 in the Omnifit Hip Stem 


\begin{tabular}{|cc|c|c|}
\hline $\begin{array}{c}\text { For } \\
\text { Omnift }\end{array}$ & $\begin{array}{c}\text { Mesh } \\
\text { Relevance }\end{array}$ & Nodes & Vertex 4 \\
\cline { 2 - 4 } Hip & 90 & 57497 & 124 \\
\cline { 2 - 4 } Stem & 80 & 55044 & 111 \\
\cline { 2 - 4 } & 70 & 53331 & 109 \\
\cline { 2 - 4 } & 60 & 50428 & 111 \\
\hline
\end{tabular}

Table 10 Mesh Relevance, Nodes, and Microstrain Values at Vertex 4 in the Omnifit Hip Stem

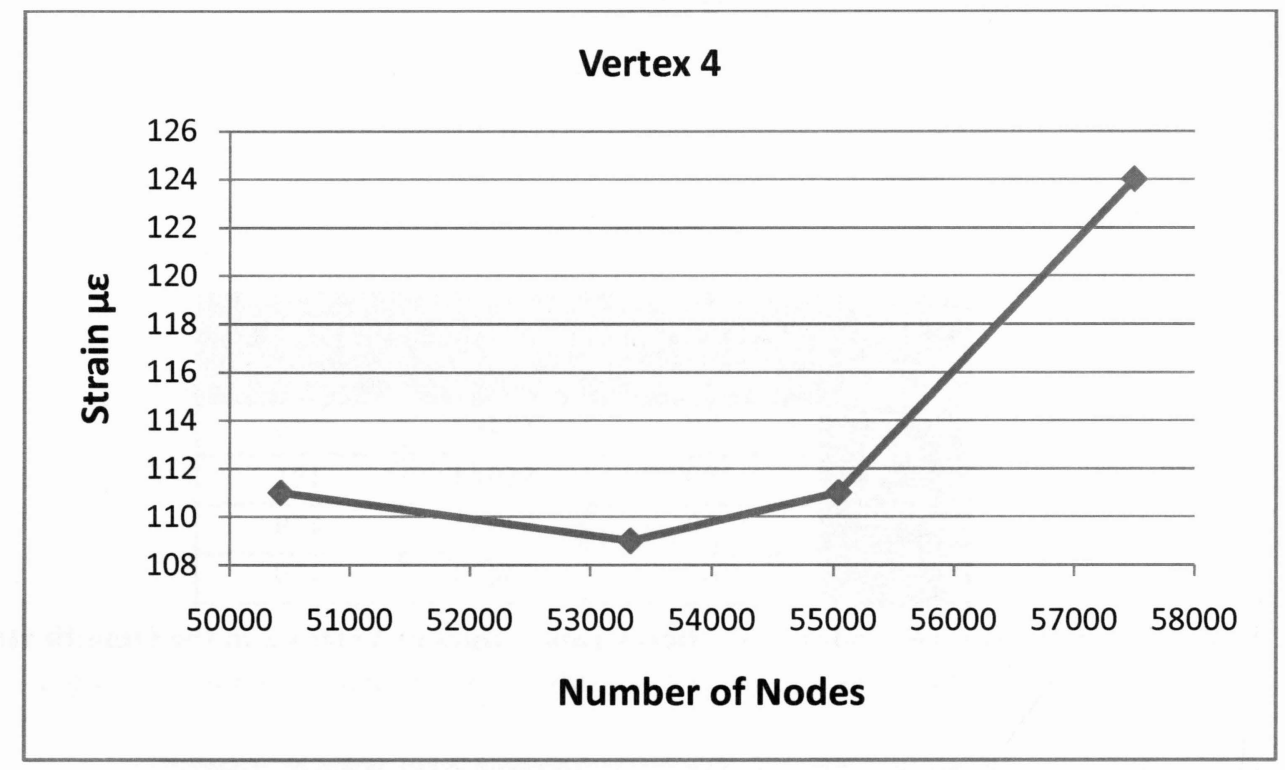

Figure 10 Change in Microstrain Values at Vertex 4 in the Omnifit Hip Stem

\begin{tabular}{cc|c|c|}
\hline $\begin{array}{c}\text { For } \\
\text { Omnift }\end{array}$ & $\begin{array}{c}\text { Mesh } \\
\text { Relevance }\end{array}$ & Nodes & Vertex 5 \\
\cline { 2 - 4 } Hip & 90 & 57497 & 208 \\
\cline { 2 - 4 } Stem & 80 & 55044 & 204 \\
\cline { 2 - 4 } & 70 & 53331 & 204 \\
\cline { 2 - 4 } & 60 & 50428 & 204 \\
\hline
\end{tabular}

Table 11 Mesh Relevance, Nodes, and Microstrain Values at Vertex 5 in the Omnifit Hip Stem 


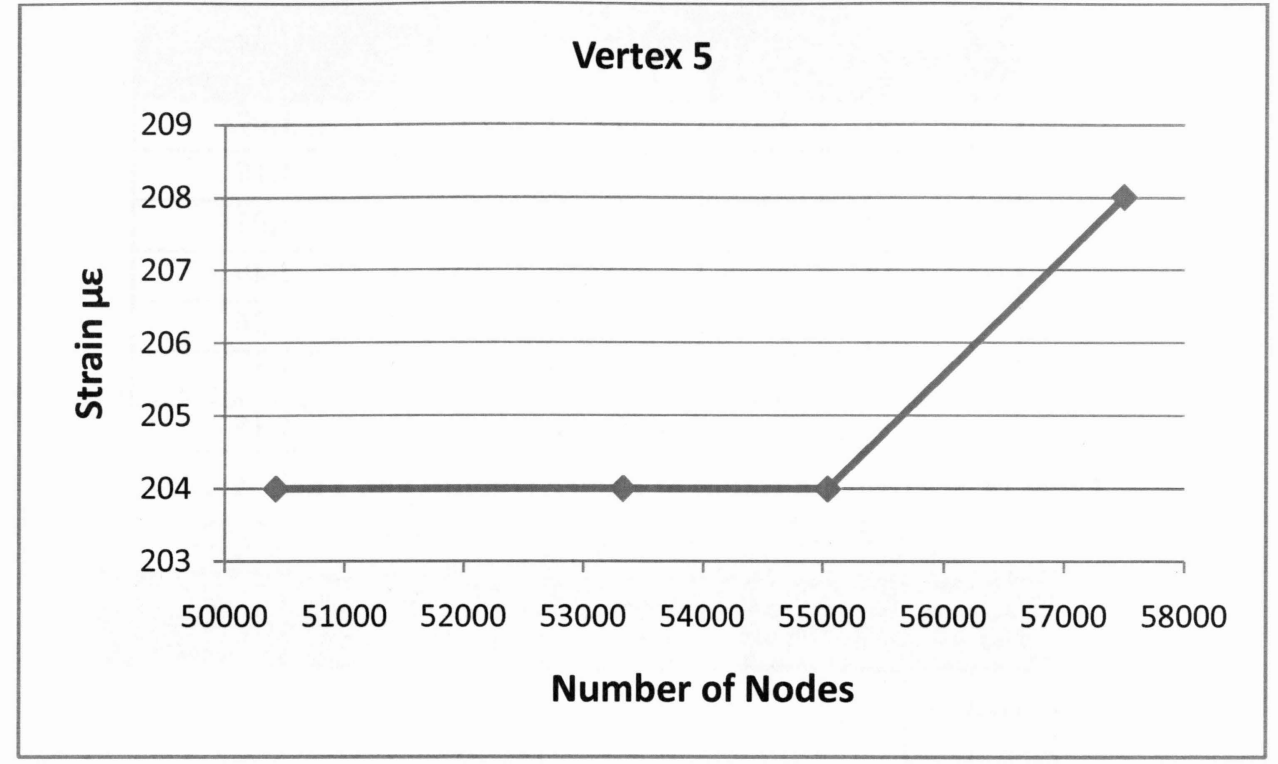

Figure 11 Change in Microstrain Values at Vertex 5 in the Omnifit Hip Stem

\begin{tabular}{|c|cc|c|c|}
\hline $\begin{array}{c}\text { Gauge } \\
\text { Side }\end{array}$ & $\begin{array}{c}\text { Gauge } \\
\text { Location }\end{array}$ & Composite & Exeter & Composite/Exeter \\
\hline \multirow{3}{*}{ Medial } & $\mathbf{1}$ & -2164 & -847 & $\mathbf{2 . 5 5}$ \\
\cline { 2 - 5 } & $\mathbf{2}$ & -4285 & -624 & $\mathbf{6 . 8 7}$ \\
\cline { 2 - 5 } & $\mathbf{3}$ & -2031 & -509 & $\mathbf{3 . 9 9}$ \\
\hline \multirow{3}{*}{ Lateral } & $\mathbf{4}$ & 1081 & 418 & $\mathbf{2 . 5 9}$ \\
\cline { 2 - 5 } & $\mathbf{5}$ & 862 & 295 & $\mathbf{2 . 9 2}$ \\
\cline { 2 - 5 } & $\mathbf{6}$ & 158 & 251 & $\mathbf{0 . 6 3}$ \\
\hline \hline \multicolumn{4}{|c|}{ Average Strain Ratio } & $\mathbf{3 . 2 6}$ \\
\hline
\end{tabular}

Table 12 Microstrain Ratios of Composite/Exeter and Their Average Value

\begin{tabular}{|c|cc|c|c|}
\hline $\begin{array}{c}\text { Gauge } \\
\text { Side }\end{array}$ & Gauge & Composite & Omnifit & Composite/Omnifit \\
\hline \multirow{3}{*}{ Medial } & $\mathbf{1}$ & -2164 & -792 & $\mathbf{2 . 7 3}$ \\
\cline { 2 - 5 } & $\mathbf{2}$ & -4285 & -528 & $\mathbf{8 . 1 2}$ \\
\cline { 2 - 5 } & $\mathbf{3}$ & -2031 & -503 & $\mathbf{4 . 0 4}$ \\
\hline \multirow{3}{*}{ Lateral } & $\mathbf{4}$ & 1081 & 298 & $\mathbf{3 . 6 3}$ \\
\cline { 2 - 5 } & $\mathbf{5}$ & 862 & 235 & $\mathbf{3 . 6 7}$ \\
\cline { 2 - 5 } & $\mathbf{6}$ & 158 & 213 & $\mathbf{0 . 7 4}$ \\
\hline \hline \multicolumn{4}{|c|}{ Average Strain Ratio } & $\mathbf{3 . 8 2}$ \\
\hline
\end{tabular}

Table 13 Microstrain Ratios of Composite/Omnifit and Their Average Value 


\begin{tabular}{|ccc|c|c|}
$\begin{array}{c}\text { Gauge } \\
\text { Side }\end{array}$ & Gauge & Exeter & Omnifit & Exeter/Omnifit \\
\hline \multirow{3}{*}{ Ledial } & $\mathbf{1}$ & -847 & -792 & $\mathbf{1 . 0 7}$ \\
\cline { 2 - 5 } & $\mathbf{2}$ & -624 & -528 & $\mathbf{1 . 1 8}$ \\
\cline { 2 - 5 } & $\mathbf{3}$ & -509 & -503 & $\mathbf{1 . 0 1}$ \\
\hline \multirow{3}{*}{ Lateral } & $\mathbf{4}$ & 418 & 298 & $\mathbf{1 . 4 0}$ \\
\cline { 2 - 5 } & $\mathbf{5}$ & 295 & 235 & $\mathbf{1 . 2 6}$ \\
\cline { 2 - 5 } & $\mathbf{6}$ & 251 & 213 & $\mathbf{1 . 1 8}$ \\
\hline \hline \multicolumn{4}{|c|}{ Average Strain Ratio } & $\mathbf{1 . 1 8}$ \\
\hline
\end{tabular}

Table 14 Microstrain Ratios of Exeter/Omnifit and Their Average Value

\begin{tabular}{|c|cc|c|c|}
\hline $\begin{array}{c}\text { Gauge } \\
\text { Side }\end{array}$ & Gauge & Composite & Exeter & Composite/Exeter \\
\hline \multirow{3}{*}{ Medial } & $\mathbf{1}$ & -2352 & -713 & $\mathbf{3 . 3 0}$ \\
\cline { 2 - 5 } & $\mathbf{2}$ & -4178 & -608 & $\mathbf{6 . 8 7}$ \\
\cline { 2 - 5 } & $\mathbf{3}$ & -4157 & -1103 & $\mathbf{3 . 7 7}$ \\
\hline \multirow{3}{*}{ Lateral } & $\mathbf{4}$ & 1070 & 452 & $\mathbf{2 . 3 7}$ \\
\cline { 2 - 5 } & $\mathbf{5}$ & 1017 & 366 & $\mathbf{2 . 7 8}$ \\
\cline { 2 - 5 } & $\mathbf{6}$ & 1274 & 988 & $\mathbf{1 . 2 9}$ \\
\hline \hline \multicolumn{4}{|c|}{ Average Strain Ratio } & $\mathbf{3 . 4 0}$ \\
\hline
\end{tabular}

Table 15 Microstrain Ratios of Composite/Exeter and Their Average Value

\begin{tabular}{|c|cc|c|c|}
\hline $\begin{array}{c}\text { Gauge } \\
\text { Side }\end{array}$ & Gauge & Composite & Omnifit & Composite/Omnifit \\
\hline \multirow{3}{*}{ Medial } & $\mathbf{1}$ & -2352 & -704 & $\mathbf{3 . 3 4}$ \\
\cline { 2 - 5 } & $\mathbf{2}$ & -4178 & -643 & $\mathbf{6 . 5 0}$ \\
\cline { 2 - 5 } & $\mathbf{3}$ & -4157 & -1660 & $\mathbf{2 . 5 0}$ \\
\hline \multirow{3}{*}{ Lateral } & $\mathbf{4}$ & 1070 & 357 & $\mathbf{3 . 0 0}$ \\
\cline { 2 - 5 } & $\mathbf{5}$ & 1017 & 222 & $\mathbf{4 . 5 8}$ \\
\cline { 2 - 5 } & $\mathbf{6}$ & 1274 & 727 & $\mathbf{1 . 7 5}$ \\
\hline \hline \multicolumn{4}{|c|}{ Average Strain Ratio } & $\mathbf{3 . 6 1}$ \\
\hline
\end{tabular}

Table 16 Microstrain Ratios of Composite/Omnifit and Their Average Value

\begin{tabular}{|c|c|c|c|c|}
\hline $\begin{array}{c}\text { Gauge } \\
\text { Side }\end{array}$ & Gauge & Exeter & Omnifit & Exeter/Omnifit \\
\hline \multirow{3}{*}{ Medial } & $\mathbf{1}$ & -713 & -704 & $\mathbf{1 . 0 1}$ \\
\cline { 2 - 5 } & $\mathbf{2}$ & -608 & -643 & $\mathbf{0 . 9 5}$ \\
\cline { 2 - 5 } & $\mathbf{3}$ & -1103 & -1660 & $\mathbf{0 . 6 6}$ \\
\hline \multirow{3}{*}{ Lateral } & $\mathbf{4}$ & 452 & 357 & $\mathbf{1 . 2 7}$ \\
\cline { 2 - 5 } & $\mathbf{5}$ & 366 & 222 & $\mathbf{1 . 6 5}$ \\
\cline { 2 - 5 } & $\mathbf{6}$ & 988 & 727 & $\mathbf{1 . 3 6}$ \\
\hline \hline \multicolumn{4}{|c|}{ Average Strain Ratio } & $\mathbf{1 . 1 5}$ \\
\hline
\end{tabular}

Table 17 Microstrain Ratios of Exeter/Omnifit and Their Average Value 


\begin{tabular}{|c|c|c|c|c|}
\hline Gauge & Gauge & \multicolumn{3}{c|}{ Composite } \\
\cline { 3 - 5 } Side & Location & EXP & FEA & \%Diff \\
\hline Medial & $\mathbf{1}$ & -2352 & -2164 & $\mathbf{8 . 7}$ \\
\cline { 2 - 5 } & $\mathbf{2}$ & -4178 & -4285 & $\mathbf{2 . 5}$ \\
\hline \multirow{2}{*}{ Lateral } & $\mathbf{4}$ & 1070 & 1081 & $\mathbf{1 . 0}$ \\
\cline { 2 - 5 } & $\mathbf{5}$ & 1017 & 862 & $\mathbf{1 7 . 9}$ \\
\hline \hline \multicolumn{3}{|r}{ Aggregate Average Difference } & $\mathbf{7 . 5}$ \\
\hline
\end{tabular}

Table 18 FEA and Experimental Surface Microstrain, \%Difference and Their Aggregate Average Difference for Composite Hip Stem

\begin{tabular}{|c|c|c|c|c|}
\hline Gauge & \multicolumn{2}{c}{ Gauge } & \multicolumn{3}{c|}{ Exeter } \\
\cline { 3 - 5 } Side & Location & EXP & FEA & $\%$ Diff \\
\hline Medial & $\mathbf{1}$ & -713 & -847 & $\mathbf{1 5 . 8}$ \\
\cline { 2 - 5 } & $\mathbf{2}$ & -608 & -624 & $\mathbf{2 . 6}$ \\
\hline \multirow{2}{*}{ Lateral } & $\mathbf{4}$ & 452 & 418 & $\mathbf{8 . 1}$ \\
\cline { 2 - 5 } & $\mathbf{5}$ & 366 & 295 & $\mathbf{2 4 . 1}$ \\
\hline \hline \multicolumn{3}{|r}{ Aggregate Average Difference } & $\mathbf{1 1 . 5}$ \\
\hline
\end{tabular}

Table 19 FEA and Experimental Surface Microstrain, \%Difference and Their Aggregate Average Difference for Composite Hip Stem

\begin{tabular}{|c|c|c|c|c|}
\hline \multirow{2}{*}{$\begin{array}{c}\text { Gauge } \\
\text { Side }\end{array}$} & \multicolumn{3}{c}{ Gauge } & \multicolumn{3}{c|}{ Omnifit } \\
\cline { 3 - 5 } Medial & $\mathbf{1}$ & -704 & -792 & $\mathbf{1 1 . 1}$ \\
\cline { 2 - 5 } & $\mathbf{2}$ & -643 & -528 & $\mathbf{2 1 . 8}$ \\
\hline \multirow{2}{*}{ Lateral } & $\mathbf{4}$ & 357 & 298 & $\mathbf{1 9 . 8}$ \\
\cline { 2 - 5 } & $\mathbf{5}$ & 222 & 235 & $\mathbf{5 . 5}$ \\
\hline \hline \multicolumn{3}{|r}{ Aggregate Average Difference } & $\mathbf{1 4 . 6}$ \\
\hline
\end{tabular}

Table 20 FEA and Experimental Surface Microstrain, \%Difference and Their Aggregate Average Difference for Composite Hip Stem 


\section{References}

[1] Dictionary.com, Dictionary.Com Unabridged (v 1.1). Random House, Inc. Available at $<\underline{\text { http://www.Dictionary.Reference.Com }>}$.

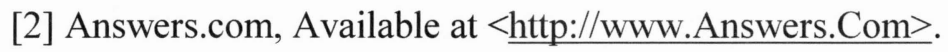

[3] Gary E. W, and Gary L. B, 2008, "Encyclopedia of Biomaterials and Biomedical Engineering," Informa Healthcare USA Inc, pp. 3110.

[4] Raymond T. M, and Stuart L. W, 2006, "Lovell and Winter's Pediatric Orthopaedics," Lippincott Williams \& Wilkins, pp. 1545.

[5] Stuart L. W, and Joseph A. B, 2005, "Turek's Orthopaedics: Principles and Their Application," Lippincott Williams and Wilkins, pp. 154.

[6] Huiskes R, Verdonschot N, Hayes W. C, and Mow V. C, 1997, "Basic Orthopaedic Biomechanics: Biomechanics of Artificial Joints," Philadelphia, PA: Lippincott-Raven, pp. 395-460.

[7] Greenwald A. S, and Saunders W. B, 1991, "The Hip and its Disorders: Biomechanics of the Hip," pp. 47-55.

[8] Hurwitz D. E, Andriacchi T. P, Callaghan J. J, Rosenberg A. G, Rubash H. E, 1998, "The Adult Hip: Biomechanics of the Hip," Philadelphia, PA: Lippincott-Raven, pp. 75-85.

[9] Lian A. L, Stephen W. C, and Miguel E. C, 1999, "Biomechanics of Total Hip Arthroplasty," The Anatomical Record (New ATAT), 257pp. 110-116.

[10] Sobie C, Zdero R, Bryant J. T, and Poitout D, 2004, "Biomechanics and Biomaterials in Orthopedics: Normal and Prosthetic Hip Biomechanics," London, UK: Springer, pp. 528-549. 
[11] Williams J. L, Steinburg M. E, 1991, "The Hip and its Disorders: Biomechanics of Total Hip Replacement," Philadelphia, PA: WB Saunders, pp. 876-904.

[12] Ikeda M, Komatsu S, Sowa I, and Niinomi M, 2002, "Aging Behavior of the Ti-29Nb-13Ta-4.6Zr New Beta Alloy for Medical Implants," Metallurgical and Materials Transactions A, 33(3) pp. 487-493.

[13] Niinomi M, 2003, "Recent Research and Development in Titanium Alloys for Biomedical Applications and Healthcare Goods," Science and Technology of Advanced Materials, 4(5) pp. 445-454.

[14] Bania P. J, Lenning G. A, Hall J. A, Boyer R. R, and Rosenberg H. W, 1984, "Titanium Alloys in the 1980's: Development and Properties of Ti-15V-3Al-3Sn-3Cr," Warrendale, PA: AIME, pp. 209-229.

[15] Mudali U. K, Sridhar T. M, and Baldev R. A. J, 2003, "Corrosion of Bio Implants," Sadhana Academy Proceedings in Engineering Sceinces, 28(3-4) pp. 601-637.

[16] Laheurte P, Eberhardt A, and Philippe M. J, 2005, "Influence of the Microstructure on the Pseudoelasticity of a Metastable Beta Titanium Alloy," Materials Science and Engineering A, 396(1-2) pp. 223-230.

[17] Furey M. J, Peterson D. R, and Bronzino J. D, 2008, "Biomechanics: Principles and Application," Boca Raton, FL: CRC Press, Ch \# 4.

[18] Siopack J. S, and Jergesen H. E, 1995, "Total Hip Arthroplasty," West J Med, 162pp. 243-249.

[19] Bargar W. L, and Steinburg M. E, 1991, "The Hip and its Disorders: New Developments and Future Trends in Total Hip Replacement," Philadelphia: WB Saunders, pp. 1125-1133.

[20] Christel P, Meunier A, Leclercq S, Bouquet P, and Buttazzoni B, 1987, "Development of a CarbonCarbon Hip Prosthesis," Journal of Biomedical Materials Research, 21pp. 191-218. 
[21] Dimitrievska S, Petit A, Ajji A, Bureau M. N, and Yahia L. H, 2008, "Biocompatibility of Novel Polymer-Apatite Nanocomposite Fibers," Journal of Biomedical Materials Research - Part A, 84(1) pp. 44-53.

[22] Bureau M. N, Shen H, Whitfield J. F, Bihun C, Ross V, Campbell M, Bougherara H, Legoux J. G, and Yahia L. H, 2006, "Osseointegration of Biomimetic HA-Coated Composite Hip Implants," Proc 52nd Ann Meeting Orthop Res Soc, Chicago, IL.

[23] Bougherara H, Klika V, Marisik F, Bureau M. N, and Yahia L. H, 2007, "Design of a Biomimetic Polymer-Composite Hip Prosthesis," Journal of Biomedical Materials Research Part A, 82A(1) pp. 27-40.

[24] Campbell M, Bureau M. N, Bougherara H. A, Denault J, and Yahia L. H, 2006, "Biomimetic Polymer Composites for Orthopedic Implants," Proceedings for the Annual Technical Conference (ANTEC) at Charlotte, NC, Anonymous Society of Plastics Engineers (SPC), 1pp. 158-162.

[25] Campbell M, Bureau M. N, and Yahia L. H, 2008, "Performance of CF/PA12 Composite Femoral Stems," Journal of Materials Science: Materials in Medicine, 19(2) pp. 683-693.

[26] Chris F, and Matt L, "Motivation Monday: Exercising with Arthritis," Available at $<$ http://www.kare11.com/news/local/mornings/motivation/motivation_article.Aspx?storyid=632862 $>$.

[27] Canadian Institute for Health Information (CIHI), 2008, "Canadian Joint Replacement Registry (CJRR) 2007 Annual Report: Hip and Knee Replacements in Canada," CIHI and Canadian Orthopaedic Association, Ottawa, ON. Available at $<$ http://secure.Cihi.ca/cihiweb/dispPage.Jsp?cw page=PG_835_E\&cw topic $=835 \& \mathrm{cw}$ rel=AR 30_Eful $1>$.

[28] Steve P, 1999, "Human Body: An Interactive Guide to the Inner Workings of the Body," Barron's, pp. 32. 
[29] John J. C, Aaron G. R, and Harry E. R, 2007, "The Adult Hip," Lippincott Williams \& Wilkins, pp. 1569.

[30] Robert W. B, James D. H, and Charles C. B, 2006, "Fractures in Adults," Lippincott Williams and Wilkins.

[31] Kent V. D. G, 2001, "Human Anatomy," The McGraw-Hill Companies, pp. 840.

[32] Frederic H. M, Michael J. T, and Robert B. T, 2009, "Human Anatomy," Pearson Education, Inc, pp. 869.

[33] Robert E. K, 2008, "Hip and Knee Surgery: A Patient's Guide to Hip Replacement, Hip Resurfacing, Knee Replacement, \& Knee Arthroscopy," Oxford University Press, pp. 216.

[34] Felson D. T, Lawrence R. C, Dieppe P. A, and Hirsch. R, 2000, "Osteoarthritis: New Insights. Part 1: The Disease and its Risk Factors," Annals of Internal Medicine, 133(8) pp. 635-646.

[35] Jon C. T, and Frank H. N, 2002, "Netter's Concise Atlas of Orthopaedic Anatomy," Icon Learning Systems, pp. 320 .

[36] Thompson D. M, 2002, "Introduction to the Study of Human Walking: Basics of Gait Terminology," Lectures on the Control of Human Movement of Biostatics and Epidemiology. Available at <http://www.Moon.Ouhsc.edu/dthompso/gait/terms.Htm>.

[37] Foucher K. C, Hurwitz D. E, and Wimmer M. A, 2008, "Do Gait Adaptations during Stair Climbing Result in Changes in Implant Forces in Subjects with Total Hip Replacements Compared to Normal Subjects?" Clinical Biomechanics, 23(6) pp. 754-761.

[38] Kaufman K. R, and Sutherland D. H, 2006, "Kinematics of Normal Human Walking: Gait Events," Lippincott Williams \& Wilkins, Philadelphia, PA. 
[39] Seedhom B. B, and Wallbridge N. C, 1985, "Walking Activities and Wear of Prostheses," Annals of Rheumatic Disease, 44(12) pp. 838-843.

[40] Gage J. R, 1990, "An Overview of Normal Walking," Instructional Course Lectures, 39pp. 291-303.

[41] Eisenhart R. R. V, Witte H, Steinlechner M, Müller G. M, Putz R, and Eckstein F, 1998,

"Quantitative Determination of Joint Incongruity and Contact Pressure in the Human Hip Joint during the Gait-Cycle," Journal of Biomechanics, 31pp. 35-35.

[42] Eberhart H. D, Inman V. T, and Saunders J. B, 1947, "Fundamental Studies of Human Locomotion and Other Information Relating to Design of Artificial Limbs," Report to the National Research Council, USA. University of California, Berkeley, CA.

[43] Andriacchi T. P, and Alexander E. J, 2000, "Studies of Human Locomotion: Past, Present and Future," Journal of Biomechanics, 33(10) pp. 1217-1224.

[44] Rasch P. J, 1958, "Notes Toward a History of Kinesiology. II," Journal of the American Osteopathic Association, 57(10) pp. 641-644.

[45] Rasch P. J, 1958, "Notes Toward a History of Kinesiology. I," Journal of the American Osteopathic Association, 57(9) pp. 572-574.

[46] Paul J. P, 1976, "Approaches to Design: Force Actions Transmitted by Joints in the Human Body," Proceedings of the Royal Society of London, Series B, Biological Sciences. A Discussion on the Treatment of Arthritis by Joint Replacement, 192pp. 163-172.

[47] Winter D. A, 1980, "Overall Principle of Lower Limb Support during Stance Phase of Gait," Journal of Biomechanics, 13(11) pp. 923-927.

[48] Sutherland D, 1997, "The Development of Mature Gait," Gait \& Posture, 6(2) pp. 163-170. 
[49] Stewart T. D, and Hall R. M, 2006, "(Iv) Basic Biomechanics of Human Joints: Hips, Knees and the Spine," Current Orthopaedics, 20(1) pp. 23-31.

[50] Sariali E, Veysi V, and Stewart T, 2008, "(i) Biomechanics of the Human Hip - Consequences for Total Hip Replacement," Current Orthopaedics, 22(6) pp. 371-375.

[51] Paul J. P, 1970, "The Effect of Walking Speed on the Force Actions Transmitted at the Hip and Knee Joints," Proceedings of the Royal Society of Medicine, 63(2) pp. 200-202.

[52] Donald L. B, Dwight T. D, and Tony M. K, 2006, "Orthopaedic Biomechanics: Mechanics and Design in Musculoskeletal Systems," Pearson Prentice Hall, pp. 370.

[53] Hurwitz D. E, Hulet C. H, Andriacchi T. P, Rosenberg A. G, and Galante J. O, 1997, "Gait Compensations in Patients with Osteoarthritis of the Hip and their Relationship to Pain and Passive Hip Motion," Journal of Orthopaedic Research, 15(4) pp. 629-635.

[54] De Groot K, Wen H. B, Liu Y, Layrolle P, and Barrere F, 2000, "Biomimetic Coatings on Orthopedic Implants: A Review," Materials Research Society Symposium-Proceedings, 599pp. 109-116.

[55] Reilly D. T, and Burstein A. H, 1974, "The Mechanical Properties of Cortical Bone," Journal of Bone and Joint Surgery, 56(5) pp. 1001-1022.

[56] Rashmir R. A. M, Richardson D. C, Aberman H. M, and De Young D. J, 1995, "The Response of Cancellous and Cortical Canine Bone to hydroxylapatite\&hyphen;Coated and Uncoated Titanium Rods," Journal of Applied Biomaterials, 6(4) pp. 237-242.

[57] Reilly D. T, and Burstein A. H, 1975, "The Elastic and Ultimate Properties of Compact Bone Tissue," Journal of Biomechanics, 8(6) pp. 393-396, IN9-IN11, 397-405. 
[58] Wirtz D. C, Schiffers N, Pandorf T, Radermacher K, Weichert D, and Forst R, 2000, "Critical Evaluation of Known Bone Material Properties to Realize Anisotropic FE-Simulation of the Proximal Femur," Journal of Biomechanics, 33(10) pp. 1325-1330.

[59] Goldstein S. A, 1987, "The Mechanical Properties of Trabecular Bone: Dependence on Anatomic Location and Function," Journal of Biomechanics, 20(11-12) pp. 1055-1061.

[60] Goulet R. W, Goldstein S. A, Ciarelli M. J, Kuhn J. L, Brown M. B, and Feldkamp L. A, 1994, "The Relationship between the Structural and Orthogonal Compressive Properties of Trabecular Bone," Journal of Biomechanics, 27(4) pp. 375-377.

[61] Kopperdahl D. L, and Keaveny T. M, 1998, "Yield Strain Behavior of Trabecular Bone," Journal of Biomechanics, 31(7) pp. 601-608.

[62] Ciarelli M. J, Goldstein S. A, Kuhn J. L, Cody D. D, and Brown M. B, 1991, "Evaluation of Orthogonal Mechanical Properties and Density of Human Trabecular Bone from the Major Metaphyseal Regions with Materials Testing and Computed Tomography," Journal of Orthopaedic Research, 9(5) pp. 674-682.

[63] Behrens J. C, Walker P. S, and Shoji H, 1974, "Variations in Strength and Structure of Cancellous Bone at the Knee," Journal of Biomechanics, 7(3) pp. 201-207.

[64] Lindhal O, 1976, "Mechanical Properties of Dried Defatted Spongy Bone," Acta Orthopaedica Scandinavica, 47(1) pp. 11-19.

[65] Carter D. R, and Hayes W. C, 1977, "The Compressive Behavior of Bone as a Two-Phase Porous Structure," Journal of Bone and Joint Surgery, 59(7) pp. 954-962. 
[66] Williams J. L, and Lewis J. L, 1982, "Properties of an Anisotropic Model of Cancellous Bone from the Proximal Tibial Epiphysis," Journal of Biomedical Engineering, 104(1) pp. 50-56.

[67] Goldstein S. A, Wilson D. L, Sonstegard D. A, and Matthews L. S, 1983, "The Mechanical Properties of Human Tibial Trabecular Bone as a Functioni of Metaphyseal Location," Journal of Biomechanics, 16(12) pp. 956-969.

[68] Hvid I, and Hansen S. L, 1985, "Trabecular Bone Strength Patterns at the Proximal Tibial Epiphysis," Journal of Orthopaedic Research, 3(4) pp. 464-472.

[69] Ciarelli M. J, Goldstein S. A, and Dickie D, 1986, "Experimental Determination of the Orthogonal Mechanical Properties, Density and Distribution of Human Trabecular Bone from the Major Metaphyseal Regions Utilizing Material Testing and Computed Tomography," Transactions of the Orthopaedic Research Society, pp. 42.

[70] Linde F, and Hvid I, 1989, "The Effect of Constraint on the Mechanical Behavior of Trabecular Bone Specimens," Journal of Biomechanics, 22(5) pp. 485-490.

[71] Ashman R. B, Rho J. Y, and Turner C. H, 1989, Journal of Biomechanics, 22(8-9) pp. 895-900.

[72] Chwee T. L, and James C. H. G, 2009, "IFMBE Proceedings: ICBME 2008-13th International Conference on Biomedical Engineering," International Federation of Medical and Biological Engineering, pp. 2303.

[73] Pablo F. G, and Jose A. M, 2005, "Early Attempts at Hip Arthroplasty 1700s to 1900s," The Iowa Orthopaedic Journal, 25pp. 25-29. 
[74] Scales J. T, 1967, "Arthroplasty of the Hip using Foreign Materials: A History," Department of Biomechanics and Surgical Materials, Institute of Orthopaedics (University of London), Royal National Orthopaedic Hospital, Stanmore, 181pp. 63-84.

[75] Ohnishi I, Bessho M, Matsuyama J, Matsumoto T, Imai K, and Nakamura K, 2007, "Prediction of Strength and Strain of the Proximal Femur by a CT-Based Finite Element Method," Journal of Biomechanics, 40(8) pp. 1745-53.

[76] Richard S, 2007, "Are there Advances in the Treatment of Extracapsular Hip Fractures in the Elderly," Orthopaedic Surgery Service, Universiyt Hospital of Geneva, Switzerland., 38(3) pp. 77-87.

[77] Mark D. M, and Brian J. C, 2004, "Textbook of Arthroscopy," Elsevier.

[78] Huiskes R, Weinans H, Grootenboer H. J, Dalstra M, Fudala B, and Slooff T. J, 1987, "Adaptive Bone-Remodeling Theory Applied to Prosthetic-Design Analysis," Journal of Biomechanics, 20(11-12) pp. $1135-1150$.

[79] Huiskes R, Weinans H, and Van R, B, 1992, "The Relationship between Stress Shielding and Bone Resorption Around Total Hip Stems and the Effects of Flexible Materials," Clinical Orthopaedics and Related Research, (274) pp. 124-134.

[80] Van R. B, Huiskes R, Weinans H, Sumner D. R, Turner T. M, and Galante J. O, 1993, "The Mechanism of Bone Remodeling and Resorption Around Press-Fitted THA Stems," Journal of Biomechanics, 26(4-5) pp. 369-382.

[81] Steven M. K, 2004, "The UHMWPE Handbook: Ultra-High Molecular Weight Polyethylene in Total Joint Replacement," Academic Press, pp. 379. 
[82] Kurtz S. M, Villarraga M. L, Herr M. P, Bergström J. S, Rimnac C. M, and Edidin A. A, 2002, "Thermo Mechanical Behavior of Virgin and Highly Crosslinked Ultra-High Molecular Weight Polyethylene used in Total Joint Replacements," Biomaterials, 23(17) pp. 3681-3697.

[83] Pilliar R. M, Lee J. M, and Maniatopoulos C, 1986, "Observations on the Effect of Movement on Bone Ingrowth into Porous-Surfaced Implants," Clinical Orthopaedics and Related Research, 208pp. 108113.

[84] Skripitz R, and Aspenberg P, 1998, "Tensile Bond between Bone and Titanium. A Reappraisal of Osseointegration," Acta Orthopaedica Scandinavica, 69(3) pp. 315-319.

[85] Tokash J. C, Stojilovic N, Ramsier R. D, Kovacik M. W, and Mostardi R. A, 2005, "Surface Analysis of Prosthetic Wear Debris," Surface and Interface Analysis, 37(4) pp. 379-384.

[86] Alhassan S, and Goswami T, 2008, "Wear Rate Model for UHMWPE in Total Joint Applications," Wear, 265(1-2) pp. 8-13.

[87] Goswami T, and Alhassan S, 2008, "Wear Rate Model for UHMWPE in Total Hip and Knee Arthroplasty," Materials \& Design, 29(2) pp. 289-296.

[88] Paul, J. P., 1999, "Strength Requirements for Internal and External Prostheses," Journal of Biomechanics, 32(4) pp. 381-393.

[89] Goswami T, 2003, "Fatigue Crack Growth Behavior of Ti-6Al-4V Alloy Forging," Materials and Design, 24(6) pp. 423-433.

[90] Chong A. C. M, Miller F, Buxton M, and Friis E. A, 2007, "Fracture Toughness and Fatigue Crack Propagation Rate of Short Fiber Reinforced Epoxy Composites for Analogue Cortical Bone," Transactions of the ASME.Journal of Biomechanical Engineering, 129(4) pp. 487-93. 
[91] Ingham E, and Fisher J, 2000, "Biological Reactions to Wear Debris in Total Joint Replacement," Proceedings of the Institution of Mechanical Engineers, Part H: Journal of Engineering in Medicine, 214(1) pp. 21-37.

[92] Hamlin F. D, Buechel F. F, and Pappas M. J, 1993, "Stress Shielding as it Relates to Proximally Porous Coated Femoral Stems of Varying Configurations: A 10-Year Cementless Total Hip Replacement Study," Journal of Orthopaedic Rheumatology, 6(2-3) pp. 57-70.

[93] Cristofolini L, 1997, "A Critical Analysis of Stress Shielding Evaluation of Hip Prostheses," Critical Reviews in Biomedical Engineering, 25(4-5) pp. 409-83.

[94] Gross $<$ FN ID="fn1" $>$ Now at Materials Research Group, School of Engineering Sciences, University of Southampton, Highfield, Southampton,SO17 1BJ, UK.</FN>,S., and Abel, E. W., 2001, "A Finite Element Analysis of Hollow Stemmed Hip Prostheses as a Means of Reducing Stress Shielding of the Femur," Journal of Biomechanics, 34(8) pp. 995-1003.

[95] Joshi M. G, Advani S. G, Miller F, and Santare M. H, 2000, "Analysis of a Femoral Hip Prosthesis Designed to Reduce Stress Shielding," Journal of Biomechanics, 33(12) pp. 1655-1662.

[96] Weinans H, Sumner D, Igloria R, and Natarajan R. N, 2000, "Sensitivity of Periprosthetic StressShielding to Load and the Bone density-modulus Relationship in Subject-Specific Finite Element Models," Journal of Biomechanics, 33(7) pp. 809-817.

[97] Raj K. S, 2002, "Hip Replacement: Current Trends and Controversies," University of Pittsburgh Medical Center, Pittsburgh, Pennsylvania. Marcel Dekker, Inc., pp. 441.

[98] Derek J. W, 2009, "Modern Hip Resurfacing," Mcminn Centre, Birmingham, United Kingdom. Springer-Verlage London Limited, pp. 428. 
[99] Tobias G. W, 2008, "Leading-Edge Composite Material Research," Nova Science Publishers, Inc, pp. 400.

[100] Ramakrishna S, Mayer J, Wintermantel E, and Leong K. W, 2001, "Biomedical Applications of Polymer-Composite Materials: A Review," Composites Science and Technology, 61(9) pp. 1189-1224.

[101] Chang H, Bastari K, Saraswati, and Philip C, 2009, "Mechanical and Biological Characterization of Pressureless Sintered Hydroxapatite-Ployetheretherketone Biocomposite," Nanyang Polytechnic, School of Engineering (Manufacturing), Biomedical Engineering Group, Sigapore. Chwee Teck Lim, James C. H. Goh (Eds): ICBME 2008, Proceedings 23, pp. 261-264.

[102] Campbell M, Bureau M. N, Bougherara H. A, Denault J, Yahia L. H, and Legoux J. G, 2006, "Biomimetic Polymer Composites for Orthopedic Hip Implants," Medical Device Materials III: Proceedings of Materials \& Processes for Medical Devices Conference at Boston, MA, November 14-16, 2005, R. Venugopalan and M. Wu, Dds. ASM International, pp. 49-54.

[103] Campbell M, Denault J, Yahia L. H, and Bureau M. N, 2008, "CF/PA12 Composite Femoral Stems: Manufacturing and Properties," Composites Part A: Applied Science and Manufacturing, 39(5) pp. 796804.

[104] Deopura B. L, 2008, Polyesters and Polyamides, Woodhead Publishing, in Association with Textile Institute and CRC Press, Cambridge, UK. Xxii, 608 p.

[105] Snyder S. M, and Schneider E, 1991, "Estimation of Mechanical Properties of Cortical Bone by Computed Tomography," Journal of Orthopaedic Research, 9(3) pp. 422-431.

[106] McNeice, G. M., 1975, "Finite Element Studies of Femoral Endoprostheses for Hip Reconstrucion," American Society of Mechanical Engineers, Applied Mechanics Division, AMD, 1pp. 89-92. 
[107] Abdullah K. A, 2008, "Finite Element Modelling of the Neck-Stem Interface of a Modular Hip Implant for Micro-Motion Study," 19th IASTED International Conference on Modelling and Simulation, Anonymous ACTA Press, Anaheim, CA, USA, pp. 364-369.

[108] Lennon, A. B., and Prendergast, P. J., 2001, "Evaluation of Cement Stresses in Finite Element Analyses of Cemented Orthopaedic Implants," Transactions of the ASME.Journal of Biomechanical Engineering, 123(6) pp. 623-628.

[109] Bougherara H, Zdero R, Miric M, Shah S, Hardisty M, Zalzal P, and Schemitsch E. H, 2009, "The Biomechanics of the T2 Femoral Nailing System: A Comparison of Synthetic Femurs with Finite Element Analysis," Proceedings of the Institution of Mechanical Engineers, Part H (Journal of Engineering in Medicine), 223pp. 303-14.

[110] Bougherara H, Klika V, Marisik F, Bureau M. N, and Yahia L. H, 2006, "Biomechanic Hip Prosthesis Including Bone Remodeling Process Induced by Dynamical Loading," Proceedings of the 7th International Sympsium on Computer Methods in Biomechanics and Biomedical Engineeirng.

[111] Ogden C. L, Fryar C. D, Carroll M. D, and Flegal K. M, 2004, "Mean Body Weight, Height, and Body Mass Index, United States 1960-2002," Department of Health and Human Services, Centers for Disease Control and Prevention (CDC), National Center of Health Statistics, USA. Available at $<$ http://www.Cdc.gov/nchs/data/ad/ad347.Pdf $>$.

[112] Pyburn E, and Goswami T, 2004, "Finite Element Analysis of Femoral Components Paper III - Hip Joints," Materials and Design, 25(8) pp. 705-713.

[113] Grasa J, Perez M. A, Bea J. A, Garcia A. J. M, and Doblare M, 2005, "A Probabilistic Damage Model for Acrylic Cements. Application to the Life Prediction of Cemented Hip Implants," International Journal of Fatigue, 27(8) pp. 891-904. 
[114] Pilliar R.M, and Bratina W. J, 1980, "Micromechanical Bonding at a Porous Surface Structured Implant Interface-the Effect on Implant Stressing," Journal of Biomedical Engineering, 2(1) pp. 49-53.

[115] Szivek J. A, and Gharpuray V. M, 2000, "Strain Gauge Measurements from Bone Surfaces," In Mechanical Testing of Bone and the Bone-Implant Interface, Y. H. an and R. A. Draughn (Eds). CRC Press, Boca Raton, FL, pp. 305-320.

[116] Vishay Micro-Measurements, 2008, "125UW General Purpose Strain Gauges-Linear Pattern," Vishay.Com. Vishay Inter Technology, Inc, Raleigh, NC, USA. Available at $<\underline{\text { http://www.Vishay.com/docs/11241/125uw.Pdf }>}$.

[117] Illinois Tool Works, 2009, "Table Model Axial Torsion: FastTrack ${ }^{\mathrm{TM}} 8874$," Instron® Materials Testing Solutions (Instron.Us). Illinois Tool Works, Inc, Norwood, MA. USA. Available at $<\underline{\text { http://www.Instron.us/wa/products/fatigue testing/table_axial_torsion.Aspx }>\text {. }}$

[118] Instron ${ }^{\circledR}$ Corporation, 2009, "Single Axis 8800 Series: Front Panel and FastTrack ${ }^{\mathrm{TM}}$ Console," $^{\circ}$ Instron ${ }^{\circledR}$ Materials Testing Solutions (Instron.Com). Available at <http://www.Instron.com/wa/library/StreamFile.Aspx?doc=1191>.

[119] Vishay Micro-Measurements, 2005, "Instruction Bulletin B-127-14: Strain Gauge Installations with M-Bond 200 Adhesive (Document \# 11127)," Vishay.Com Vishay Intertechnology, Inc, Raleigh, NC,

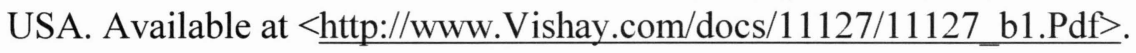

[120] National Intruments, 2008, "How is Temperature Affecting Your Strain Measurement Accuracy?" NI Developer Zone. National Instruments Corporation, Austin, TX, USA. Available at $<$ http://zone.Ni.com/devzone/cda/tut/p/id/3432>.

[121] Anonymous Stryker Corporation, Mahwah, NJ, USA. Available at $<$ http://www.Stryker.Com $>$. 
[122] Sun W, Starly B, Nam J, and Darling A, 2005, "Bio-CAD Modeling and its Applications in Computer-Aided Tissue Engineering," Computer-Aided Design, 37(11) pp. 1097-1114.

[123] García J. M, Doblaré M, and Cegoñino J, 2002, "Bone Remodeling Simulation: A Tool for Implant Design," Computational Materials Science, 25(1-2) pp. 100-114.

[124] Perez M. A, Garcia A. J. M, Doblare M, Seral B, and Seral F, 2006, "A Comparative FEA of the Debonding Process in Different Concepts of Cemented Hip Implants," Medical Engineering and Physics, 28(6) pp. 525-533.

[125] Perez M. A, Garcia A. J, and Doblare M, 2009, "Does Increased Bone-Cement Interface Strength have Negative Consequences for Bulk Cement Integrity? A Finite Element Study," Annals of Biomedical Engineering, 37(3) pp. 454-466.

[126] Abdul-Kadir M, Hansen U, Klabunde R, Lucas D, and Amis A, 2008, "Finite Element Modeling of Primary Hip Stem Stability: The Effect of Interference Fit," Journal of Biomechanics, 41(3) pp. 587-594.

[127] Schileo E, Taddei F, Malandrino A, Cristofolini L, and Viceconti M, 2007, "Subject-Specific Finite Element Models can Accurately Predict Strain Levels in Long Bones," Journal of Biomechanics, 40(13) pp. 2982-2989.

[128] Srinivasan S, de Andrade J. R, Biggers Jr. S. B, and Latour Jr R. A, 1999, "3-D Global/Local Analysis of Composite Hip Prostheses - A Model for Multiscale Structural Analysis," Composite Structures, 45(3) pp. 163-170.

[129] Evans S. L, and Gregson P. J, 1998, "Composite Technology in Load-Bearing Orthopaedic Implants," Biomaterials, 19(15) pp. 1329-1342. 
[130] Schmid D. M, Wullschleger L, and Derler S, and Schmitt K, 2008, "Development of a New Design of Hip Protectors using Finite Element Analysis and Mechanical Tests," Medical Engineering \& Physics, 30(9) pp. 1186-1192.

[131] Weisse B, Zahner M, Weber W, and Rieger W, 2003, "Improvement of the Reliability of Ceramic Hip Joint Implants," Journal of Biomechanics, 36(11) pp. 1633-1639.

[132] Kaddick C, Stur S, and Hipp E, 1997, "Mechanical Simulation of Composite Hip Stems," Medical Engineering \& Physics, 19(5) pp. 431-439.

[133] Senalp A. Z, Kayabasi O, and Kurtaran H, 2007, "Static, Dynamic and Fatigue Behavior of Newly Designed Stem Shapes for Hip Prosthesis using Finite Element Analysis," Materials \& Design, 28(5) pp. 1577-1583.

[134] Lemaire V, Tobin F. L, Greller L. D, Cho C. R, and Suva L. J, 2004, "Modeling the Interactions between Osteoblast and Osteoclast Activities in Bone Remodeling," Journal of Theoretical Biology, 229(3) pp. 293-309.

[135] Giannoudis P. V, Kanakaris N. K, and Tsiridis E, 2007, "Principles of Internal Fixation and Selection of Implants for Periprosthetic Femoral Fractures," Injury, 38(6) pp. 669-687.

[136] Mahmoud A, Wakabayashi N, Takahashi H, and Ohyama T, 2005, "Deflection Fatigue of Ti-6Al7Nb, Co-Cr, and Gold Alloy Cast Clasps," The Journal of Prosthetic Dentistry, 93(2) pp. 183-188.

[137] ANSYS Inc, 2009, "SOLID187 3-D 10-Node Tetrahedral Structural Solid," Kxcad.Net; Release 11.0 Documentation for ANSYS. Available at $<\underline{\text { http://www.Kxcad.net/ansys/ANSYS/ansyshelp/Hlp_E_SOLID187.html\#solid187.Tab.2.Ft.6> }}$. 
[138] ANSYS Inc, 2009, "TARGE170 3-D Target Segment," Kxcad.Net; Release 11.0 Documentation for ANSYS. Available at <http:/www.Kxcad.net/ansys/ANSYS/ansyshelp/Hlp_E_TARGE170.Html>.

[139] Sumner D. R, Turner T. M, Igloria R, Urban R. M, and Galante J. O, 1998, "Functional Adaptation and in-Growth of Bone Bary as a Function of Hip Implant Stiffness," Journal of Biomechanics, 31(10) pp. 909-917.

[140] Jacobs J. J, Sumner D. R, and Galante J. O, 1993, "Mechanisms of Bone Loss Associated with Total Hip Replacement," 24pp. 583-590.

[141] Nishii T, Sugano N, Masuhara K, Shibuya T, and Ochi T, Tamura S, 1997, "Longitudinal Evaluation of Time Related Bone Remodeling After Cementless Total Hip Arthroplasty," Clin Orthop Relat Res, 339pp. 121-131.

[142] Spiers A. D, Heller M. O, Taylor W. R, Duda G. N, and Perka C, 2007, "Influence of Changes in Stem Positioning on Femeral Loading After THR using a Short Stemmed Hip Implant," Clinical Biomech, 22pp. 431-439.

[143] Akay M, and Aslan N, 1996, "Numerical and Experimental Stress Analysis of a Polymeric Composite Hip Joint Prosthesis," Journal of Biomedical Materials Research, 31(2) pp. 167-182.

[144] Bougherara H, Burea M. N, and Yahia L, 2009, "Bone Remodeling in a New Biomimetic Polymer Composite Hip Stem," J Biomed Mater Res A.

[145] Bergmann G, Graichen F, and Rohlmann A, 1993, "Hip Joint Loading during Walking and Running, Measured in Two Patients," Journal of Biomechanics, 26(8) pp. 969-990.

[146] Duda G. N, Heller M, Albinger J, Schulz O, Schneider E, and Claes L, 1998, "Influence of Muscle Forces on Femoral Strain Distribution," Journal of Biomechanics, 31(9) pp. 841-846. 
[147] Burgers T. A, Mason J, Niebur G, and Ploeg H. L, 2008, "Compressive Properties of Trabecular Bone in the Distal Femur," Journal of Biomechanics, 41(5) pp. 1077-1085.

[148] ANSYS online modeling, Available at $<$ http://www.Ansys.Com $>$. 